\title{
An Assessment of Desiccant Cooling and \\ Dehumidification Technology
}

\author{
By \\ V. C. Mei and F. C. Chen \\ Energy Division \\ Oak Ridge National Laboratory \\ Z. Lavan \\ Illinois Institute of Technology \\ R. K. Collier, Jr. \\ Collier Engineering Services \\ and \\ G. Meckler \\ Gershon Meckler Associates, P.C. \\ DATE PUBLISHED: JULY 1992
}

Prepared by the

OAK RIDGE NATIONAL LABORATORY

Oak Ridge, Tennessee 37831-6285

managed by

MARTIN MARIETTA ENERGY SYSTEMS, INC. for the

U.S. DEPARTMENT OF ENERGY under Contract No. DE-AC05-84OR21400

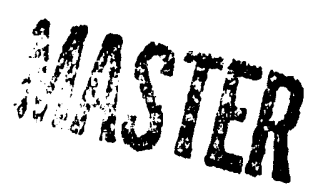




\section{TABLE OF CONTENTS}

LIST OF FIGURES $\ldots \ldots \ldots \ldots \ldots \ldots \ldots \ldots \ldots \ldots \ldots \ldots \ldots \ldots \ldots \ldots$ vii

LIST OF TABLES $\ldots \ldots \ldots \ldots \ldots \ldots \ldots \ldots \ldots \ldots \ldots \ldots \ldots \ldots \ldots \ldots \ldots \ldots$ ix

EXECUTTVE SUMMARY $\ldots \ldots \ldots \ldots \ldots \ldots \ldots \ldots \ldots \ldots \ldots \ldots \ldots \ldots \ldots \ldots$

ACKNOWLEDGMENTS $\ldots \ldots \ldots \ldots \ldots \ldots \ldots \ldots \ldots \ldots \ldots \ldots \ldots \ldots \ldots \ldots \ldots$ xiii

ABSTRACT $\ldots \ldots \ldots \ldots \ldots \ldots \ldots \ldots \ldots \ldots \ldots \ldots \ldots \ldots \ldots \ldots \ldots \ldots \ldots \ldots$

1. TECHNOLOGY INTRODUCTION $\ldots \ldots \ldots \ldots \ldots \ldots \ldots \ldots \ldots \ldots \ldots \ldots \ldots$

1.1. Principles of Desiccant Cooling and Dehumidification (DCD) $\ldots \ldots \ldots \ldots \ldots$

1.2. Advantages and Potential Limitations of DCD Systems $\ldots \ldots \ldots \ldots \ldots \ldots$

2. HISTORIC OVERVIEW $\ldots \ldots \ldots \ldots \ldots \ldots \ldots \ldots \ldots \ldots \ldots \ldots \ldots \ldots \ldots$

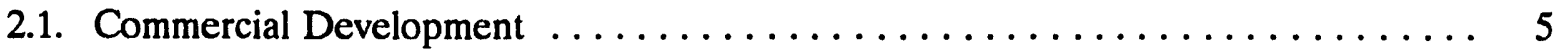

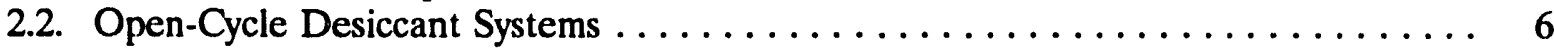

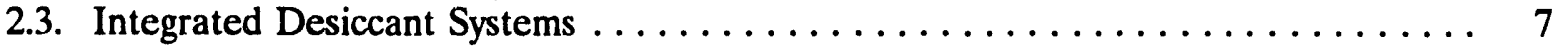

2.4. Closed-Cycle Desiccant Systems $\ldots \ldots \ldots \ldots \ldots \ldots \ldots \ldots \ldots \ldots \ldots \ldots \ldots \ldots$

2.5. Liquid Desiccant Systems $\ldots \ldots \ldots \ldots \ldots \ldots \ldots \ldots \ldots \ldots \ldots \ldots \ldots \ldots \ldots \ldots$

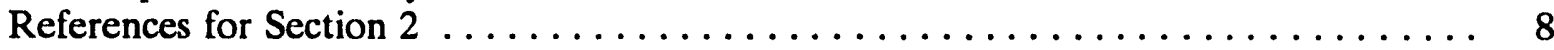

3. TECHNOLOGY OPTIONS $\ldots \ldots \ldots \ldots \ldots \ldots \ldots \ldots \ldots \ldots \ldots \ldots \ldots \ldots \ldots$

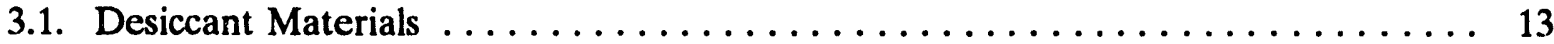

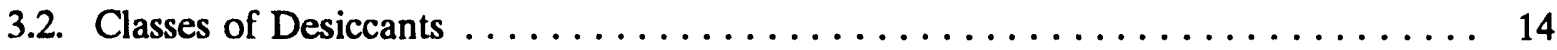

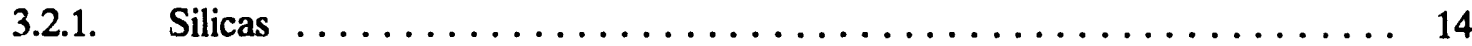

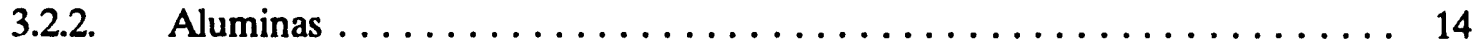

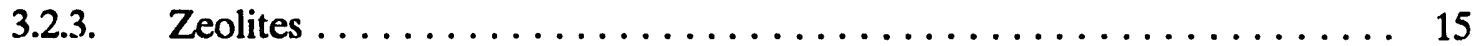

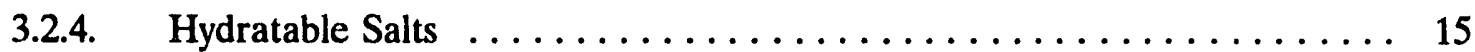

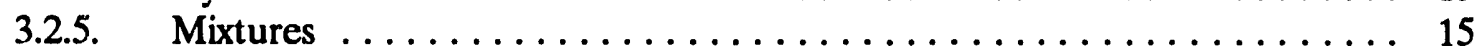

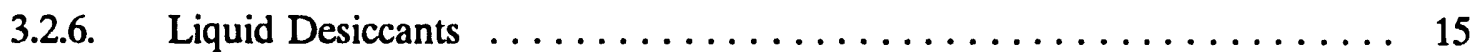

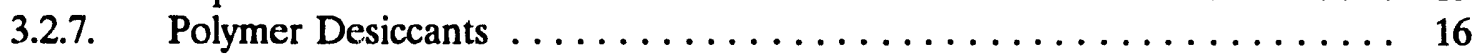

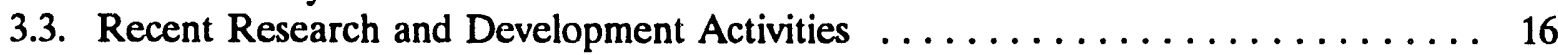

3.4. Desiccant Cooling and Dehumidification (DCD) Systems $\ldots \ldots \ldots \ldots \ldots \ldots \ldots$

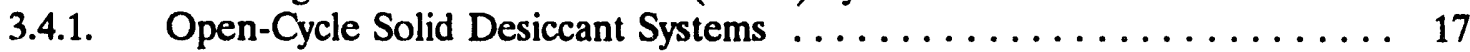

3.4.2. Closed-Cycle Solid Desiccant Systems . . . . . . . . . . . . . 17

3.4.2.1. Intermittent Adsorption Closed-Cycle Systems . . . . . . . . . . . 18

3.4.2.2. Regenerative Adsorption Closed-Cycle Systems . . . . . . . . . . . 19

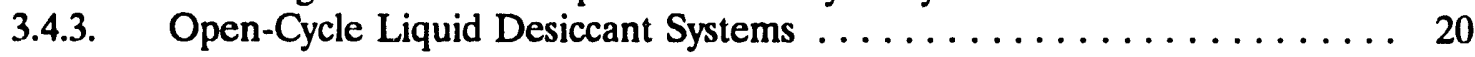

3.4.4. Closed-Cycle Liquid Desiccant Systems . . . . . . . . . . . . . 21

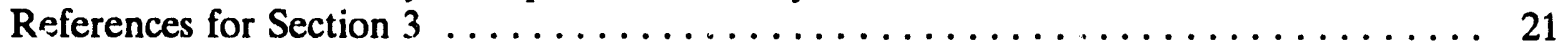

4. RECENT RESEARCH AND DEVELOPMENT HISTORY PROGRAMMATIC

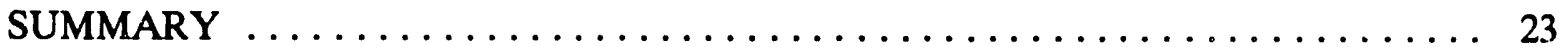

4.1. Government, Research Institutes, and Universities . . . . . . . . . . . 23

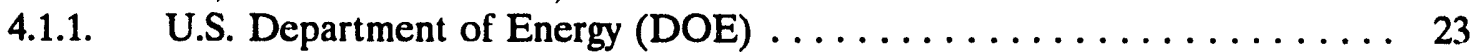

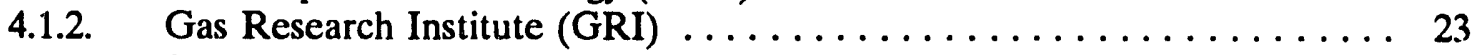

4.1.3. Solar Energy Research Institute $\ldots \ldots \ldots \ldots \ldots \ldots \ldots \ldots \ldots \ldots$ 


\section{TABLE OF CONTENTS (continued)}

\section{RECENT RESEARCH AND DEVELOPMENT HISTORY PROGRAMMATIC}

SUMMARY (continued)

4.1.4. University of Illinois at Chicago (UIC) $\ldots \ldots \ldots \ldots \ldots \ldots \ldots \ldots \ldots$

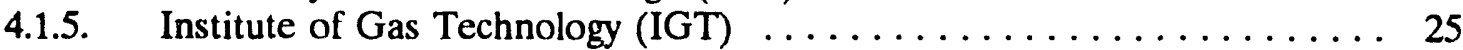

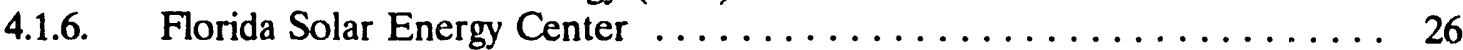

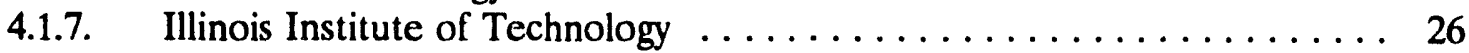

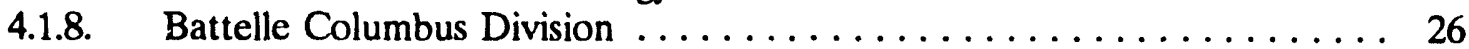

4.1.9. Georgia Institute of Technology (GIT) $\ldots \ldots \ldots \ldots \ldots \ldots \ldots \ldots \ldots$

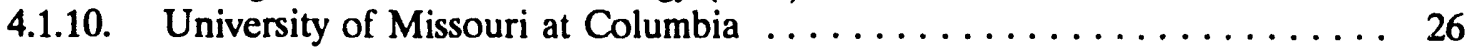

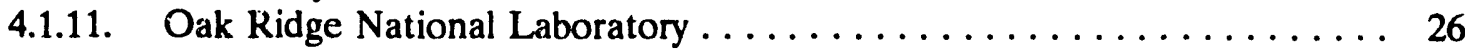

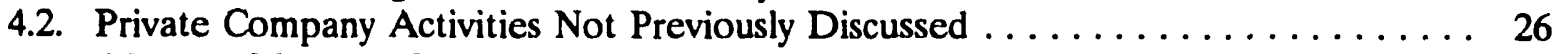

4.2.1. Munters Cargocaire, Amesbury, Massachusetts ............ 26

4.2.2. The Meckler Group, Encino, California . . . . . . . . . . . . 27

4.2.3. Gershon Meckler Associates, P.C., Herndon, Virginia . . . . . . . . . 27

4.2.4. ICC Technologies, Philadelphia, Pennsylvania .............. 27

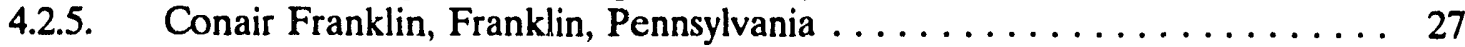

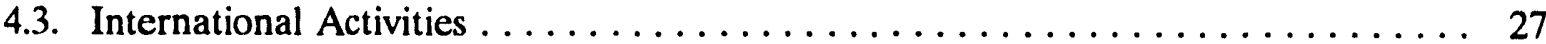

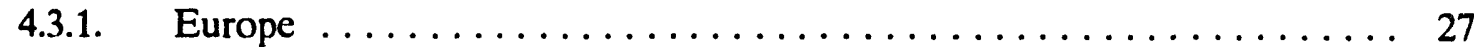

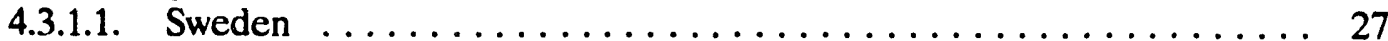

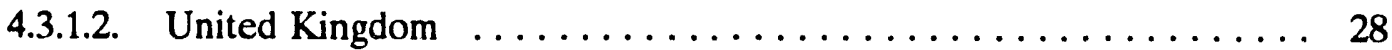

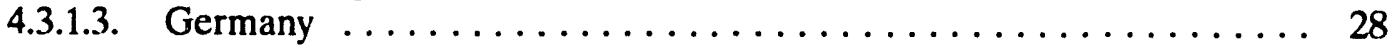

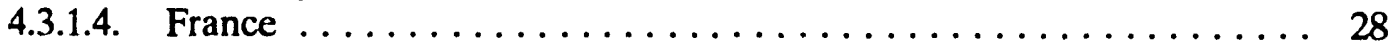

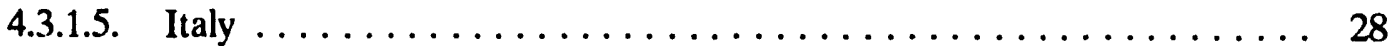

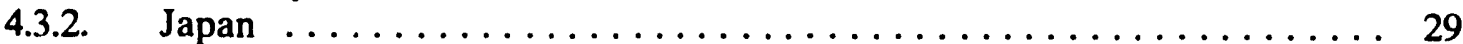

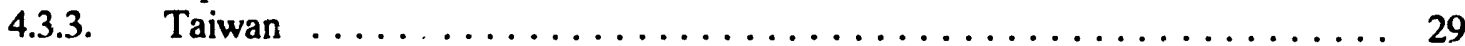

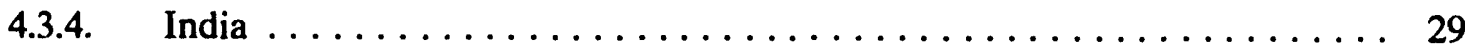

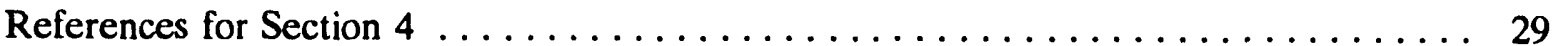

5. TECHNOLOGY STATUS SUMMARY $\ldots \ldots \ldots \ldots \ldots \ldots \ldots \ldots \ldots \ldots$

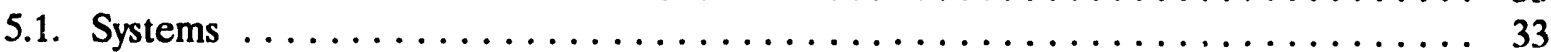

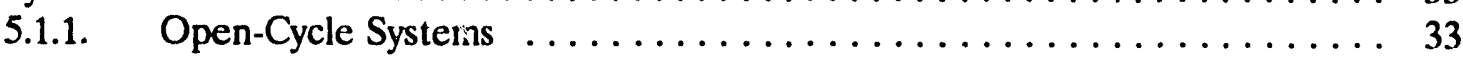

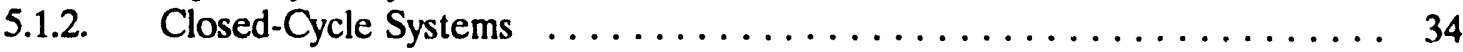

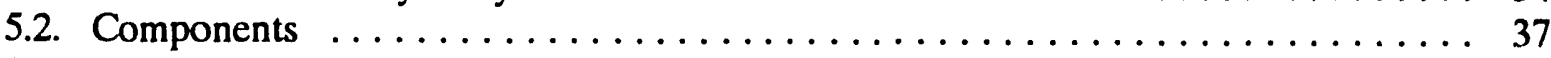

5.3. Desiccant Materials ........................... 39

5.4. Computer Models ................................ 39

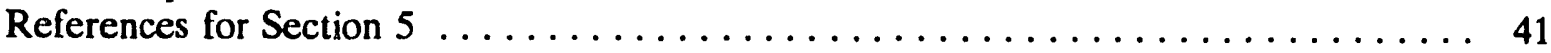

6. RESEARCH AND DEVELOPMENT NEEDS $\ldots \ldots \ldots \ldots \ldots \ldots \ldots \ldots \ldots \ldots \ldots \ldots$

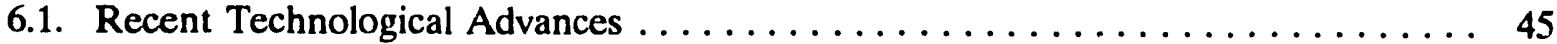

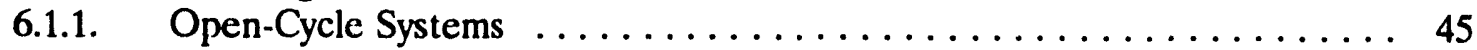

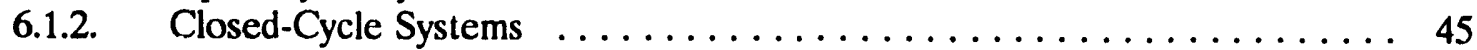

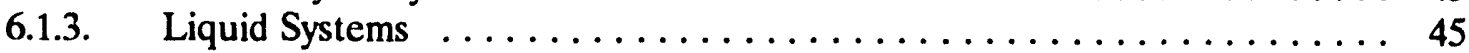

6.1.4. Integrated Systems $\ldots \ldots \ldots \ldots \ldots \ldots \ldots \ldots \ldots \ldots \ldots \ldots \ldots$ 


\section{TABLE OF CONTENTS (continued)}

6. RESEARCH AND DEVELOPMENT NEEDS (continued)

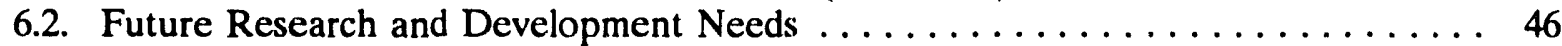

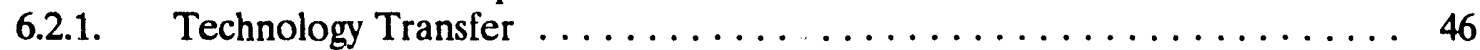

6.2.2. Desiccant Materials . . . . . . . . . . . . . . . . . . . . 47

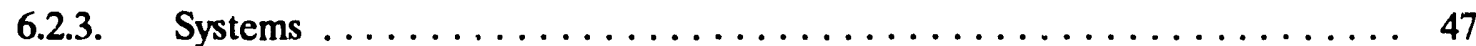

6.2.4. Components $\ldots \ldots \ldots \ldots \ldots \ldots \ldots \ldots \ldots \ldots \ldots \ldots \ldots \ldots \ldots \ldots$

6.2.5. Theoretical Analysis $\ldots \ldots \ldots \ldots \ldots \ldots \ldots \ldots \ldots \ldots \ldots \ldots \ldots$

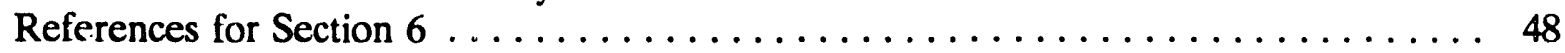

7. ASSESSMENT OF OPPORTUNITIES FOR INTRODUCING DESICCANT HVAC SYSTEMS INTO THE COMMERCIAL BUILDING MARKET $\ldots \ldots \ldots \ldots \ldots \ldots 51$

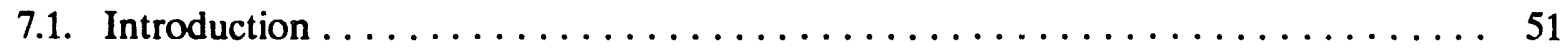

7.1.1. Existing Desiccant Market: Industrial and Military $\ldots \ldots \ldots \ldots \ldots \ldots$. 51

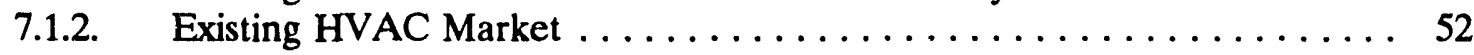

7.1.3. GMAPC Experience with Desiccant HVAC Systems .......... 52

7.2. Commercial Desiccant HVAC: Benefits and Supporting Trends . . . . . . . . . 53

7.3. Conditions Needed to Encourage the Spread in Use of Desiccant HVAC Systems . 54

7.4. Appropriate Commercial Building Applications $\ldots \ldots \ldots \ldots \ldots \ldots \ldots \ldots$

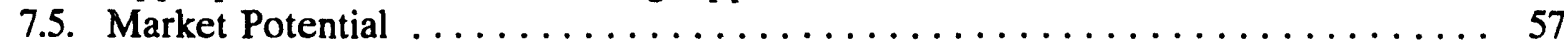

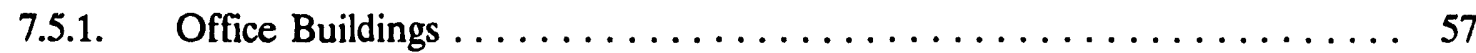

7.5.2. Supermarkets and Small Commercial Buildings $\ldots \ldots \ldots \ldots \ldots \ldots$

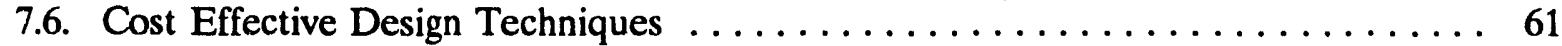

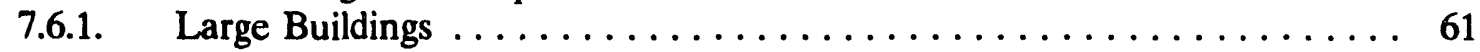

7.6.2. Small Commercial Buildings ................... 69

7.7. Impact on Energy Consumption and Energy Cost $\ldots \ldots \ldots \ldots \ldots \ldots \ldots$

7.9. Conclusion ................................. 74

8. ENERGY IMPACTS OF DESICCANT COOLING SYSTEMS $\ldots \ldots \ldots \ldots \ldots \ldots$

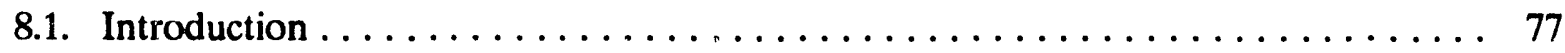

8.2. Residential Cooling $\ldots \ldots \ldots \ldots \ldots \ldots \ldots \ldots \ldots \ldots \ldots \ldots \ldots \ldots \ldots$

8.4. Industrial Dehumidification and Drying $\ldots \ldots \ldots \ldots \ldots \ldots \ldots \ldots \ldots \ldots \ldots$

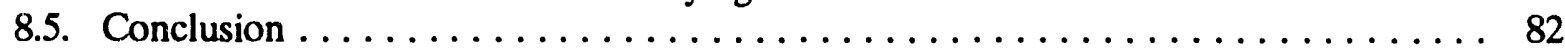

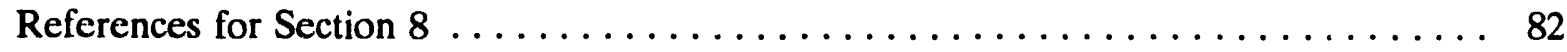

Appendix I - Optimizing Solid Desiccant Material Properties $\ldots \ldots \ldots \ldots \ldots \ldots$

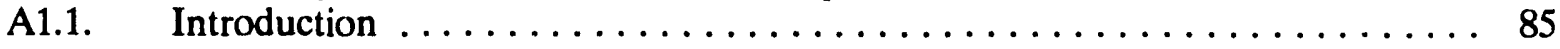

A1.2. Significance of Desiccant Material Properties $\ldots \ldots \ldots \ldots \ldots \ldots \ldots$

A1.3. Sorption properties of desiccants $\ldots \ldots \ldots \ldots \ldots \ldots \ldots \ldots \ldots \ldots \ldots$

A1.4. Adsorption energy properties of desiccants $\ldots \ldots \ldots \ldots \ldots \ldots \ldots \ldots$

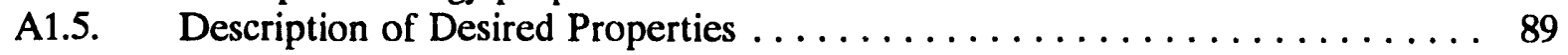

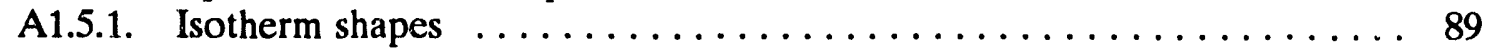

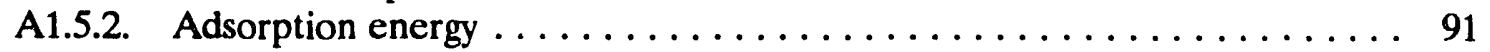

A1.5.3. Maximum uptake $\ldots \ldots \ldots \ldots \ldots \ldots \ldots \ldots \ldots \ldots \ldots \ldots \ldots \ldots$

A1.5.4. Chemical and physical stability .................. 92 


\section{TABLE OF CONTENTS (continued)}

Appéndix I - Optimizing Solid Desiccant Material Properties (continued)

A1.6. Shortfalls in Current Desiccant Materials and Components . . . . . . . . . . 93

Appendix II - Description and Comparison of Desiccant Computer Models . . . . . . . 95

A2.1. Model Descriptions .............................. 95

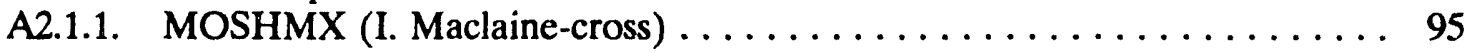

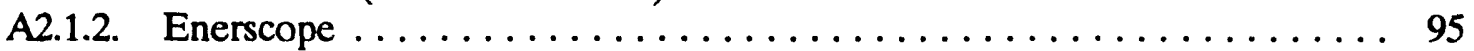

A2.1.3. The University of Illinois at Chicago (W. Worek) $\ldots \ldots \ldots \ldots \ldots \ldots$

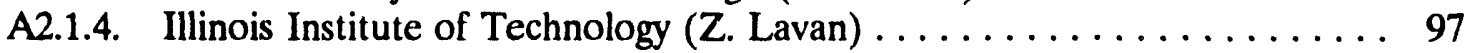

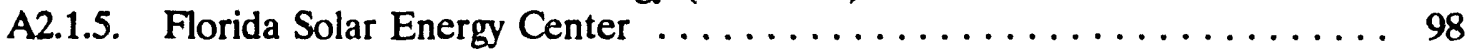

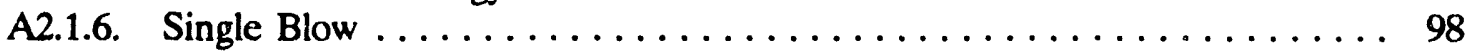

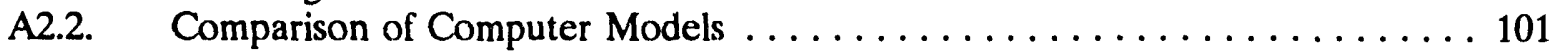

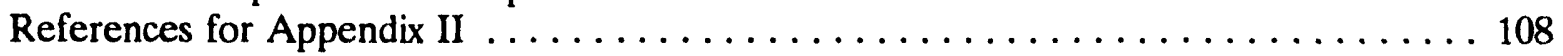




\section{LIST OF FIGURES}

E1 Potential annual energy reduction due to the use of desiccant-based air conditioning .. xi

E2 Typical open-cycle solid desiccant system $\ldots \ldots \ldots \ldots \ldots \ldots \ldots \ldots \ldots \ldots \ldots \ldots \ldots$

E3 Typical open-cycle liquid desiccant system $\ldots \ldots \ldots \ldots \ldots \ldots \ldots \ldots \ldots \ldots \ldots$ xiii

E4 Desiccant system configurations and technology implications $\ldots \ldots \ldots \ldots \ldots \ldots \ldots$

E5 Principal cost elements of installed desiccant systems $\ldots \ldots \ldots \ldots \ldots \ldots \ldots \ldots$

1.1 Schematic on one type of open-cycle desiccant cooling system

1.2 Psychrometric representation of the system shown in Figure 1.11

3.1 Isoteres showing the water-zeolite $13 x$ adsorption cycle $\ldots \ldots \ldots \ldots \ldots \ldots$

3.2 Regenerative adsorption system when valves are in position 1 , container 1 is

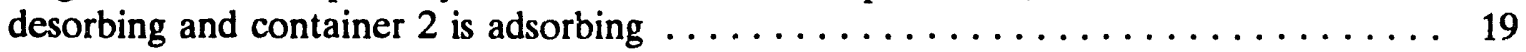

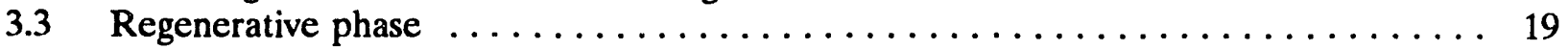

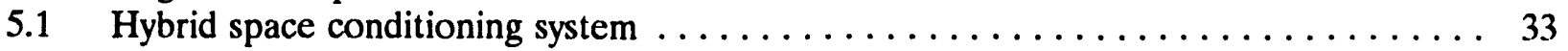

5.2 Two-stage desiccant dehumidifier intergrated cold air VAV system . . . . . . . . . 34

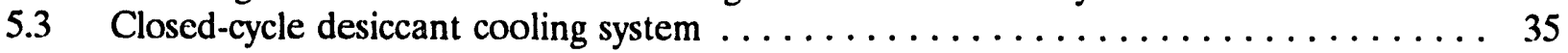

5.4 Regenerative phase: the walls of the container act as a condenser $\ldots \ldots \ldots \ldots \ldots$

5.5 Adsorption phase: the walls of the container act as an evaporator $\ldots \ldots \ldots \ldots$

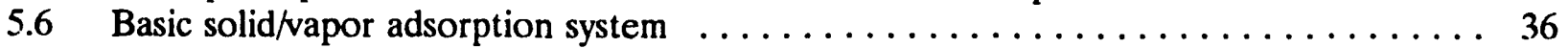

5.7 Thermal wave solid/vapor adsorption system $\ldots \ldots \ldots \ldots \ldots \ldots \ldots \ldots \ldots \ldots \ldots$

7.1 Regions used in Table 7.1 (U.S. Census Regions) . . . . . . . . . . . . . . 59

7.2 Conventional all-air VAV system with electricity-driven vapor compression

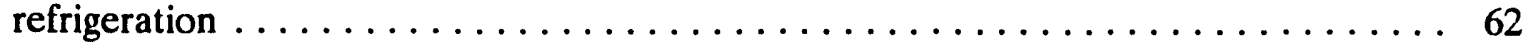

7.3 Air-conditioning psychrometric process for Fig. $7.2 \ldots \ldots \ldots \ldots \ldots$

7.4 Two-stage desiccant air-water gas cooling system with cold $\left(40^{\circ} \mathrm{F}\right)$ primary air . . . . 64

7.5 Air-conditioning psychrometric process for Fig. $7.4 \ldots \ldots \ldots \ldots \ldots \ldots$

7.6 One-stage liquid desiccant air-water gas cooling system $\ldots \ldots \ldots \ldots \ldots \ldots \ldots$

7.7 Air-conditioning psychrometric process for Fig. $7.6 \ldots \ldots \ldots \ldots \ldots$

7.8 Two-stage gas energized desiccant cold-air unit for small commercial buildings

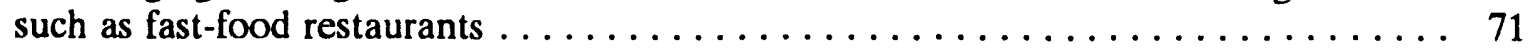

7.9 Two-stage gas energized desiccant/congeneration unit for supermarkets $\ldots \ldots \ldots \ldots 72$

A1.1 Outlet air conditions in process and reactivation air streams leaving a silica gel

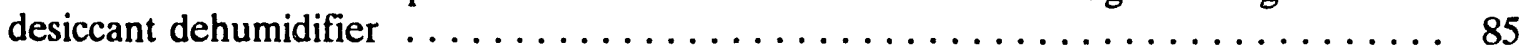

A1.2 Brunauer isotherms of types 1 and 3 compared to a linear sorption isotherm ..... 87

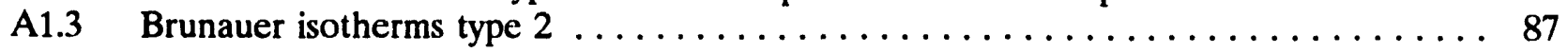

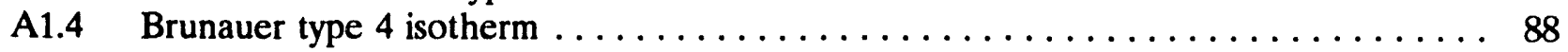

A1.5 Brunauer type 5 isotherm $\ldots \ldots \ldots \ldots \ldots \ldots \ldots \ldots \ldots \ldots \ldots \ldots \ldots \ldots$

A1.6 Adsorption isotherms of typical desiccants $\ldots \ldots \ldots \ldots \ldots \ldots \ldots \ldots$

A1.7 Ideal isotherm for desiccant cooling applications $\ldots \ldots \ldots \ldots \ldots \ldots \ldots \ldots \ldots \ldots$

A1.8 Type $1 \mathrm{M}$ isotherm, including the effects of heat of adsorption $\ldots \ldots \ldots \ldots \ldots$

A1.9 Simulated isotherms for various types of desiccants $\ldots \ldots \ldots \ldots \ldots \ldots \ldots \ldots \ldots$

A2.1 Model comparisons for type $1 \mathrm{M}$ isotherm $\ldots \ldots \ldots \ldots \ldots \ldots \ldots \ldots$

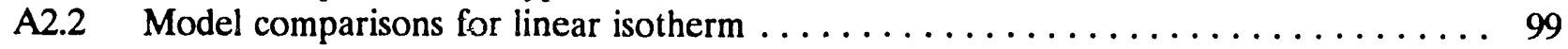

A2.3 Model behavior for various time steps - MOSHMX $\ldots \ldots \ldots \ldots \ldots \ldots$ 


\section{LIST OF FIGURES (continued)}

A2.4 Model behavior for various time steps - Enerscope $\ldots \ldots \ldots \ldots \ldots \ldots \ldots$

A2.5 Comparison of adsorption process outlet humidities $\ldots \ldots \ldots \ldots \ldots \ldots \ldots \ldots \ldots$

A2.6 Comparison of reactivation outlet humidities $\ldots \ldots \ldots \ldots \ldots \ldots \ldots \ldots \ldots \ldots \ldots$

A2.7 Comparison of adsorption outlet himidities $\ldots \ldots \ldots \ldots \ldots \ldots \ldots \ldots \ldots \ldots \ldots \ldots$

A2.8 Comparison of reactivation outlet humidities $\ldots \ldots \ldots \ldots \ldots \ldots \ldots \ldots \ldots \ldots$

A2.9 MOSHMX adsorption process outlet humidities (constant time step vs two

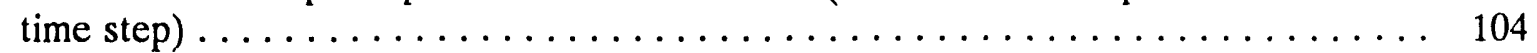

A2.10 MOSHMX adsorption reactivation outlet humidities (constant time step vs two

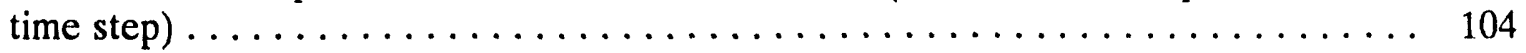




\section{LIST OF TABLES}

7.1 Desiccant HVAC systems office space potential market 10 -year application $\ldots \ldots \ldots 58$

7.2 Supermarket desiccant/cogeneration unit - potential 20 year applications $\left(30,000 \mathrm{ft}^{2}\right.$

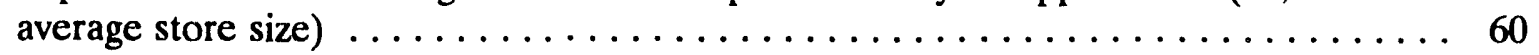

7.3 Small commercial building desiccant heating/cooling unit-potenital 10 year applications

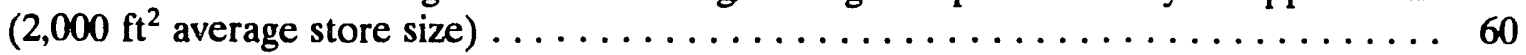

7.4 Buiding characteristics, design conditions, peak loads, and site utility rates $\ldots \ldots \ldots 75$

8.1 Estimated electrical energy used for residential cooling $\ldots \ldots \ldots \ldots \ldots \ldots \ldots$

8.2 Estimated desiccant cooling system energy impact (in quads) for residential sector with COP of conventional cooling system assumed to be $2.0 \ldots \ldots \ldots \ldots \ldots \ldots$

8.3 Estimated desiccant cooling system energy impact (in quads) for residential sector with COP of conventional cooling system assumed to be $3.0 \ldots \ldots \ldots \ldots \ldots \ldots$

8.4 Estimaed electrical energy used for commercial cooling $\ldots \ldots \ldots \ldots \ldots$

8.5 Estimated desiccant cooling system energy impact (in quads) for commercial sector with COP of conventional cooling system assumed to be $2.0 \ldots \ldots \ldots \ldots \ldots \ldots$

8.6 Estimated desiccant cooling system energy impact (in quads) for commercial sector with COP of conventional cooling system assumed to be $3.0 \ldots \ldots \ldots \ldots \ldots \ldots$

A2.1 Performace comparison among various models $\ldots \ldots \ldots \ldots \ldots \ldots \ldots$

A2.2 Comparison of dehumidifier performace predictions - UIC and IIT models . . . . 106

A2.3 Comparison of dehumidifier performace predictions - UIC, MOSHMX, and

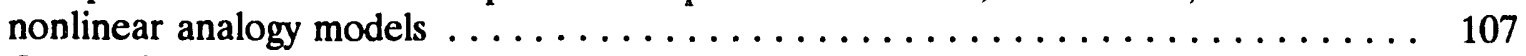

A2.4 Comparisons of cooling system performace predictions $\ldots \ldots \ldots \ldots \ldots \ldots \ldots$ 


\section{EXECUTTVE SUMMARY}

Traditional vapor compression cooling systems use electrical power to cool and dehumidify air. In contrast, desiccant systems use thermal energy to accomplish the same effect. When properly applied, desiccant systems can save energy compared to traditional systems, and can provide other benefits as well. For example, desiccant systems can:

- Control the humidity of air independently of its temperature, and they can control humidity at very low levels.

- Operate without using Chlorinated Fluorocarbon Compounds (CFCs), identified as contributors to depletion of the ozone layer.

- Balance a large air conditioning energy requirement between several fuel sources-the desiccant system controls humidity using thermal energy and a vapor-compression system controls building temperature.

- Avoid the high humidity which creates indoor air quality problems.

- Avoid wasting energy used to replace materials damaged by water, moisture corrosion and mildew.

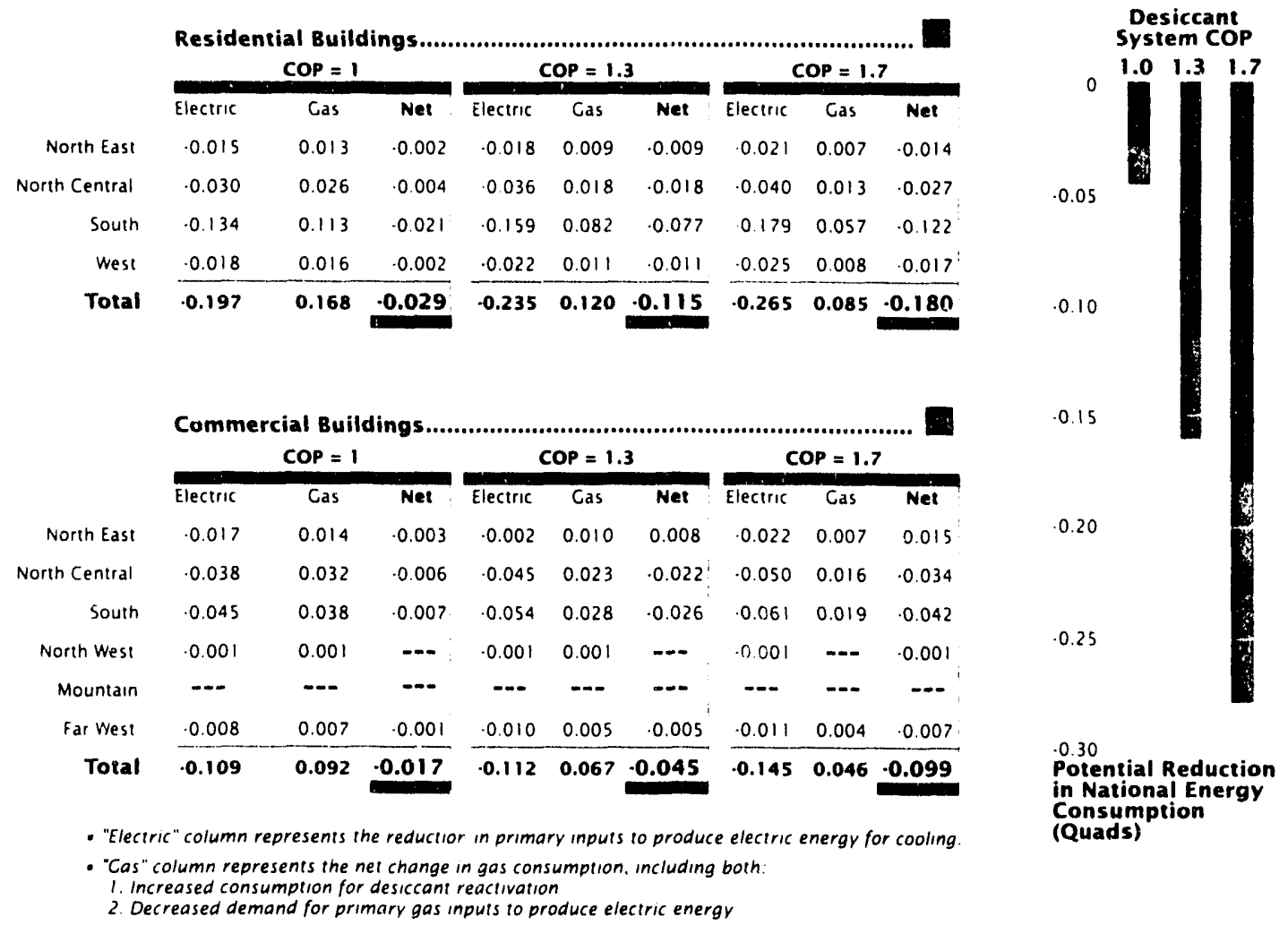

Figure E1 Potential annual energy reduction due to the use of desiccant-based air conditioning 
Until recently, the efficiency of desiccant cooling systems was below break-even. The energy invested in running the system was more than the air cooling effect at typical comfort conditions. Low efficiency limited the use of desiccant systems to narrow markets where the benefits described above outweigh the energy premium. However, technological advances show promise of improved coefficients of performance (COPs). These advances can reduce national energy consumption significantly.

\section{How Desiccant Systems Work}

A desiccant is a solid or liquid which dries air by attracting water molecules onto the desiccant surface. The dry air is then cooled by direct or indirect evaporation and sent to the air conditioned space.

After the desiccant becomes saturated, it is heated to release the moisture it attracted from the air. This is called "reactivating" the desiccant. Many materials can collect and release moisture from air in this manner. For example, even nylon can collect up to $7 \%$ of its dry weight in moisture. However, materials used commercially as desiccants have a large capacity for moisture (between 30 and $1200 \%$ of their dry weight). Also, desiccant materials can be reactivated (dried) at temperatures low enough to allow economical operation (between $120^{\circ}$ and $250^{\circ} \mathrm{F}$ ).

\section{Solid Desiccant Systems}

In solid desiccant systems, air is circulated through a bed of absorptive material like silica gel or zeolite. As the moist air passes through the bed, it gives up water vapor to the desiccant. Then the saturated desiccant is heated. This releases moisture to a different air stream, drying the desiccant so it can be used once again. Typically, the desiccant is loaded into a rotating tray or impregnated into a honeycomb-form wheel, which rotates slowly between the dry air stream (process) and the heated air stream (reactivation). This constant reactivation allows the equipment to provide a continuous stream of dry air to the air conditioned space.

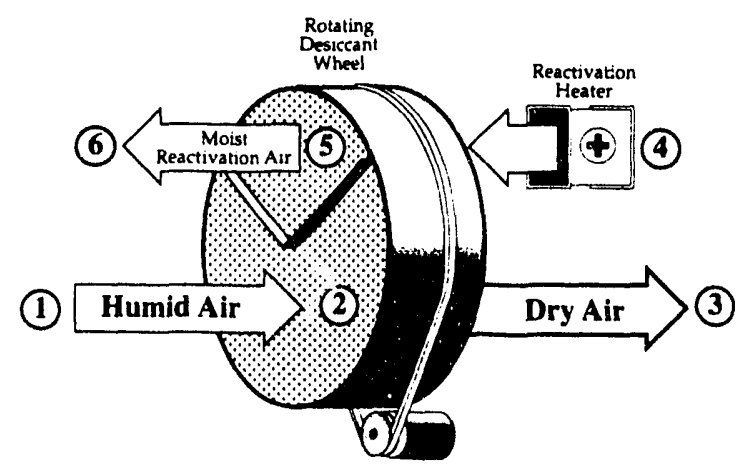

1. Humid air enters the roating bed of dry desiccant

2. As air passes through the bed, the desiccant attracts moisture from the air.

3. Air leaves the desiccant bed warm and dry. Cooling is accomplished by separaie components downstream of the desiccant bed.
4. A small air stream is heated and passed though the desiccant bed to raise its temperature.

6. Heated desiccant gives off its collected moisture to the small warm air stream coming from the heater.

6. The moist reactivation air stream is vented to the weather, carrying excess humidity away from the building being $\mathrm{c}$ ir conditioned.

Figure E2 Typical open-cycle solid desiccant system 


\section{Liquid Desiccant Systems}

In liquid desiccant systems, humid air is passed through a cooling coil, or through a contact surface like cooling tower packing, which has been wetted with liquid desiccant. The desiccant absorbs moisture from the air, which makes the liquid solution more dilute. The dilute desiccant is sent through a heater and sprayed into a small reactivation air stream. The reactivation air carries away water vapor given off by the warm desiccant, so the re-concentrated solution can be used for drying air once again.

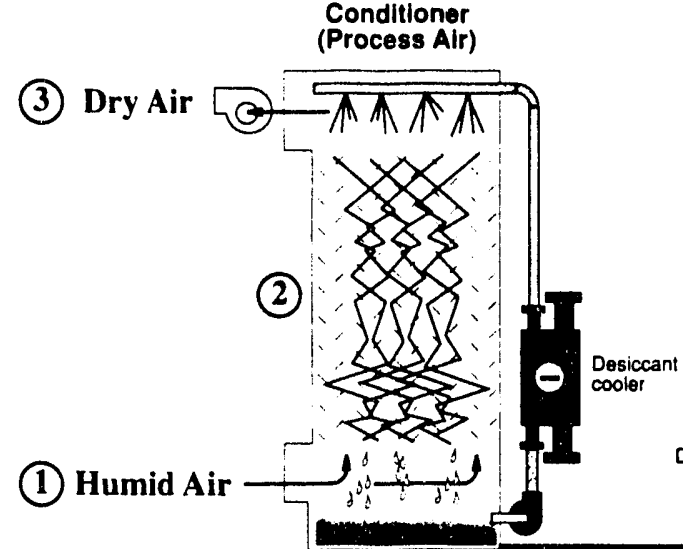

(4)

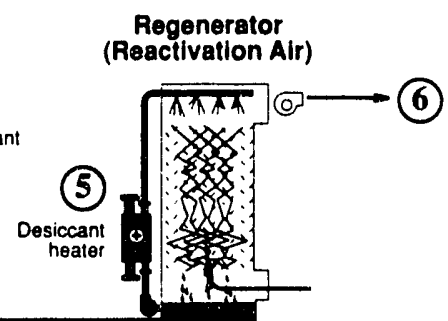

(7)
1. Warm, humid air enters the desiccant system at the base of a packed tower.

2. Liquid desiccant is sprayed over the packing material. As air passes across the wetted bed, it gives up heat and moisture to the liquid desiccant.

3. Air leaves the desiccant system cool and dry.

4. The liquid desiccant collects as a dilute solution at the base of the packed tower. Then it circulates to the regenerator to be reconcentrated.
5. A heater raises the temperature of the dilute desiccant solution.

6. A small purge air stream removes moisture from the heated liquid desiccant.

7. The reconcentrated liquid desiccant collects at the bottom of the regenerator. The liquid is recirculated back to the conditioner so it can dry more air.

\section{Figure E3 Typical open-cycle liquid desiccant system*}

*Source: Dehumidification Handbook, published by Munters Cargoaire, 1990

In both liquid and solid desiccant units, the desiccant material itself is quite stabile, allowing tens of millions of cycles (several years operation) before the desiccant must be replaced.

\section{Making The Best Use Of Current Desiccant Technology}

In general, desiccant systems are most advantageous when:

1. Thermal energy is available and inexpensive, or when electrical energy is limited or costly. For example, use desiccant systems where electrical demand is high and available capacity is low, or where waste heat is available. 
2. The moisture component of the air conditioning load is high compared to the sensible heat load. For example, air conditioning systems for supermarkets have a very low heat load since the display cases also cool the store. The remaining load is mostly moisture.

3. Low humidity control levels are advantageous. For example, steel warehouses can be dehumidifie 1 rather than heated during the winter, saving energy and avoiding rust, but the dehumidification system must be operate at a low temperature and a low humidity control level.

4. An air conditioning system must operate without high relative humidity in duct work and without condensed water in drain pans. For exarnple, air distribution systems in buildings can harbor fungi which create indoor air quality problems. Desiccant systems keep the air dry in the ductwork, preventing microbial growth.

\section{Historic Overview}

Desiccant systems have been used in the United States since the early 1930's, primarily for industrial applications where there is an economic benefit to close-tolerance humidity control at low levels.

For 60 years, desiccant systems have been successful where there is a great deal of money, or a large capital asset at risk, and where the cost of the desiccant equipment is low by comparison. For example, micro-electronic circuits are produced in rooms which cost hundreds of thousands of dollars per day to operate. If the process is interrupted because of high humidity, the lost production pays for a desiccant system installation within a matter of hours.

In other examples, the brewing industry has used desiccant systems in fermentation cellars, maintaining humidity low enough to prevent sanitation problems. The pharmaceutical industry has traditionally used low-humidity environments to avoid product contamination, extend shelf-life and eliminate manufacturing problems. The marine industry has used desiccant equipment to avoid condensation and corrosion in ship cargoes, and the military has used the equipment to preserve armaments and equipment in storage.

Comfort-conditioning applications for desiccants have benefits associated with humidity control which are more difficult to quantify than benefits associated with industrial applications. Consequently, installations in commercial buildings have not been common until the last ten years.

Early desiccant applications in comfort control involved semi-process installations such as medical buildings, which profit from the air cleaning and sterilization effects of liquid desiccant systems. But in general, comfort-related applications have been dominated by vapor-compression cooling technology because to date, it has enjoyed some basic advantages over desiccants in operating efficiency. By way of comparison, vapor-compression air conditioning systems may operate with coefficients of performance (COP's) of 2.5 to 3.5 in the comfort range, where typical COP's ior desiccant systems have been below 1.0.

Since 1985, however, desiccant systems have become more widely applied in comfort-related installations such as supermarkets. This is because of advances in the basic technology, and changes in the cost difference between electrical power and thermal energy. 
In the future, desiccant systems are likely to expand their range of applications. Trends which suggest this conclusion include:

- Increased competition among desiccant manufacturers.

- Basic advances in desiccant materials, with resulting improvements in system COP.

- The current trend to increase the amount of fresh air used in buildings (Which increases the latent fraction of the total building heat load.

- Recognition by building design engineers of the harmful effects of excess humidity on indoor air quality, building furnishings and structural elements.

\section{Technology Options - Materials and Systems}

Technology options for desiccant systems fall into one of two broad categories:

1. Desiccant-only systems

2. Systems which combine desiccant components with vapor compression cooling elements

Systems which rely on desiccants for all cooling and dehumidification can use the advantage of using low-temperature, inexpensive energy. However, such systems tend to be large compared to conventional cooling because they use larger air flows and smaller temperature differences to cool a given space. Also, desiccant-only systems rely on indirect or direct evaporative cooling for sensible temperature control, and the resulting water-side maintenance issues can be an installation and operational disadvantage.

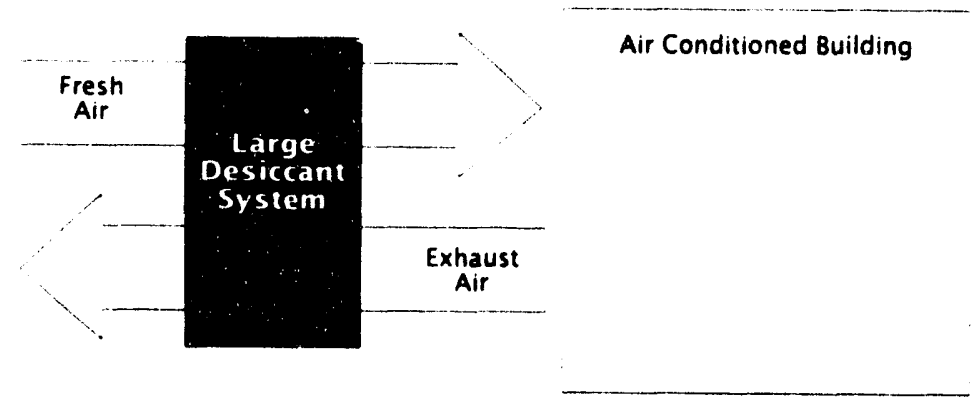

\section{Option 1 - All Desiccant}

+ Lowest operating cost

+ Ample ventilation

+ Least energy consumption

- Expensive first cost

- Large equipment \& large ductwork

- Requires water (evaporative cooling)

- Ideal desiccant reactivated at low temperaturtes

- Heat exchanger efficiency is critical

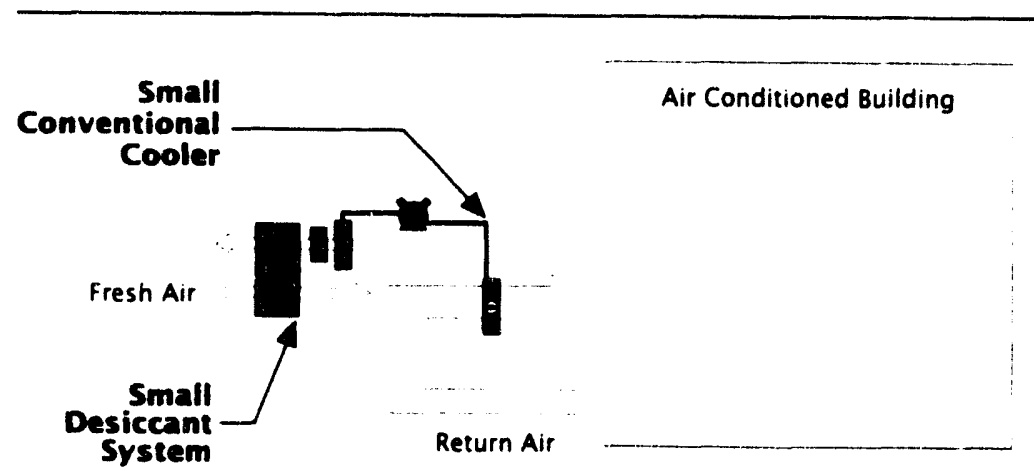

Option 2 - Combined System

+ Lowest installed cost

+ Small equipment \& ductwork

+ Simple to maintain (no water)

- Somewhat more energy

- CFC's still in use

- Cooling-desiccant integration required

- Ideal desiccant has deep-drying capacity

- Cooling system must be adapted to high temperature differences

Figure EA Desiccant system configurations and technology implications 
Systems which combine desiccants with conventional cooling are lower in first cost than desiccant-only systems because they use smaller equipment and smaller air flows to cool a given space. However, they use more high-cost energy than desiccant-only systems.

To date, the lower installed cost and perceived lower maintenance of combined systems has given them an advantage in the commercial market place.

\section{Technology Status}

In the last ten years, significant progress has been made in five basic components of desiccant technology. These include:

1. Desiccant-air contactors

2. Reactivation energy sources

3. Cooling sources

4. Reactivation energy storage (peak-shifting)

5. Desiccant materials

Desiccant contactors

In desiccant systems, the component which presents the desiccant to the air stream (the desiccant contactor) is one of the most critical elements of the system, and the one which most influences the net energy consumption of the system.

Ideally, the desiccant contactor would have an infinitely large surface area for desiccant-air interaction, but infinitely low mass, so no excess material must be heated and cooled along with the desiccant. Further, the contact media must be very durable, as it is repeatedly wetted and dried as the desiccant moves through the sorption-desorption cycle.

In rotating, honeycomb-form dry desiccant systems, the state-of-the-art contactor is a silica gel-impregnated rotor consisting mainly of fibrous glass paper with a silicate binder. These "silica gel wheels" are better suited to commercial and residential desiccant systems than rotors which use lithium chloride as the principal desiccant. Silica gel is more fault-tolerant than lithium chloride.

In rotating tray-type dry desiccant systems, manufacturers have recently developed segmented-bed designs for the rotating trays which support the granular desiccant. Partitions inside the desiccant bed reduce air leakage, which in turn allows the process and reactivation air streams to be arranged for counter flow heat and mass transfer. This counter flow arrangement has reduced the energy consumed by rotating tray units by $50 \%$, a major improvement in the technology. Segmented-bed designs are now energy-competitive with honeycomb-form rotary units.

In liquid systems, the state-of-the-art contactor consists of a corrugated extended surface much like the contact media in a cooling tower. Recent R\&D activities have centered on adding low-energy internal cooling to the contact surface. In this arrangement, liquid desiccant is sprayed onto one side of a plate-type air-to-air-heat exchanger, where it absorbs moisture from the process air. On the second side of the heat exchanger, a water spray cools the surface, removing the heat of absorption from the desiccant flowing across the opposite side of the air-to-air heat exchanger. This device, 
called a "three-way heat exchanger" shows great promise for raising the COP of liquid systems above 1.0.

\section{Reactivation energy sources}

The largest energy expenditure in a desiccant system is the heat used to reactivate the saturated desiccant. Considerable effort has been invested to reduce both the amount and the cost of this energy, centering mainly on the use of waste heat normally available within building air conditioning systems.

In systems, which use desiccants as a component in a larger vapor-compression cooling system, waste heat from refrigerant condensers is used for desiccant reactivation. In addition to providing low-cost reactivation heat, the extra heat exchange surface in the refrigeration condenser has a beneficial eiffect on the COP of the cooling system.

Manufacturers have also introduced desiccant systems which include cogeneration components as well as vapor-compression cooling systems. In these designs, waste heat from the electrical generator provides low-cost reactivation energy.

The advances in desiccant contactors for rotating honeycomb-form dry desiccant systems have allowed significant reductions in reactivation energy when natural gas is used as a heat source. Unlike lithium chloride, silica gel is not sensitive to the products of combustion of natural gas. Where lithium chloride rotors need to use indirect gas heaters, silica gel rotors can use direct-fired burners, allowing a 20 to $30 \%$ increase in energy utilization.

Finally, "Staged reactivation" is being used by many manufacturers to reduce the size of the desiccant unit while also using low-cost heat sources for reactivation. Low-temperature waste heat can be used by itself for reactivation, but it forces the use larger, more costly desiccant hardware. Essentially, the surface is increased to compensate for the smaller driving force of the low-temperature heat. Manufacturers have recognized and minimized this problem by developing two-stage reactivation circuits. Low-temperature heat is used to pre-heat the desiccant, and a much smaller amount of high-temperature heat is used to dry the desiccant more deeply. These two stages of reactivation provide the necessary capacity to allow the use of smaller, lower cost equipment.

\section{Cooling}

Sensible cooling accounts for the second largest energy expenditure in a desiccant system. Heat must be removed from the desiccant and from the air.

In both liquid and solid systems, manufacturers have focused efforts on ways to cool the process air by moving its heat to the reactivation circuit. This reduces both the cost of cooling and the cost of reactivation heat.

In solid systems, air-to-air heat exchangers are now used to cool the warm air leaving the process section of the unit and pre-heat the air entering reactivation. Either heat pipes or plate-type heat exchangers are used for this purpose. Such an arrangement reduces cooling requirements by more than $30 \%$ and reduces reactivation energy requirements by more than $20 \%$ in typical comfort-conditioning applications. 
In liquid systems, the warm desiccant leaving the regenerator is cooled by the dilute desiccant coming from the conditioner by a shell-and-tube or plate-frame liquid heat exchanger. As in solid systems, such an "intercooler" reduces energy in both cooling and desiccant reactivation.

Additionally, the three-way heat exchanger described earlier as a means of improving a liquid desiccant contactor also improves the economics of cooling a liquid desiccant system. As a result, manufacturers and research institutions have devoted considerable resources to lowering the cost and improving the reliability of this component for liquid systems.

\section{Energy storage}

As in traditional cooling systems, the peak load determines the capacity and cost of the system. However, the peak load is only experienced for $2 \%$ of the hours in the year. The system may need $50 \%$ reserve capacity to be able to cool a building on a peak load day.

In order to reduce the size of the desiccant system and therefore reduce both initial cost and operating cost, research has been focused on reactivating desiccant during off-peak hours and storing it for use during peak periods.

In a liquid system, this is easily accomplished by adding desiccant storage tanks to the system. These hold concentrated desiccant for use during peak periods. The more difficult challenge is economic. Presently, the cost of the additional desiccant together with the controls, tanks and piping is larger than the cost of a system with enough basic capacity to meet the peak load.

In a solid system, the great bulk of dry desiccant required for storage makes such a strategy impractical.

However, considerable basic research has been invested in determining the sorption capacity and dynamics of building structures themselves. Gypsum, carpeting and fabrics can all attract and hold water vapor. In the future, it may be possible to take advantage of this effect by drying the building slightly when reactivation energy is available at low cost. This effectively uses the entire hygroscopic building mass as a means of storing energy.

This promising concept is currently limited by existing, older-generation building energy simulation programs, which cannot account for the sorption-desorption effect of building components on system energy consumption.

\section{Desiccant materials}

The behavior of all desiccant system components is profoundly influenced by the operating characteristics of the desiccant materials they contain. Recognizing this fact, research institutions and manufacturers have focused on material science to develop desiccants which are especially suited to air conditioning applications.

These efforts have had two primary goals; to develop desiccants which:

1. Use less energy for reactivation and therefore need less energy for cooling

2. Are more stable and fault-tolerant and therefore require less maintenance 
Research supported by the Gas Research Institute has identified the sorption characteristics which are best suited to minimizing the costs of desiccant air conditioning systems in typical residential and

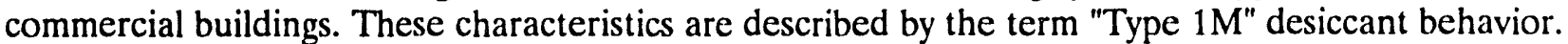
The name originates from a classification system for desiccant characteristics suggested by Stephen Brunauer in 1945. The system classifies material behavior according to the shape of its sorption isotherm. Materials with type 1 behavior adsorb moisture very rapidly above a certain relative humidity, and desorb moisture readily when the surrounding air falls below that threshold relative humidity.

Most Type 1 materials adsorb moisture readily at relative humidities below $5 \%$. However, the ideal desiccant for air conditioning applications would adsorb and desorb moisture across a narrow threshold between 35 and $55 \%$ relative humidity. Therefore, the material is described as having "Type 1 - Modified" behavior, or more briefly, "Type 1M".

While some progress has been made by manufacturers, as yet there is no Type $1 \mathrm{M}$ desiccant material available commercially. A durable, low-cost Type $1 \mathrm{M}$ material will make significant improvements in desiccant system cost and energy consumption.

\section{Future Research \& Development Needs}

Research project alternatives can be judged according to a simple standard; To what extent and how quickly will they contribute to realizing energy savings through the adoption of desiccant air conditioning in buildings?

The most productive research will focus on improving the cost-benefit ratio of desiccant equipment. At present, the costs of such systems are often too high to be balanced by a "Two-year Payback"; the criterion commonly employed by building owners as they judge the attractiveness of new technology. This ratio can be improved by research which lowers the costs of desiccant technology, and by projects which increase its benefits.

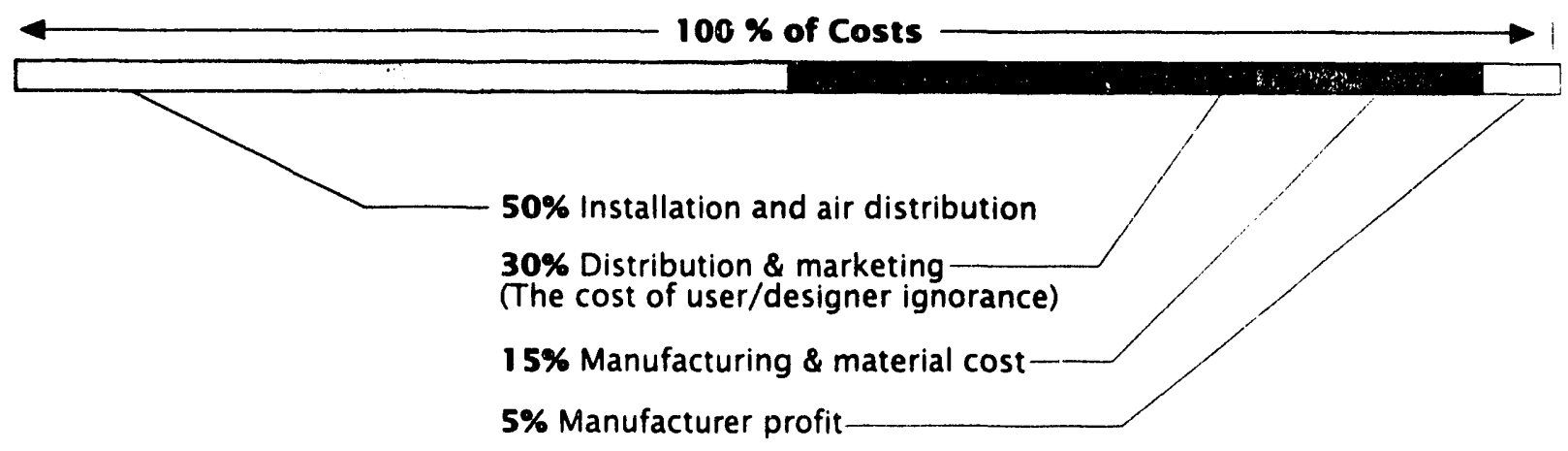

Figure E5 Principal cost elements of installed desiccant systems 
Reducing costs

The largest costs associated with desiccant technology are its installation and its distribution. R\&D projects can contribute to reducing these costs:

1. Reduce the cost of ignorance by increasing tech transfer (research data-to-manufacturer).

The results of tens of millions of dollars in desiccant research are not widely distributed to equipment manufacturers. In fact, most manufacturers of air conditioning equipment are not even aware of the scope and results of these efforts. Projects to broadly disseminate the results of research will likely be even more productive than projects to further advance the technology itself.

2. Reduce the cost of ignorance by increasing tech transfer (research data-to-designer/end user).

While many buildings could currently benefit from desiccant technology, the designer/user base is generally neither aware of the potential benefits nor familiar enough with the technology to make an informed assessment concerning them. Projects to develop tools to assess the technology and to explain its costs and benefits clearly will reduce the largest cost of desiccants; its distribution and installation. Designer/user ignorance is the largest component of the current cost of desiccant equipment.

3. Improve equipment reliability and simplify maintenance.

Desiccant technology does not enjoy a fully-developed support infrastructure. Consequently, service costs are comparatively high. Research projects which increase reliability and serviceability of desiccant materials, components and systems will significantly reduce current costs of the technology.

Increasing benefits

The energy conservation benefit of desiccant technology can also be improved through research and development:

1. Improve desiccant component integration with conventional cooling.

Desiccant systems use heat productively and require sensible cooling. Vapor compression cooling systems provide waste heat and provide economical sensible cooling. Projects to improve the integration of desiccant sub-systems into conventional building air conditioning systems will improve the benefits supplied by both technologies.

\section{Improve cooling COP of desiccant systems.}

State-of-the-art desiccant systems often have coefficients of performance below 1.0. To increase the benefits offered by this technology, its operating efficiency must be improved.This can be accomplished by research projects to develop: materials with Type $1 \mathrm{M}$ behavior, components 
to cool air in the system more efficiently, better methods of controlling system operation and lower cost reactivation methods.

Other important benefits of desiccant system include improvements in indoor air quality. Desiccants provide the low humidity needed to eliminate the growth of microorganisms in duct work, building structures and in furnishings. The materials can also be used to adsorb many volatile organic compounds (VOCs) from indoor environments. Research and development can help enhance these end user benefits:

1. Improve indoor air quality through reduced microbial growth.

Dry air is known to reduce the growth of microorganisms both in the air and in humid materials. However, the nature and quantitative aspects of this phenomenon are not well understood. Research in this area can have substantial public health and worker productivity benefits which may exceed the energy benefits of desiccant systems.

2. Improve indoor air quality by removing air pollutants with desiccants.

Desiccant materials can collect more than just water vapor from air. In industry, desiccants are widely used to perform separations from complex mixtures of organic and inorganic compounds. Research projects to quantify the pollutant-removal effects and establish a strong theoretical basis for understanding these phenomena will substantially increase the benefit of desiccant components in building air conditioning systems.

3. Improve useful life of buildings, materials and products through dry air technology.

Buildings and products suffer from the effects of excess humidity. The American Hotel and Motel Association estimates that 8,000 of the 45,000 hospitality structures in the US spend over $\$ 68$ million each year due to mold and mildew damage brought on by excess moisture. The National Association of Corrosion Engineers estimates that metallic corrosion costs the US economy over $\$ 220$ billion a year. Farm crop losses due to excess moisture exceed $\$ 300$ billion annually. All of these costly problems can be significantly reduced by the use of dry air technology. Research projects which quantify the actual benefits and establish engineering guidelines for the use of dry air will provide significant benefits for the national economy.

\section{Conclusion}

Desiccant technology has the potential to make major contributions to energy conservation, improve indoor air quality and to reduce the cost of moisture damage to buildings and products. However, state-of-the-art materials, components and systems are not widely understood or in use in the building industry. Well-coordinated research and development efforts of industry, government and research institutions will be needed to fully realize the benefits of this established, but under-utilized technology. 


\section{ACKNOWLEDGMENTS}

The authors would like to thank Mr. P. D. Fairchild for his close supervision and many useful discussions of this project. The authors deeply appreciate Messrs. J. Ryan and E. Kweller of the Department of Energy for their constant support and encouragement throughout this project. The Authors appreciate Mr. G. Hadder's providing data for the energy impact study. The authors would like to thank Mr. L. Harriman of Mason-Grant Co. for his technical editing work on this report. Finally, the authors appreciate the preparation of this report by Ms. D. Penland. 


\begin{abstract}
Desiccant systems are heat-actuated cooling and dehumidification technology. With the recent advances in this technology, desiccant systems can now achieve a primary energy coefficient of performance (COP) between 1.3 and 1.5 , with potential to go to 1.7 and higher. It is becoming one of the most promising alternatives to conventional cooling systems.

Two important and well-known advantages of desiccant cooling systems are that they are CFC free and they can reduce the electricity peak load. Another important but lesser-known advantage of desiccant technology is its potential for energy conservation. The energy impact study in this report indicated that a possible $13 \%$ energy saving in residential cooling and $8 \%$ in commercial cooling is possible. Great energy saving potential also exists in the industrial sector if industrial waste heat can be used for desiccant regeneration.
\end{abstract}

The latest study on desiccant-integrated building heating, ventilating, and air conditioning (HVAC) systems indicated that the initial cost for the conventional cooling equipment was greatly reduced by using desiccant technology because of downsized compressors, fans, and ductworks. This cost reduction was more than enough to offset the cost of desiccant equipment. Besides, the system operation cost was also reduced. All these indicate that desiccant systems are also cost effective.

This study provides an updated state-of-the-art assessment for desiccant technology in the field of desiccant materials, systems, computer models, and theoretical analyses. From this information the technology options were derived and the future research and development needs were identified.

A historic overview lists what has already been done and who is doing what. This information will help us to project the future of this technology.

Because desiccant technology has already been applied in the commercial building sector with very encouraging results, it is expected that future market breakthroughs will probably start in this sector. A market analysis for the commercial building application is therefore included.

While this report shows that a great amount of work has already been accomplished, it also indicates that much more work is needed before this economically promising and environmentally safe technology can reach its full potential. 


\section{TECHNOLOGY INTRODUCTION}

\subsection{Principles of Desiccant Cooling and Dehumidification (DCD)}

Desiccant heating and cooling is based on the physical process by which water vapor is collected and released (sorbed and desorbed) by desiccant materials, which can be either liquids or solids. Evaporation of the water provides the cooling effect and its condensation produces the heating effect. The desorption process, and therefore the desiccant cycyle, is driven by heat. When desiccant materials are hot, they give up moisture. The control, capacity, efficiency, and economics of DCD systems largely depend on the management of thermal energy within the system. DCD systems can be operated on either open or closed cycles. The main difference is that open cycles operate at close to atmospheric pressure, while closed cycles are usually operated at r ither higher or lower than the atmospheric pressure.

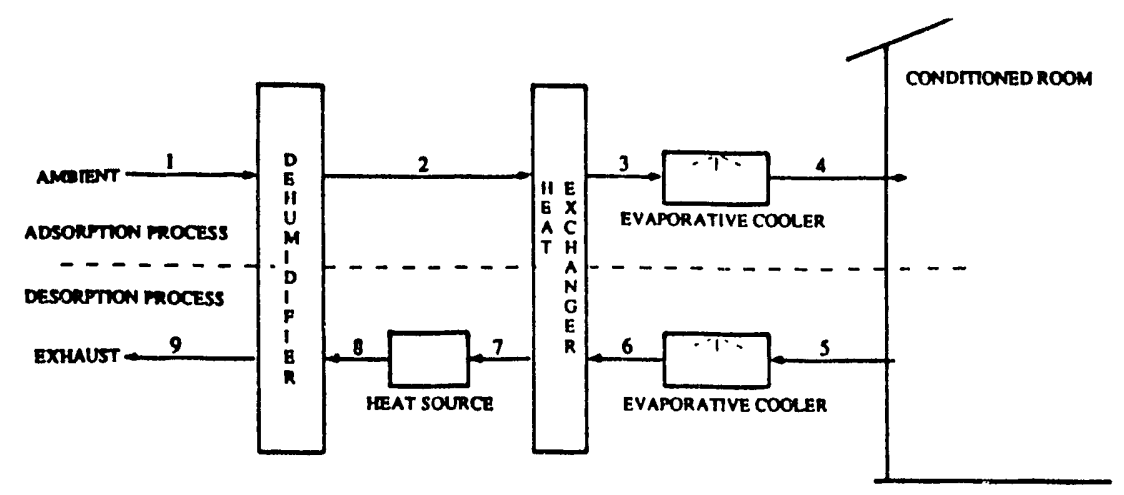

Figure 1.1 Schematic of one type of open-cycle desiccant cooling system

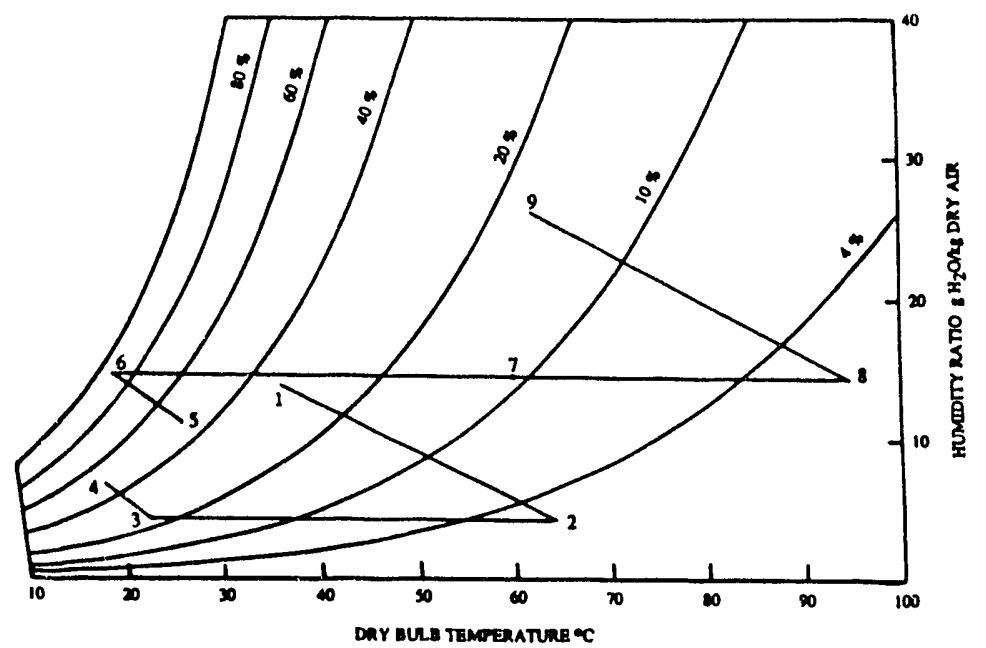

Figure 1.2 Psychrometric representation of the system shown in Figure 1.1

Figure 1.1 shows an open-cycle DCD system with $100 \%$ fresh air. This is the most common DCD system. The ambient air, point 1 , flows through a desiccant dehumidifier and becomes hot and dry, 
point 2. This air then flows through a sensible heat exchanger to be cooled down, point 3 . The dry, cooler air then flows through an evaporative cooler to be cooled toward its wet bulb temperature and is delivered to the house, point 4. The exhaust air from the house at point 5 flows through the evaporator to be cooled to point 6 , and then flows through the sensible heat exchanger to exchange heat with processed air. The exhaust air from the heat exchanger, point 7 , flows through a heat source to elevate its temperature to point 8 . This hot exhaust air is used to regenerate the desiccant dehumidifier. Figure 1.2 shows the same state point on a psychrometric chart. The system is operated in the recirculating mode if indoor air is used at point 1.

Such regenerative drying of air by desiccants has extensive commercial and industrial applications. For open-cycle systems, the processed air temperature usually is limited to $10^{\circ} \mathrm{C}\left(50^{\circ} \mathrm{F}\right)$ or higher because water is involved in the cooling process. For closed-cycle systems (see the Technical Option Section) no such limit is imposed because ordinary refrigerants can be used. It is possible to operate a closed-cycle system for refrigeration.

\subsection{Advantages and Potential Limitations of DCD Systems}

There are many advantages of DCD systems; some are related to the environment, some to energy conservation, and some to reduced equipment initial cost and operating cost. These advantages are discussed below.

- No CFC refrigerants are used. Because the majority of DCD systems will be open-cycle systems, water and air are the only fluids used. DCD systems are an environmentally acceptable alternative to vapor compression cooling systems.

- Figures 1.1 and 1.2 show that DCD systems are heat-actuated cooling devices, which only need a small amount of parasitic electric power for system operation. DCD systems will therefore reduce the consumption of electricity. This is significant because it reduces the peak load as well.

- $\quad$ DCD can be operated with low-temperature heat. If waste heat is available to regenerate desiccant material, the efficiency of such a system will be very high. If no prime fuel is used in regenerating desiccant material, besides saving energy, DCD also reduces the emission of carbon dioxide to the atmosphere.

- When a DCD system is integrated into a conventional cooling system to remove latent load, it enables the conventional system to handle sensible load only. This removal of latent load will reduce the size of compressors, fans, ductwork, etc., and thus will reduce the initial equipment cost - usually more than enough cost reduction to offset the cost of desiccant equipment.

- With additional material, such as activated carbon, added on to desiccant dehumidifiers, they can also absorb undesirable odor and particles, and thus improve indoor air quality.

- Because DCD operation (open cycle) is near atmospheric pressure, construction, and maintenance are simplified. 
- DCD systems use a minimum number of moving parts which also reduces the operating and maintenance costs.

- DCD systems are very effective for conditioning spaces with high latent load when $100 \%$ fresh air is required, and for humidity-sensitive applications.

- For closed-cycle systems, high system COP can be achieved when the concept of heat regeneration is used and sharp thermal waves are sustained.

- For closed-cycle DCD systems, systcm performance is practically independent of condenser temperature.

- With closed-cycle systems, low refrigeration temperatures can be achieved.

- For liquid DCD, energy storage is convenient since energy is stored as chemical rather than thermal energy.

The potential limitations of all desiccant systems are a relatively high installed cost and the lack of a large, nation-wide base of qualified service personnel.

For liquid DCD systems, the desiccant used is sometimes corrosive and can damage systems or ancillary components. Solid systems can suffer desiccant attrition or clogging, and the cost of rotating desiccant wheels can, like the cost of replacing a refrigeration compressor, be comparatively expensive.

Recent DCD developments include two-stage systems for office buildings, closed-cycle systems for refrigeration or energy storage, a heat-wave-catching operating strategy, plastic polymer desiccants, a newer approach in making desiccant wheels, etc. All these advances in DCD indicate that desiccant technology is well on its way to becoming an economically viable cooling alternative to conventional vapor compression systems. 


\section{HISTORIC OVERVIEW}

Much work has been accomplished in the DCD field in the past. This section briefly survey the commercial history of the technology and then describes more recent research-oriented developments.

\subsection{Commercia' Development}

Desiccant air conditioning technology developed in the United States before the advent of vaporcompression cooliag. The Kathabar liquid desiccant system, introduced in 1910, was the first air conditioning use of a technology that had previously been used largely in chemical process and petroleum refining operations. During the 1930's, the Niagara Blower Company began using a desiccant solution (Triethylene Glycol) as a means of removing frost from evaporator coils in refrigeration systems. The system had dehumidification as well as defrosting capabilities, and continues in use today.

Parallel to the development of liquid systems, solid desiccant systems were put into use by the Lectrodryer Company in the form of large, dual-tower and other static-bed designs. During the middle 1930's, Lectrodryer, along with a division of the Bryant Heater Company (now named BRY-AIR) and Cargocaire Engineering Corporation (now named Munters Cargocaire), manufactured various types of fixed-bed desiccant systems, principally for applications in industry.

In 1940, however, an article in the Cleveland Press (Jan. 22, 1940, "Today's Business - Bryant's New Product") [1] indicates that manufacturers of desiccant equipment retained an interest in comfort-conditioning markets. During the 1950's, Kathabar successfully applied their liquid desiccant system to hospital ventilation systems. This application takes advantage of the bacteriocidal characteristics of lithium chloride to scrub the air free of microorganisms in addition to removing excess humidity and delivering air at a controlled temperature.

During the 1950's, manufacturers of solid desiccant systems turned to rotating-bed designs, because of their considerable thermal and cost advantages over fixed-bed designs in ambient-pressure applications. In addition to designs developed at Bryant Company, the Airflow Company introduced a line of counterflow, segmented-bed machines which made major improvements in the operating economics of dry desiccant systerns.

In 1960, Munters Cargocaire Corporation introduced a dry desiccant dehumidifier based on the patents of Neil Pennington [2], an American inventor, and Carl Munters [3], the Swedish inventor of the absorption refrigeration system. The basic design concept, which uses a honeycomb-form wheel impregnated with desiccant, remains the state-of-the-art in dry desiccant systems.

In liquid systems, further improvements were made to the Kathabar system during the 1970's, reducing the mass and pressure drop of the contact media for the desiccant. Recent R\&D projects in liquid systems have concentrated on reducing the cost and increasing the effectiveness of heat exchange components which remove the heat of absorption from the liquid desiccant.

In solid systems, considerable research has been invested in developing rotating granular-bed units which do not leak air from process to reactivation. These efforts culminated in the introduction of 
a multiple vertical bed design by BRY-AIR in the early 1980 's. In rotating honeycomb-form desiccant wheels, research by manufacturers has concentrated on reducing the cost and increasing the longevity of the wheel structure. While cost remains an issue, durability has been improved by the use of silica gel as a desiccant, replacing lithium chloride, which can over-absorb moisture in many applications.

In addition to developments on the mechanical side of dry desiccant technology, research has been invested in developing desiccant materials tailored specifically to comfort-conditioning applications. These materials are expected to enter the market during 1991 and 1992, and may change the operating economics of dry desiccant systems in a fundamental and positive way.

Concurrent with these commercial developments, research by government and private institutions has been proceeding on many forms and different aspects of desiccant systems. These efforts are described in sections 2.2 and 2.3 .

\subsection{Open-Cycle Desiccant Systems}

In connection with desiccant dry air conditioning, a rotary exchanger has been described by Pennington [2] and Dunkle [4]. Bullock and Threlkeld [5] numerically solved the silica-gel adiabatic adsorption problem. Their approach gives satisfactory results only if the entire bed is in equilibrium with the inlet fluid at the end of each cycle. Bank, Close, Maclaine-cross and Dunkle have published a series of papers [6-10] to analyze the performance of a silica-gei dehumidifier. They uncoupled the coupled mass and energy balance equations. The uncoupled equations have the form of the heat transfer equations that were solved by Nusselt [11]. They then compared the analytical solutions with the numerical results and claimed that the difference was within an acceptable range. Lunde published a series of papers [12-14] dealing with a rotary silica-gel dehumidifier. Using a computer simulation to predict the cyclic performance of the unit, he predicted a coefficient of performance (COP) of around 0.6. Nelson used Bank's assumptions to uncoupled the coupled mass and energy balance equations [15]. In his investigation, numerical models of the basic open-cycle machine components were developed. His analysis showed that real system performance was significantly lower than ideal performance. Roy and Gidaspow theoretically analyzed a cross-cooled desiccant dehumidifier problem [16,17]. Green's functions and the integral equation technique were used to solve a set of coupled, nonlinear partial differential equations. Their results show that a cross-cooled dehumidifier should work very well. Mathiprakasam studied the theoretical performance of silica-gel sheet desiccant cooling systems with the assumption that a moisture gradient existed across the thickness of silica-gel sheets representing mass transfer resistance [18]. Worek and Lavan [19] and Mei and Lavan [20] applied the same assumption to numerically calculate a cross-cooled desiccant dehumidifier performance and then experimentally prove the theory. In their experiment, silica-gel sheets were formed with a teflon web. A two-ton solar-powered desiccant cooling system using cross-cooled dehumidifiers has been designed, built, and tested by Monnier [21]. The system consists of two fixed beds. Grolmes and Epstein suggested that the addition of inert heat capacity to the desiccant would improve system performance [22].

Rousseau has developed a solar desiccant dehumidifier [23]. The desiccant bed was a silica-gel granular packed drum. His system had a 1.35-ton capacity with a COP of 0.6. Schlepp built a desiccant wheel model with silica gel bonded on a pressure- sensitive tape [24]. The wheel was used to validate the theoretical calculations. Pesaran and Mills derived a heat and mass transfer model in a packed bed of desiccant particles [25]. The model accounted for surface diffusion within the 
particles. Pesaran and Zangrando established a test facility for desiccant materials [26]. Both adsorption and desorption experiments using isothermal conditions could be performed with their facility. Schlepp et al. designed a facility for cyclic testing of desiccant dehumidifiers [27]. The Institute of Gas Technology (IGT) built a molecular sieve desiccant wheel [28]. The unit performed well except that the regeneration temperature was high. Munters Cargocaire has successfully developed commercial desiccant systems for supermarket HVAC [29]. In 1984, American Solar King Company introduced and marketed solid desiccant (lithium chloride) cooling systems for domestic use. Bry-Air, Inc., has manufactured air drying products for industrial applications for many years [30]. Niagara Blower Company has used an ethylene glycol solution for no-frost refrigeration units and air conditioners with successful results [31]. Cohen et al. reported the study of desiccant-based space-conditioning systems for supermarket applications [32]. Cohen et al. had experimentally compared different types of desiccant wheels [33]. Bartz et al. studied integrated gas-fired desiccant dehumidification and vapor compression cooling systems [34]. LaRoche Chemical is presently developing desiccant wheels under a Gas Research Institute (GRI) contract. These wheels will incorporate modified desiccants to yield optimum performance, and it is expected that low-cost wheel production will be achieved.

Scalabrin and Scaltriti theoretically compared dehumidification using an air-to-air heat pump system with that using a liquid desiccant system [35]. They concluded that the desiccant system could save 1.0 to $1.75 \mathrm{~kW} / \mathrm{kg}$ of water removed. Calton described using a lithium-chloride desiccant cooling system for a supermarket with positive results [36]. Burns et al. analyzed hybrid desiccant cooling systems in supermarket applications [37]. They concluded that substantial savings in air conditioning cost were possible. Collier [38] and Collier et al. [39] reintroduced the concept of stage regeneration, in which air from the sensible heat exchanger is used for the first fraction of the dehumidifier wheel, and hot air is used for the remaining fraction. This concept was first patented by Glav [40], but was not put to use until recently.

\subsection{Integrated Desiccant Systems}

These systems combine desiccant dehumidifiers with conventional chillers. The chiller can be a vapor compression type or an absorption type. The dehumidifier provides the latent cooling load, and the chiller provides the sensible cooling load. In all cases, at least part of the heat required to regenerate the desiccant is obtained from the chiller. This results in reduced energy consumption, smaller equipment and duct size, reduced volume of circulated cold air, and reduced mildew problems since drier air is circulated. In addition, independent control of temperature and humidity is possible. Curren gave several examples of possible integration of desiccant systems with conventional chillers [41]. Maclaine-cross proposed using a desiccant system with a gas-engine-driven chiller [42]. Relatively high-grade waste heat from the gas engine ran be used for desiccant regeneration. M. Meckler discussed the integrated desiccant cold air distribution systems for commercial buildings [43]. He concluded that the costs of initial HVAC equipment and energy consumption could be reduced. G. Meckler proposed a two-stage desiccant dehumidification system integrated into a commercial building HVAC system, which would significantly increase the system's thermal COP and lower the initial equipment cost $[44,45]$. 


\section{Closed-Cycle Desiccant Systems}

Tchernev and Emerson designed, constructed, and tested a regenerative closed-cycle desiccant (zeolite) cooling system [46]. They claimed to have a seasonal cooling COP of 1.2 and a heating COP of 1.8, yet the initial equipment cost was comparable to that of electric heat pumps. Shelton et al. analyzed the square wave of the solid-vapor adsorption heat pump [47]. Their calculation indicated a heating COP of 1.75 with an ammonia/zeolite adsorption pair. Meunier studied closed-cycle DCD systems in France [48].

\section{Liquid Desiccant Systems}

Two liquid desiccant cooling/dehumidification systems are being marketed commercially in the United States. One is the "Hygrol" system manufactured by the Niagara Blower Company [31], and the other is the Kathabar System [49] manufactured by Midland-Ross Corporation. The Niagara system consists of a conditioner (absorber) and a concentration (regenerator) section. The desiccant solution, triethylene glycol, is sprayed into the absorber, and the solution is cooled by water that is externally refrigerated. The humidity of the processed air that passes through the absorber is controlled by the liquid concentration, and the dry bulb temperature is controlled by a cooling coil that is cooled by externally refrigerated water. The weak solution leaving the absorber is sprayed into an air stream in the regenerator while a heating coil enhances the evaporation of water. The Kathabar system uses "Kathene," which is a solution of water and lithium chloride. The system is similar to that of the Hygrol system. These two commercial liquid desiccant systems have been available for some time. It should be recalled that they use an external refrigeration source to provide cold water for the conditioner. Kakabaev et al. experimentally investigated the concept of an open regenerator that consists of a liquid film flowing over a slanted, blackened surface [50,51]. Robison built a liquid desiccant system with well-water for sensible load and triethylene glycol solution for latent load [52]. Lof studied several variations of liquid desiccant cooling system arrangements [53,54]. An intensive research program studying the heat and mass transfer from binary falling films is ongoing at Arizona State University [55]. The studies are both experimental and analytical, and they encompass open as well as glazed films. The effect of the presence of nonabsorbable gas is also considered.

\section{References for Section 2}

1. G.D. Guler, "Air Conditioning System," U.S. Patent 2,328,974, September 7, 1943.

2. N.A. Pennington, "Humidity Changer for Air Conditioning," U.S. patent No. 2,700,537, January, 1955.

3. Carl G. Munters, "Air Conditioning System," U.S. Patent 2,926,502. March 1, 1960.

4. R.C. Dunkle, "A Method of Solar Air Conditioning," Inst. Engr. Australia Mech. and Chem. Eng. Trans. 1, 73-78 (1965).

5. P.J. Bullock and J.L. Threlkeld, "Dehumidification of Moist Air by Adiabatic Absorption," ASHRAE Trans. 72, (Pt) 1, 301-313 (1966). 
6. R.V. Dunkle and D.J. Norris, "General Analysis of Regenerative Evaporative Cooling Systems," Proceeding, 12th Int. Congress of Refrigeration, Madrid, Spain, Aug. 30 - Sept. 6, 1967.

7. P.J. Banks, "Coupled Equilibrium Heat and Single Adsorbate Transfer in Fluid Flow Through a Porous Medium - I. Characteristic Potentials and Specific Capacity Ratio," Chem Engineering Science, 27, 1143-1155 (1972).

8. P.J. Banks and D.J. Close, "Coupled Equilibrium Heat and Single Adsorbate Transfer in Fluid Flow Through a Porous Medium -II. Predictions for a Silica Gel Air-Drier Using Characteristic Chart," Chemical Eng. Science, 27, 1157-1169 (1972).

9. P.J. Banks, D.J. Close, and I.L. Maclaine-cross, "Coupled Heat and Mass Transfer in Fluid Flow Through Porous Media - An Analogy with Heat Transfer," 4th Int. Heat Transfer Conf., V. VII, T. 3.1, Elsevier Publishing Co., Amsterdam, Holland, 1970.

10. I.L. Maclaine-cross and P.J. Bank, "Coupled Heat and Mass Transfer in Regenerators-Prediction Using an Analogy with Heat Transfer," Int. J. Heat and Mass Transfer, 15, 1225-1241 (1972).

11. W. Nusselt, "Die Theorie des Winderhitzers," Z. Ver. Deut. Ing., 71, 85-91 (1927).

12. P. Lunde and F. Kester, "Chemical and Physical Gas Adsorption in Finite Multimolecular Layers," Chem. Eng. Science, 30, 1497-1505 (1975).

13. P. Lunde, "Solar Powered Desiccant Air Conditioning System," CEM 4171-526 report, Center for the Environment and Man, Hartford, Conn., April 1975.

14. P. Lunde, Preliminary Design of a Solar-Powered Desiccant Air Conditioning System Using Silica-Gel, CEM 4186-555 Report, Center for the Environment and Man, Hartford, Conn., Oct. 1976.

15. J.S. Nelson, "An Investigation of Solar Powered Open Cycle Air Conditioners," M.S. Thesis, University of Wisconsin, Madison, 1976.

16. D. Ray and D. Gidaspow, "A Cross-Flow Regenerator - A Green's Matrix Representation," Chem. Eng. Science, 29, 779-793 (1974).

17. D. Roy and D. Gidaspow, "Non-Linear Coupled Heat and Mass Exchanger in a Cross-Flow Regenerator," Chem. Eng. Science, 29, 2101-2114 (1974).

18. B. Mathiprakasam, "Performance Prediction of Silica Gel Desiccant Cooling system," Ph.D. thesis, Illinois Institute of Technology, Chicago, 1980.

19. W.M. Worek and Z. Lavan, "Performance of a Cross-Cooled Desiccant Dehumidifier Prototype," ASME J. of Solar Energy Eng. 104, (3), 187-196 (1982).

20. Mei, V.C., and Lavan, Z., "Performance of Cross-Cooled Desiccant Dehumidifiers," ASME J. Solar Energy Eng. 105, (3), 300-304 (1983). 
21. J.B. Monnier, "Cooled-Bed Solar Powered Desiccant Cooling: Field-Testing and Second Law Analysis," Ph.D. Thesis, Illinois Institute of Technology, Chicago, 1981.

22. M.A. Grolmes and M. Epstein, Desiccant Cooling System Performance: A Simple Approach, Final Report for the Gas Research Institute under Contract 5081-343-0477, 1981.

23. J. Rousseau, Development of a Solar Desiccant Dehumidifier -Phase II, Final Summary Report, DOE/CS/31591-T8, U.S. Dept. of Energy, Washington, D.C., Nov. 1982.

24. D. Schlepp, A High-Performance Dehumidifier for Solar Desiccant Cooling Systems, SERI/TP-252-1979, Solar Energy Research Inst., Golden, Colo., May 1983.

25. A.A. Pesaran, and A.F. Mills, Modeling of Solid-Side Mass Transfer in Desiccant Particle Beds, SERI/TP-252-2170, Solar Energy Research Inst., Golden, Colo., February 1984.

26. A.A. Pesaran and F. Zangrando, Experiments on Sorption Hysteresis of Desiccant Materials, SERI/TP-252-2382, Solar Energy Research Inst., Golden, Colo. August 1984.

27. D. Schlepp, K. Schultz, and F. Zangrando, Facility Design for Cyclic Testing of Advanced Solid Desiccant Dehumidifiers, SERI-TP-252-2464, Solar Energy Research Inst., Golden, Colo., Aug. 1984.

28. W.F. Rush, L.R. Staats, L.R. Wright, and J. Wurm, "The Operation and Performance of a Solar-MEC Absorption Unit," Proceeding, 3rd Inter-University Energy Conference, Springfield, ILL., April 1, 1976.

29. Engineering Bulletin No. TB75 and No. 3313, Cargocaire Engineering Corp., Amesbury, Mass.

30. MVB series product catalog and engineering data, Bry-Air, Inc., Sunbury, Ohio (1986).

31. Research Bulletin RB-11-14-88, Bulletins 162A, 179, and Application Bulletin 2107, Niagara Blower Co., Buffalo, N.Y. 1989.

32. B.M. Cohen, D.L. Manley, R. Arora, and A.H. Levine, Field Development of a Desiccant - Based Space - Conditioning System for Supermarket Applications, GRI 84/0111, Gas Research Institute, Chicago.

33. B. Cohen, R. Wysk, and R. Slosbery, Advanced Desiccant Cooling System Development Desiccant Wheel Sample Performance Testing, GRI-89/0036.1, Gas Research Institute, Chicago.

34. D. Bartz, A. Zografos, and J. Marsala, Integrated Gas-Fired Desiccant Dehumidification Vapor Compression Cooling system for Residential Application, GRI-89/0218, Gas Research Institute, Chicago.

35. G. Scalabrin and G. Scaltriti, "A New Energy Saving Process for Air Dehumidification: Analysis and Applications," ASHRAE Trans. 91, pt. 1A, 426-441 (1985). 
36. D.S. Calton, "Application of a Desiccant Cooling System to Supermarket," ASHRAE Trans. 95, (pt. 1B), 441-446 (1985).

37. P.R. Burns, J.W. Mitchell, and W.A. Beckman, "Hybrid Desiccant Cooling Systems in Supermarket Applications," ASHRAE Trans. 95, (pt. 1B), 457-468 (1985).

38. R.K. Collier, "Desiccant Properties and Their Effect of Cooling System Performance," ASHRAE Trans. 95, paper No. CH-89-11-1 (1989).

39. R.K. Collier, D. Novosel, and W.M. Worek, "Performance Analysis of Open-Cycle Desiccant Cooling Systems," ASHRAE Trans. 96, paper No. AT-90-19-2 (1990).

40. B.O. Glav, "Air Conditioning Apparatus," U.S. patent 3,251,402, May 1966.

41. H.M. Curran, Hybrid Refrigeration/Sorption Solar Cooling Systems, DOE ICS-30202, 1972.

42. I.L. Maclaine-cross, "Proposal for a Hybrid Desiccant Air conditioning System," Proceedings of the symposium on Desiccant Cooling Applications, ASHRAE Winter Annual Meeting, Dallas, 1988.

43. M. Meckler, "Integrated Desiccant Cold Air Distribution System," ASHRAE Trans. 95, (pt. 2), paper No. VA-89-21-1 (1989).

44. G. Meckler, "Two-Stage Desiccant Dehumidification in Commercial Building HVAC Systems," ASHRAE Trans. 95, (pt. 2), paper No. VA-89-21-4 (1989).

45. G. Meckler, "Use of Desiccant to Produce Cold air in Gas-Energized Cold Air HVAC System," ASHRAE Trans. 96, (pt. 1), paper No. AT-90-19-1 (1990).

46. D.I. Tchernev and D.T. Emerson, "High-Efficiency Regenerative Zeolite Heat Pump," ASHRAE Trans. 94, (pt. 2), 2024-2032 (1988).

47. S.V. Shelton, W.J. Wepfer, and D.J. Miles, "Ramp Wave Analysis of the Solid/Vapor Heat Pump," Journal of Energy Resources Technology, 112 (No. 1), $69-78$ (1990).

48. F. Meunier, "Pompes a Chaleur, Adsorption: Etat de L'art er Devemoppment", 136-145, in Proceedings of Pompes de Chaleur Chimiy:es de haute Performances, Perpignan, Sept. 1988.

49. Kathabar Systems, Somerset Technologies, Inc. Bulletin KSC-175 and Data Sheet KTC-751, Brunswick, N.J.

50. A. Kakabaev, and M. Golaev, "Glazed Flat Surface as a Solution Regenerator for Use in an Absorption Cooling System," Geliotekhnika, 7 (No. 4), 44-49 (1971).

51. A. Kakabaev, A. Klandurdyev, O. Klyshchaeva, and N. Kurbanov, "A Large Scale Solar Air Conditioning Pilot Plant and Its Test Results," International Chem. Eng. 16 (No. 1), 60-64 (1976).

52. H.I. Robison, "Operational Experience with Liquid Desiccant Heating and Cooling Systems," Proceedings of the 18th Intersociety Energy Conversion Engineering Conference, Vol. 4, 1983. 
53. G.O.G. Lof, G. Cler, and T. Brisbane, "Performance of a Solar Desiccant Cooling System," Proceedings of the ASME-JSME-JSES Solar Energy Conference, Honolulu, 1986.

54. G.O.G. Lof and J. Appleyard, "Preliminary Performance of Simplified Advanced Solar Desiccant Cooling System Employing Air-to-Water Exchanger Coil and Partial Air Recirculation," Proceedings of the Tenth Annual ASME Solar Energy Conference, Denver, 1988.

55. B.D. Wood and T.A. Ameel, "Heat and Mass Transfer in Laminar Wavy Falling Film Absorption with the Presence of Low Concentrations of Non-Absorbable Gases," ASME-JSME-JSES International Solar Energy Conference, Reno, March 17-22 (1990). 


\section{TECHNOLOGY OPTIONS}

Among the current technology options, there are various types of desiccants and many different kinds of systems which employ those desiccants to cool and/or dehumidify air. This chapter discusses these options, and suggests further sources of information for more detailed investigation.

\subsection{Desiccant Materials}

Practically all materials have some affinity ror water vapor. This technically makes them desiccants. However, there are certain properties of commercially viable desiccant materials that separate them from the others. These properties are:

- Chemical and physical stability over many cycles

- Ability to hold large weight fractions of water

- Ability to separate water vapor from other constituents

- Ability to attract water vapor at desired partial pressures.

Many of the materials that are able to attract water vapor do not remain stable during the sorption process. If the structure of the material is altered by the sorption process, chances are that its sorption properties will not remain stable with cycling. Many of the clay materials fall into this category. Viable commercial materials obviously must be able to cycle water in and out of the material many times reversibly.

The term "large weight fractions" can be misleading. Lithium chloride, for example, can absorb up to many times its weight in water, while a molecular sieve can adsorb only about $25 \%$ of its weight. This does not necessarily make lithium chloride a better desiccant material. Other factors come into play when making that judgement. The term "large" is relative to the amount of water common materials will hold.

Almost any material will hold what is called a monolayer of water. A monolayer is a surface layer that is one molecule thick. If the amount of surface area per unit of volume for the material is not large, then the amount of water captured will be on the order of 1 to $2 \%$. This water capacity is not considered adequate to make the desiccant a viable material.

Many times, the purpose of the desiccant is to separate water vapor from other constituents. In these cases, the selectivity of the desiccant will be an important consideration. From our previous example, although lithium chloride will hold much more water per unit mass than molecular sieve, the sieve material will be much more selective in the species that are adsorbed than will the lithium chloride.

A great many common materials have the ability to attract and hold large quantities of water vapor. Wool and paper are two materials that possess great affinities for water vapor, but only at vapor pressure close to the air saturation pressure. For many applications, the affinity for water vapor must take place at much lower vapor pressures in order to meet the needs of the application. 


\subsection{Classes of Desiccants}

There are many ways to classify desiccant materials. One obvious way is liquid vs solid. Another way that is not so obvious is by the sorption mechanism. Absorption refers to the process by which water is bonded within the molecular structure of the material. Adsorption refers to the process by which water is bonded to the surface of the material. Although it is mostly correct to assume that all liquid desiccant reactions are absorption and that all solid desiccant reactions are adsorption, there is one major exception. Hydrates of many metal salts are solid, yet they desiccate by absorption.

Another classification used by physical chemists is the concept of physisorption vs chemisorption. This is an arbitrary designation that reflects the strength of the bond between the adsorbed species (the adsorbate) and the surface of adsorption (the adsorbent). For all practical purposes, the class of adsorption reactions associated with moisture removal from air will always be considered physisorption, and these reactions will have low bond strength. The strength of the bond in moisture sorption must be low in order to make the energy efficiency of a cyclic operation high.

Within the general class of solid desiccants there are several subclasses of materials:

$\begin{array}{ll}\text { 1. } & \text { Silicas } \\ \text { 2. } & \text { Aluminas } \\ \text { 3. } & \text { Zeolites } \\ \text { 4. } & \text { Hydratable salts } \\ \text { 5. } & \text { Mixtures } \\ \text { 6. } & \text { Liquid Desiccants } \\ \text { 7. } & \text { Polymers }\end{array}$

Activated carbons have purposely been left off this list of typical materials. Although activated carbons will adsorb water at vapor pressures less than saturation pressure, the surface is actually hydrophobic (repels water). Because of the very high surface-to-volume ratio, the pores of activated carbon will fill with water because of capillary forces. However, carbon is excluded from this list because it will preferentially adsorb practically every other chemical species before it absorbs water. This is why activated carbons make such excellent water filters. Isotherms depicted for activated carbon and water were measured with "pure" material. After any significant atmospheric exposure, carbon's capacity for water will be seriously degraded, eventually loosing any significant capacity.

\subsection{Silicas}

The silica materials are commonly referred to as "gels". They have been manufactured to obtain very high surface-to-volume ratios and have been surface-treated to produce an affinity for water. Such gels are formed by condensing soluble silicates from solutions of water or other solvents. They have the advantage of being relatively low in cost and easily customizable in terms of pore size and pore distribution.

\subsubsection{Aluminas}

Aluminas are also referred to as "gels" for the same reasons as the silicates. They are chemically aluminum oxides and hydrides and are manufactured in much the same ways as silica gel. Generally speaking, the aluminas do not possess the ultimate sorption capacity of the silicas, but they are 
refractory in nature and are therefore able to withstand higher-temperature environments without damage.

\subsubsection{Zeolites}

Zeolites fall into two categories, natural and synthetic. The natural zeolites are minerals that are mined in much the same manner as salt. The sediment beds of ancient bodies of water are the most common locations for these deposits. Synthetic zeolites are, as the name implies, manufactured materials. The characteristics that relate the natural and the synthetic materials are their chemical and structural similarities.

Zeolites are aluminosilicate materials. Their crystalline structure is cage-like; the cage structure forms the sites for preferential water sorption. It is this cage-like structure that also forms the basis for the other designation of zeolites, which is the term "sieve." So-called molecular sieves are synthetic zeolites that have been engineered to possess a specific dimension of the cage. When this dimension is controlled, certain molecules will fit inside and others will be too large. This results in the effective separation of gaseous species.

\subsection{Hydratable Salts}

Hydratable salts are a special class of solid desiccants. Generally metal halides, these materials typically experience a transition between solid and liquid phases. Salts that have soluble hydrates are called congruent salts. If the desired desiccant material is a solid, then an incongruent salt would be desired. Hydratable salts, existing as solids, are commonly used in applications where a water vapor pressure that is lower than is possible using liquid is desired. The salt will transit between the anhydrous state and the multiple hydrates state. Lithium chloride is the most common hydratable salt material used. Other hydratable salts are aluminum and copper sulfate, calcium chloride, and lithium bromide.

\subsubsection{Mixtures}

Using mixtures of desiccants is another common method of developing desiccant materials that have the desired sorption properties. For example, some desiccants have large total uptakes for moisture, but are not able to achieve very low humidity levels. Other materials may have marginal moisture uptake, but are capable of achieving extremely low humidity levels. For example, lithium chloride has an unparalleled capacity for moisture absorption at high relative humidities, but below $10 \% \mathrm{rh}$, its moisture absorption is negligible. Combining that desiccant with silica gel, which has a larger capacity at low humidities, can provide adequate moisture capacity throughout a wide range of operating conditions. For best performance, desiccant mixtures are selected such that both desiccants can be reactivated at similar temperatures.

\subsubsection{Liquid Desiccants}

For the few office buildings with HVAC systems that are integrated with desiccant cooling technology, liquid lithium chloride was used almost exclusively as the desiccant material. Somerset Technologies, Inc., has a series of dehumidification products with lithium chloride solution as the desiccant. Their catalog provides a detailed description of lithium chloride solution properties [1]. Calcium chloride brine and sodium chloride brine can also be used as liquid desiccants or even be 
considered as secondary coolants [2]. Ethylene glycol solutions have been used by Niagara Blower Co. for many years on commercial refrigeration for no-frost units. They were used on air conditioners, as well [3]. Test results indicated that the antibacterial effectiveness of glycol solutions is excellent.

\subsubsection{Polymer Desiccants}

To consider plastic polymers as advanced desiccant materials, the same general criteria as for any desiccant material must be satisfied. They must have a favorable performance/cost ratio, provide satisfactory performance, and have cost-effective lifetimes. Czanderna [4] made the following assessment of the currently available polymer desiccants:

- Polymers have the potential for being modified so that sorption isotherms of both the desired shape and heats of adsorption of about $2508 \mathrm{~kJ} / \mathrm{kg}$ are obtained.

- Polymers have the potential for sorbing water from 5\% to more than $80 \%$ of their own weight.

- Polymers have the potential for being readily fabricated into shapes required for desiccant dehumidifiers.

- Polymer structures have the potential for being synthesized to provide high diffusivities of water vapor through the material.

- Polymers have the potential for being fully regenerated at temperatures below $176^{\circ} \mathrm{F}$.

- Polymers have the potential for maintaining long-term stability through thousands of sorption-desorption cycles.

- Commercial polymers are available at less than $\$ 2.00 / \mathrm{lb}$, comparable to the cost of commercial grade silica-gel.

Accordingly, polymeric materials could not only serve as both the desiccant and the support structure in a desiccant wheel, but also could be replaced easily and inexpensively. Czanderna listed the isotherm data for 22 potential polymeric desiccant materials [4].

\subsection{Recent Research and Development Activities}

Recently, much research and development work has focused on searching for, manufacturing, and testing "Type $1 \mathrm{M}$ " desiccants. Type $1 \mathrm{M}$ refers to the shape of the desiccant sorption isotherm, which compares the weight of water absorbed by the desiccant to the relative humidity of the surrounding air. For a full discussion of the importance of isotherm shape in relation to desiccant system performance, see Appendix I. Polymers, porous glass, nano-composite materials, double-metal hydroxides, etc., have been identified as the potential Type $1 \mathrm{M}$ desiccants [5]. 


\subsection{Desiccant Cooling and Dehumidification (DCD) Systems}

There are two basic types of desiccant systems, described as either "open" or "closed". These descriptions refer to whether the desiccant comes into direct contact with the air being cooled or dehumidified (open), or whether it does not (closed).

\subsubsection{Open-Cycle Solid Desiccant Systems}

In an open-cycle DCD system, the latent load is met iy removing moisture from the air via sorption by a desiccant dehumidifier. The dehumidifier may be operated adiabatically, or it can be designed so that the desiccant matrix is being cooled while the process air is being dehumidified. Sensible cooling is met by incorporating direct or indirect evaporative coolers following the desiccant unit in the dry air stream.

While beds of granular desiccant are occasionally used in such systems, the more common central component of these systems is the desiccant wheel. Ideally, it should meet the following criteria:

- The wheel matrix should not be carcinogenic or combustible.It should be durable to the extent that it can endure typical commercial/residential HVAC operating conditions - unattended operation for a minimum of five years of continuous operation.Ideally, the wheel media and desiccant should be washable without degradation of performance.

- The desiccant should be stable over 262,000 sorption/desorption cycles (five years operation at $6 \mathrm{rph}$ ) and have good uptake and isotherm characteristics.

- The desiccant should be bonded well to the matrix so that no desiccant powder shall enter the dwelling area.

- The desiccant should not deliquesce even at $100 \%$ relative humidity

- The airflow channels should be uniform and of optimal size to minimize pressure drop and subsequent fan energy consumption.

- The resistance to heat and mass transport inside he solid desiccant and its supporting structure should be minimized.

- There should be minimum leakage between the adsorption and desorption streams both inside the wheel structure and at the seals which separate the process from the reactivation air stream at the faces of the wheel.

In addition, the effectiveness of the heat exchanger which transfers sensible heat from process to reactivation air must be very high ( 0.83 or better).

\subsubsection{Closed-Cycle Solid Desiccant Systems}

There are two types of closed systems where the desiccant does not contact the dehumidified air stream directly; those in which the desiccant is regenerated continuously and others where the desiccant is regenerated intermittently. Intermittent regeneration is suited to applications where the 
moisture/cooling load is either very low or intermittent, or where the energy source for regeneration is itself intermittent, such as solar heat.

\subsubsection{Intermittent Adsorption Closed-Cycle Systems}

The principal of an intermittent single effect adsorption closed-cycle can be easily understood when represented in a "T,TS" diagram such as Figure 3.1.

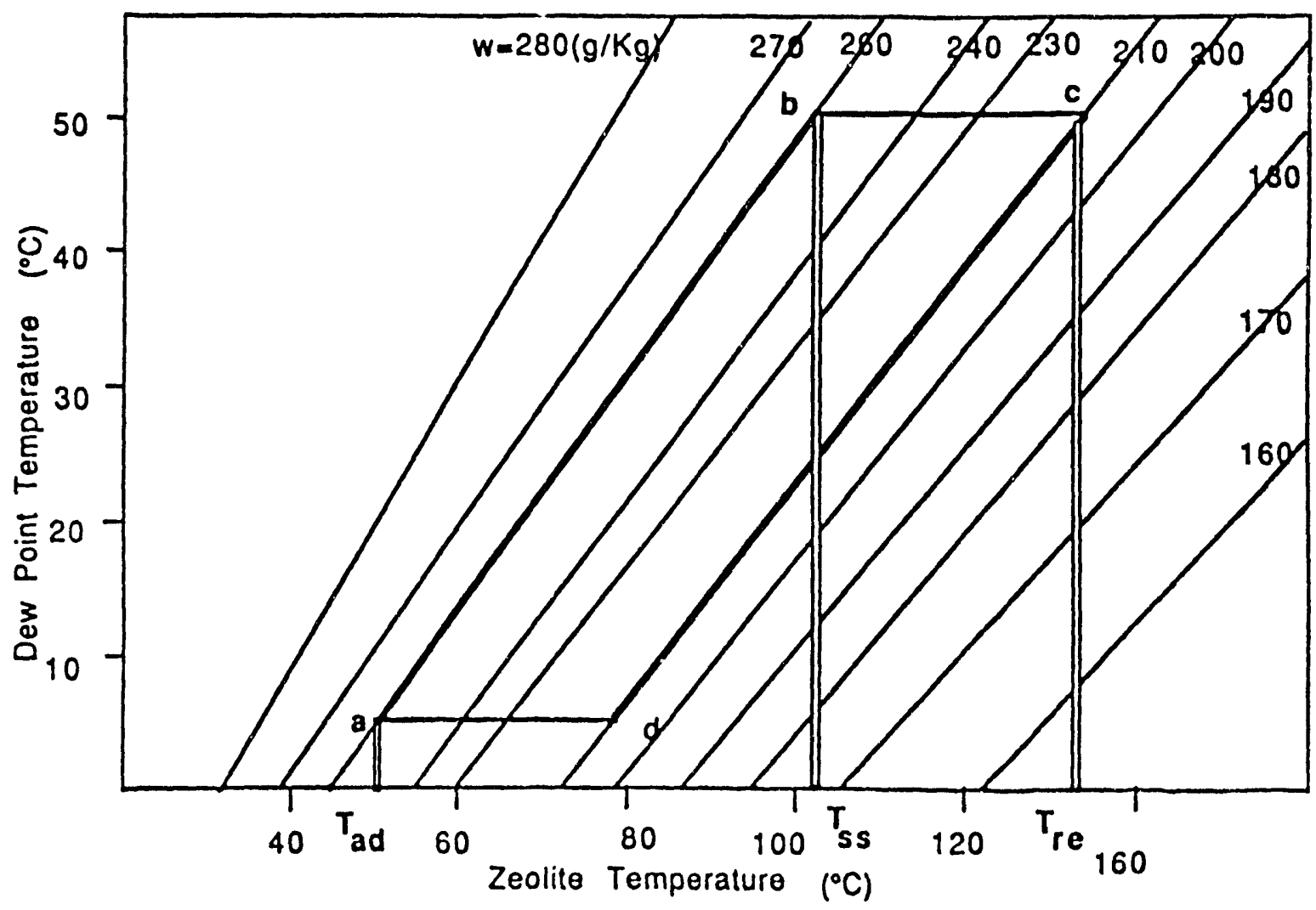

Figure 3.1 Isoteres showing the water-zeolite $13 \mathrm{x}$ adsorption cycle

$\mathrm{T}$ is the sorbent temperature and TS is the saturation temperature corresponding to the pressure of the gas phase. In such a diagram, the isosteres (lines of constant sorbate mass fraction) are approximately straight lines. Figure 3.1 is the diagram for the pair Zeolite $13 \mathrm{X}$-water on which a cooling cycle is represented by the points a-b-c-d-a. This cycle consists of two operating modes, the regeneration mode and the adsorption mode.

- Regeneration Mode.

At the end of adsorption (point a), the adsorbent is at its minimum temperature Tad and the adsorbate gas is at pressure Pev of the evaporator. As the adsorbent is heated up, desorption starts and the pressure of the gas phase increases. When the condenser pressure Pco is reached (point b), condensation of the desorbed species begins and desorption continues until the adsorbent is at its maximum temperature Tre (point $\mathrm{c}$ ). 
- Adsorption Mode.

When the adsorbent is cooled, adsorption starts and the pressure of the adsorbate gas decreases. When the pressure reaches the value Pev, evaporation starts (point $d$ ). This phase of cooling production continues until the adsorbent is at its minimum temperature, Tad (point a).

Such systems are called intermittent because the desired cooling or heating effect is produced during one of these two modes only.

\subsubsection{Regenerative Adsorption Closed-Cycle Systems}

A twin-reactor adsorption system can have significantly increased performance over that of the single, intermittent regeneration system. Twin reactor systems recover the heat generated during the adsorption phase and the sensible heat stored in the sorbent container as means to increase the COP. Such systems were developed in the U.S. by Tchernev [6] and by Shelton [7]. Tchernev's system, shown in Figure 3.2, is explained here. It consists of two solid desiccant containers, a boiler, a bi-directional pump, and two liquid-to-air heat exchangers. The liquid can be oil or any other suitable and safe liquid. The cooling and heating effects are achieved by the evaporation and condensation of the refrigerant on the walls of the desiccant containers. The two desiccant containers act alternately as an evaporator and condenser. Each of the containers has an interior desiccant-fluid heat exchanger, located at the center (see details in Figures 3.2 and 3.3), and coils that are integrated into the external walls. The energy is provided to the system in the form of heat by the boiler. The bi-directional pump is used to circulate the fluid in a closed loop from the boiler through the desiccant-fluid heat exchangers and the fluid-air heat exchangers. The fluid-air heat exchangers are used to cool the fluid to the outdoor or cold sink temperatures before the fluid enters the container where adsorption takes place.

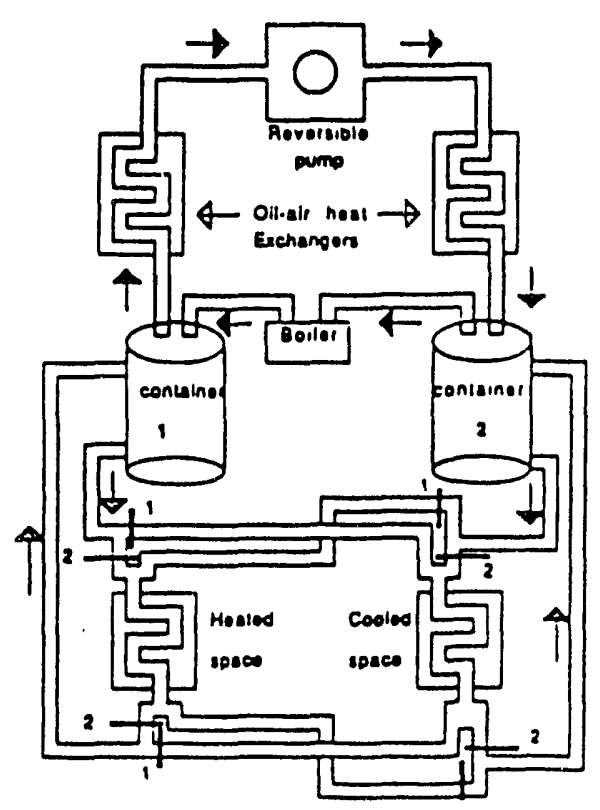

Figure 3.2 Regenerative adsorption system when valves are in position 1 , container 1 is desorbing and container 2 is adsorbing

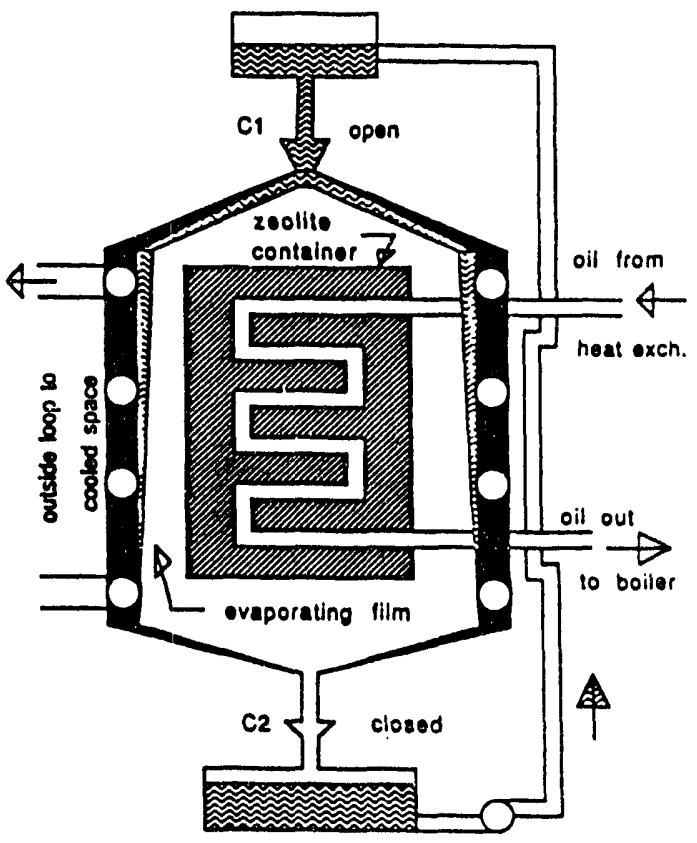

Figure 3.3 Regenerative phase - the walls of the container act as a condenser 
In order to ensure efficient performance, care should be given to the following points:

- The heat wave should have a sharp front: heat transfer in the radial direction should be much faster than in the longitudinal direction.

- The choice of the adsorbent/adsorbate pair should be appropriate for the particular application.

- The design should ensure fast heat and mass transfer (fast approach to adsorption equilibrium).

\subsubsection{Open-Cycle Liquid Desiccant Systems}

In liquid desiccant systems, the air is dehumidified by being brought into contact with a strong solution of liquid desiccant. When the solution is weakened by absorption of moisture, it is directed to the regeneration vessel where heat drives out the moisture and the strengthened solution is returned to the dehumidifier. To provide sensible cooling in addition to dehumidification, either an externally refrigerated cold liquid is provided to the dehumidifier, or moisture is added to the air exiting the dehumidifier in order to lower its temperature by adiabatic saturation before it enters the space to be conditioned. The main advantages of these systems are that energy can be stored in the form of chemical energy (closed-cycle) rather than thermal energy, and that the geometry of the components is simple.

There are three basic configurations of a liquid desiccant dehumidifier vessel. It can be a spray chamber, a packed tower, or a sprayed coil arrangement. In a spray chamber, the liquid desiccant is atomized into the air stream using high pressure nozzles. In a packed tower, a liquid film flows downward over the surface of the packing while air is passed in the opposite direction through the packing. The dry air exiting the spray chamber or the packed tower is then cooled by a sensible heat exchanger to remove the heat of sorption. In contrast, a sprayed coil dehumidifier combines dehumidification and sensible cooling in a single piece of equipment. The liquid desiccant is sprayed over finned coils that carry water supplied by a cooling tower or other means.

The regeneration process can also utilize a spray chamber, a parked tower, or a sprayed coil arrangement analogous to the corresponding components in the dehumidifier. In all cases, heat must be provided for regeneration. In addition, regeneration can be accomplished by exposing a falling-liquid solution film to solar radiation and ambient. A transparent cover may be placed over the liquid film to form a rectangular channel for airflow. This increases the liquid temperature, but the air humidity in the channel is higher than that of ambient air.

The selection of a suitable liquid desiccant is of paramount importance. The following guidelines should be considered when choosing liquid desiccants:

- They should have suitable water vapor pressures for absorption and desorption throughout the expected range of operating conditions of the process air stream.

- They should be nontoxic, noncorrosive, nonflammable, and odorless.

- Their solutions should not crystallize within the operating limits. 
- They should have good heat and mass transfer properties and low viscosity.

- The desiccant vapor pressure should be low to prevent loss during regeneration.

\subsubsection{Closed-Cycle Liquid Desiccant Systems}

Closed-cycle liquid desiccant systems are more commonly known as absorption chillers. In such systems, the liquid desiccant, generally lithium bromide, performs a role similar to that of a compressor in a conventional vapor compression refrigeration system.

Concentrated liquid desiccant inside a closed system attracts vapor from water, which evaporates inside closed tubes just as a conventional halocarbon refrigerant evaporates inside a vapor compression system. The evaporating water removes heat from a liquid, which is circulated to cooling coils, chilling the air which moves throughout the building.

Inside the closed system, heat is used to drive moisture out of the desiccant into a condenser, where the water vapor condenses back to a liquid, and returns to the evaporatur to absorb more heat from the circulating liquid.

In recent years, there have been many advances in absorption chilling both in terms of technical improvements and reductions in the size and cost of such systems. A complete discussion of these advances and the basic technology is outside the scope of this report. Basic information on absorption cooling can be found in Chapter 13 of the 1988 ASHRAE Handbook of HVAC Equipment.

\section{References for Section 3}

1. Catalog for "Kathbar" products, Somerset Technologies, Inc., New Brunswick, N.J.

2. ASHRAE Fundamentals Handbook, Chapter 18, American Society of Heating, Refrigeration, and Air Conditioning Engineers, Atlanta, Ga. 1989.

3. Niagara no frost refrigeration unit catalog and research bulletin, Niagara Blower Co., Buffalo, N.Y.

4. A.W. Czanderna, "Polymers as Advanced Materials for Desiccant Applications: 1 - Commercially Available Polymers," ASHRAE Trans. 95 (pt. 2), (1989).

5. D. Kosar and D. Novosel, Summary of Desiccant Cooling Program, Gas Research Institute, Chicago, Jan. 1990.

6. Tchernev, D.I., and Emerson, D.T., "High-Efficiency regenerative Zeolite Heat Pump," ASHRAE Trans. 94 (pt. 2), 2024-2032, (1988).

7. S.V. Shelton, "Solid Adsorbent Heat Pump System," U.S. patent 4,610,148, Sept. 1986.

8. Harriman, Lewis G. III, The Dehumidification Handbook. Munters Cargocaire, 79 Monroe St. Amesbury, MA 01913. 1990. 


\section{RECENT RESEARCH AND DEVELOPMENT HISTORY PROGRAMMATIC SUMMARY}

This section describes the recent research and development activities in desiccant dehumidification and cooling technology. It is based on currently available information from a literature search and from personal contacts to organizations and institutes. The main purposes of this section are to find out who is doing what and what has already been done so that a better picture of current work can be formed.

\subsection{Government, Research Institutes, and Universities}

\subsubsection{U.S. Department of Energy (DOE)}

DOE has supported research work at Solar Energy Research Institute (SERI), Oak Ridge National laboratory (ORNL), Florida Solar Energy Center, and other organizations, such as A.D. Little.

\subsubsection{Gas Research Institute (GRI)}

GRI is the main funding source, other than DOE, for desiccant technology research and development. GRI mentioned that funding for desiccant dehumidification and cooling will be approximately \$4.0 million each year between 1987 and 1991 [1]. In their 1990 Summary of Desiccant Cooling Program [2], they mentioned the following activities.

- Cargocaire. Development of SuperAire: an integrated desiccant-dehumidification/electric-airconditioning system for supermarkets. This project has been completed. A total of 135 units were sold.

- Kathabar. Development of Kathabar humidity pump, a 5,000 scfm inake-up air module for general low rise commercial buildings. Field experiments are completed; lower cost component development has been initiated.

- Battelle. Development of a 40-ton breadboard integrated absorption-chiller/liquid-desiccantdehumidifier. The project was terminated because of lack of manufacturer commitment and concern over high initial system cost.

- McDonald's. Field evaluation of 5-ton desiccant dehumidifiers as make-up air units integrated with existing air conditioners for restaurants. The project was completed, and restaurant package development was initiated with the American Gas Association (AGA).

- Meckler Energy Group. Liquid-desiccant storage system utilizing prime-mover waste heat (engine chiller or cogenerator). It is currently undergoing application assessment and system analysis. 
- Tecogen.

- 3- to 5-ton laboratory prototypes of the Pennington-Cycle desiccant cooling system. Literature search was completed.

- Field experiment of a gas-fired, whole-house liquid desiccant dehumidifier and development of commercial prototype. Field experiment was completed; Bacchus Industries joined as commercialization partner.

- Perform technology developments in areas of liquid desiccant systems and component modeling, corrosion control, and air quality control. Modeling work is continuing, corrosion work has been initiated, and air quality study has been completed.

- Arthur D. Little. Laboratory breadboard of a 1- to 3-ton integrated desiccant-dehumidifier/ electric-air-conditioner and field experiment on a water heater-powered stand-alone desiccant dehumidifier. The former project is to be completed by the second quarter of 1990 , and the latter has already been completed, with commercialization activities initiated.

- Enerscope.

- Identify desirable properties of advanced desiccant materials for comfort conditioning applications. Project completed.

- Develop a low-cost, desiccant-based air conditioning system design using Type 1M materials. On-going project.

- Eaton Corp. Develop Type $1 \mathrm{M}$ desiccant based on ionic gel polymers. Study of polymers as liquid desiccants has been initiated.

- LaRoche Chemicals. Develop Type $1 \mathrm{M}$ desiccant based on hydratable salts and capable of direct, gas-fired regeneration. Phases I and II completed. Development of advanced desiccant matrix initiated.

- Michigan Technical University. Develop Type 1M desiccant based on porous glass. On-going project.

- Penn State University. Determine capability of nano-composite materials to perform as effective desiccants. Type $1 \mathrm{M}$ composites identified; further characterization is underway.

- University of Pittsburgh. Determine the capability of layer double-metal hydroxides to perform as effective desiccants. Type $1 \mathrm{M}$ materials have been identified and are undergoing further characterization.

- Semco. Develop a low-cost solid desiccant dehumidifier design and cost-effective manufacturing techniques. Work has just been initiated.

- $\quad 3$ M. Determine feasibility of using substrates made with fibrous web materials to cage desiccant particles. Project completed. 
- University of Missouri at Columbia. Develop data base of contaminant removal capabilities of liquid and solid desiccants. Phase I (literature search) will be completed by the third quarter of 1990.

- Gard. Incorporated desiccant system models in DOE 2.1 building energy analysis code. New version $\mathrm{D}$ was released at the end of 1989.

- Florida Solar Energy Center. Develop more realistic latent and sensible building load. Research version released 1989.

\subsubsection{Solar Energy Research Institute}

SERI has developed several desiccant wheels. They have desiccant equipment testing facilities for the following functions [3-6]:

- Sorption, desorption, and hysteresis effects of solid and liquid desiccants

- Performance of desiccant dehumidifiers

- Heat and mass transfer characteristics of dehumidifier matrices, and

- Desiccant degradation due to contamination and thermal cycling

SERI's test facilities have been intensively utilized for evaluating both in-house materials and materials developed by other companies. SERI has also studied the commercially available polymers as advanced desiccant materials.

\subsubsection{University of Illinois at Chicago (UIC)}

At UIC, work is being conducted to design and develop advanced, gas-fired desiccant systems that have performance superior to conventional systems, and which can compete economically with conventional cooling technologies. The UIC numerical simulation program is a versatile model that contains routines for a solid desiccant wheel, a constant-effectiveness heat exchanger, a regenerative heat exchanger and both direct and indirect evaporative coolers. A periodic dynamic test facility also was developed at the university of Illinois at Chicago to test single and multilayered desiccant sections under varying conditions encountered in the field. Experimental testing of the new desiccant materials, as they are developed, is being done in the dynamic sorption channel. These results are used to determine the heat and mass transfer resistances within the materials and are used to compare with results obtained from mathematical modeling studies.

\subsubsection{Institute of Gas Technology (IGT)}

IGT has been developing the Solar MEC (Munters Environmental Control) unit for several years. Recently they built and tested a desiccant wheel made of nonflammable cellulose matrices containing $52 \%$ (by weight) $13 \mathrm{X}$ molecular sieve. They found that for optimal performance there is a specific temperature regeneration profile that depends on system loading. The amount of heat, as well as the position at which the heat is introduced, are of paramount importance. This information was obtained using four separate electric heaters for regeneration. IGT feels that commercial units will be more cost-effective than small domestic units. They are therefore now working on a unit with 25-ton cooling capacity. 


\subsubsection{Florida Solar Energy Center}

This group has performed advanced desiccant material assessment and computer ende development for desiccant dehumidifiers $[7,8,9]$. Other activities include research on desiccant-enhanced nocturnal radiation, passive dehumidification, and an enthalpy storage system.

\subsubsection{Illinois Institute of Technology}

They have developed, with IGT, silica gel sheets held in a teflon web (see ref. [10] for detailed description of making silica gel sheets). Based on this development, several cross-cooled fixed-bed desiccant dehumidifiers were built and tested in their laboratory and in a solar house. They have also developed desiccant material testing facilities.

\subsubsection{Battelle Columbus Division}

Under the sponsorship of GRI, they have studied liquid desiccant hybrid systems [11-12].

\subsubsection{Georgia Institute of Technology (GIT)}

GIT has analyzed solid desiccant-vapor refrigerant heat pumps. They used a wave-catching technique to enhance the system performance [13]. Under the sponsorship of the Southern Co., they have also performed a technology survey for desiccant cooling systems [14].

\subsubsection{University of Missouri at Columbia}

Under the cosponsorship of GRI and ASHRAE, they are to develop a data base of the capabilitics of solid and liquid desiccants for indoor air quality control.

\subsubsection{Oak Ridge National Laboratory}

ORNL has sponsored several projects involving desiccant-integrated heat-actuated heat pumps [15] and desiccant-integrated engine-driven heat pumps (such as the work ORNL contracted SERI to do on a waste heat powered desiccant-integrated cooling system). These projects studied the application of waste heat for desiccant regeneration.

\subsection{Private Company Activitics Not Previously Discussed}

\subsubsection{Munters Cargocaire, Amesbury, Massachusetts}

Working with support from GRI, this company developed and introduced the first successful rooftop desiccant air conditioning system for commercial buildings. Current R\&D activities include development of a silica gel desiccant wheel, and the design and field testing of a prototype desiccant-based ventilation air pre-treatment system incorporating advanced components. The system is designed to dry the make-up air, which in turn removes excess moisture from the building structure and furnishings, which prevents the mold and mildew damage and musty odors that frequently cause problems in buildings. The American Hotel and Motel Association's Executive Engineer's Committec estimates these problems cost the hotel industry alone over $\$ 82$ million each year [16]. 


\subsection{The Meckler Group, Encino, California}

Development of commercial desiccant-integrated HVAC systems [17]. Designing and evaluating the practical application and economic viability of a liquid desiccant storage system.

\subsection{Gershon Meckler Associates, P.C., Herndon, Virginia}

Development of two-stage desiccant system integrated into conventional HVAC systems for commercial buildings for cost effective HVAC systems [18].

\subsection{ICC Technologies, Philadelphia, Pennsylvania}

This company has developed a two-wheel, rooftop, desiccant-based air conditioning system designed primarily for supermarket installations. A unique aspect of this system is an internal cogeneration set, which provides power to the store in addition to heat for desiccant reactivation.

\subsection{Conair Franklin, Franklin, Pennsylvania}

Conair manufactures desiccant dehumidifiers used primarily for drying plastic resins, an application which comprises the largest single market for desiccant equipment in terms of the number of units installed each year. In 1989, the company introduced a significantly improved version of the classic multiple-tower, rotating bed design. In the improved design, the desiccant material has been formed into a monolithic structure to reduce air channelling and desiccant settling. It also includes a state-of-the-art radiant gas burner, which improves reactivation heating efficiency and improves temperature uniformity throughout the bed.

\subsection{International Activities}

\subsubsection{Europe}

The following European organizations are involved in desiccant dehumidification technology research \& development. Details of most of their activities are not well known.

\subsubsection{Sweden}

A.B. Carl Munters, a member of the Munters-Incentive Division of AREA, is the largest manufacturer of ambient-pressure desiccant dehumidifiers in the world. The company has an active R\&D program, most of which remains proprietary. In general, activities have centered around improvements in dry desiccant wheel structures. Additional work has been accomplished on design and prototype testing of combined systems which use heat rejected from vapor compression cooling to reactivate the desiccant.

A new division of the company, Munters ZEOL, has developed several forms of hydrophobic zeolites for use in pollution control applications. When loaded into a honeycomb-form wheel, these zeolites selectively remove organic contaminants from the process air, concentrating them in the smaller reactivation air stream. This means the equipment for disposing of the contaminants, such as fume incinerators or solvent condensers, can be much smaller and less costly. Such selective adsorbers have 
considerable promise for improving indoor air quality of commercial and residential buildings as well as industrial exhaust systems.

\subsubsection{United Kingdom}

Munters Ltd., the U.K. subsidiary of the Munters-Incentive Division of AREA, has developed a series of modular desiccant system components which allow construction of commercial-grade, combined cooling, humidification and desiccant wheel dehumidification systems in air flow ranges from 2 to $20 \mathrm{M} 3 / \mathrm{sec}$. The importance of this development is less technical than commercial. By designing the components to meet ISO standards 7807 and 9000 part I, the engineering community is free to apply desiccant systems to other than industrial buildings throughout Europe.

\subsubsection{Germany}

The Technical University of Munich and RUHRGAS are conducting research on a closed-cycle zeolite/water heat pump. The Scheidel Company, also of Munich, currently markets a line of closed-cycle zeolite/water heat pumps with cooling capacities from 58 to $582 \mathrm{KW}$ (16 to 165 tons). KaliChemi of Hannover, a manufacturer of desiccant materials, is also conducting research on both closed-cycle and open-cycle desiccant air conditioning systems.

\subsubsection{France}

- Centre National de la Recherche Scientifique (CNRS)

- Fixed bed adsorption cycles using two sorbent-sorbate pairs were studied. Zeolite-water and activated carbon-methanol. The latter is capable of producing a temperature of $-20^{\circ} \mathrm{C}$ Also, a three-adsorber cycle combining a high-temperature two-adsorber Zeolite-water cycle and a low-temperature intermittent activated carbon methanol cycle was studied. This yielded a COP of 1.0 for air conditioning.

The zeolite-water pair has the capability of a large temperature lift (around $70^{\circ} \mathrm{C}$ ), whereas the activated carbon-methanol pair can provide only a small temperature lift (around $30^{\circ} \mathrm{C}$ ). The three container system yielded cogeneration of chilled water $\left(2^{\circ} \mathrm{C}\right)$ and hot water $\left(70^{\circ} \mathrm{C}\right)$ with cooling and heating COPs of 1.2 and 1.1 , respectively. Cogeneration of refrigeration $\left(-10^{\circ} \mathrm{C}\right)$ and hot water $\left(70^{\circ} \mathrm{C}\right)$ provides cooling and heating COPs of 0.65 and 0.9. Douss et al [19-21] summarized recent work at CNRS.

- Perpignan

- Chemisorption systems using ammoniacates were studied for various applications such as cooling at $-27^{\circ} \mathrm{C}$ and heating at $175^{\circ} \mathrm{C}$ from waste heat at $120^{\circ} \mathrm{C}$. The work done in Europe was mainly fundamental, such as that of Spinner [22] and Dantzer [23].

\subsubsection{Italy}

Istituto per la Tecnica del Freddo, C.N.R., Padova. Lithium chloride water solution integrated into a heat pump cycle. 


\subsubsection{Japan}

Basic research and feasibility studies of desiccant cooling systems have been carried out at universities, government institutes, and private companies. Desiccant systems are difficult to commercialize as long as the prices of fuels are low. Matsuki and Saito have discussed desiccant cooling research and development in Japan [24].

Seibu Giken Co. and Kumanoto University have recently developed a silica-gel/zeolite desiccant wheel. The experimental data indicated that the new wheel performs much better than silica-gel alone. Daikin Industries manufactures wheels with silica gel or lithium chloride as desiccant materials. Nichias Corp. manufactures desiccant wheels with silica gel, lithium chloride, and molecular sieve as desiccants. Sharp makes lithium chloride wheels. Toyobo makes activated-carbon desiccant wheels.

Berner International, the Japanese subsidiary of the Munters-Incentive Division of AREA, has developed dry desiccant dehumidifiers reactivated with kerosene for agricultural applications and third-word countries where neither electrical energy nor natural gas is available to reactivate desiccant units.

\subsubsection{Taiwan}

Very little basic research is going on in Taiwan. There are at least three universities, however, that have publications on desiccant dehumidification technology. Their effort is focused more on product development.

The Energy and Resource Laboratory (ERL, under Industrial Technology Research Institute) has developed two desiccant wheels. One was based on SERI's Mylar tape approach. A more advanced approach was successfully developed for the second wheel. Silica gel was chemically formed on the ceramic stems. This approach, even though similar to the one developed at Seibu Giken Co. of Japan, was developed independently by ERL researchers. ERL is ready to transfer the technology to local manufacturing companies. The proceedings of a recent desiccant technology workshop held in Taipei (seven papers, in Chinese) discussed in detail the development of desiccant technology in Taiwan [25].

\subsubsection{India}

BRY-AIR India, a licensee of BRY-AIR of Sunbury, Ohio, has developed a small rotating granular bed dehumidifier which has heat pipes installed between the process-leaving and reactivation air-entering air streams. By transferring the heat from process to reactivation the heat pipe reduces the post-cooling requirement for the process air as well as the energy required for desiccant reactivation.

\section{References for Section 4}

1. D. Kosar and D. Novosel, Outline of Gas Research Institute's Desiccant Cooling Program, Gas Research Institute, Chicago, March 1987. 
2. D. Kosar and D. Novosel, Summary of Desiccant Cooling Program, Gas Research Institute, Chicago, January 1990.

3. D. Schlepp, A High-Performance Dehumidifier for Solar Desiccant Cooling Systems, SERI/TP-252-1979, Solar Energy Research Inst., Golden, Colo., May 1983.

4. A.A. Pesaran and A.F. Mills, Modeling of Solid-Side Mass Transfer in Desiccant Particle Beds, SERI/TP-252-2170, Solar Energy Research Inst., Golden, Colo., Feb. 1984.

5. A.A. Pesaran and F. Zangrando, Experiments on Sorption Hysteresis of Desiccant Materials, SERI/TP-252-2382, Solar Energy Research Inst., Golden, Colo. Aug. 1984.

6. D. Schlepp, K. Schultz, and F. Zangrando, Facility Design for cyclic Testing of Advanced Solid Desiccant Dehumidifiers, SERI-TP-252-2464, Solar Energy Research Inst., Golden, Colo., Aug. 1984.

7. R.K. Collier, Jr., Advanced Desiccant Materiais Assessment -- Phase II, GRI-88/0125, Gas Research Institute, Chicago, 1988

8. R.K. Collier, Jr., D. Novosel, and W.M. Worek, "Performance Analysis of Open-Cycle Desiccant Cooling Systems," ASHRAE Trans. 96 (pi. 1), 1990.

9. R.K. Collier, Jr., Computer Models of Desiccant Process, unpublished report to Oak Ridge National Laboratory, Oak Ridge, Tn. Aug. 1990.

10. Z. Lavan, D. Gidaspow, and M. Onischak, U.S. patent 4,341,539, June 1982.

11. W.H. Wilkinson, D.K. Landstrom, and D. Novosel, "DOBLSORB -- A Universal Desiccant Hybrid Approach," ASHRAE Trans. 94 (pt. 1), 563-574 (1988).

12. W.H. Wilkinson, "Liquid Desiccant Hybrids -- Complexity Made Simple," ASHRAE Trans. 94 (pt. 2), 2010-2023 (1988).

13. S.V. Shelton, W.J. Wepfer, and D.J. Miles, "Ramp Wave Analysis of the Solid/Vapor Heat Pump," J. of Energy Resources Technology, 112 (No. 1), $69-78$ (1990).

14. S.M. Jeter and E.E. Chant, "Desiccant Cooling Technology," prepared for the Southern Co. End Use Committee, by the Department of Energy and Mechanical Engineering, Georgia Institute of Technology, Atlanta, Ga. Aug. 1988.

15. R.H. Turner, J.D. Kleiser, R.F. Chen, N. Domingo, and F. Chen, "Assessment of Thermally Activated Heat Pumps with Desiccant Cooling," ASHRAE Trans. 94 (pt. 1) (1988).

16. Mold and Mildew in Hotels and Motels, Report of the Executive Engineer's Committee of The American Hotel \& Motel Association, Washington, DC. 1991.

17. M. Meckler, "Integrated Desiccant Cold Air Distribution System," ASHRAE Trans. 95 (pt. 2), (1989). 
18. G. Meckler, "Use of Desiccant to Produce Cold air in Gas-Energized Cold air HVAC System," ASHRAE Trans. 96 (pt. 1), (1990).

19. N. Douss, F.E. Meunier, and L.M. Sun, "Predictive Model and Experimental Results for a Two-Adsorber Solid Adsorption Heat Pump," Ind. Eng. Chem. Res., 27, 310-316 (1988).

20. N. Douss, K. Abdallah, P.H. Grenier, J.J. Guilleminot, J. Gurgel, L.M. Sun, H. Sahnoune, and F. Meunier, "Dynamic Study of Solid Adsorption Heat Pumps: Experiments and Numerical Simulation, Economic analysis for Development", CNRS, France, Feb. 1989.

21. N. Douss and F. Meunier, "Experimental Study of Cascading Adsorption Cycles," Chem. Eng. Sc., 44 (No. 2), 225-235 (1989).

22. B. Spinner, in "Pompes a Chaleur Chimiques de Hautes Performances," Perpignan, Lavoisier Editeur (1988).

23. E. Dantzer, and A. Orgaz et Guillot in "Pompes a Chaleur Chimiques de Hautes Performances," Perpignan, Lavoisier Editeur (1988).

24. K. Matsuki and Y. Saito, "Desiccant Cooling R \& D in Japan," ASHRAE Trans. 94 (pt. 1), 537-551 (1988).

25. Proceeding of the Solid Adsorption Dehumidification Air Conditioning Technology Workshop, Thermal Science Group, Energy and Resource Laboratory, Industrial Technology Research Institute, Hsin-Chu, Taiwan, R.O.C., 1989. 


\section{TECHNOLOGY STATUS SUMMARY}

State-of-the-art desiccant cooling and dehumidification technology has been loosely discussed in the last three sections. This section provides an in-depth summary of the latest developments. The summary is subdivided into systems, components, desiccant materials, and models.

\subsection{Systems}

\subsubsection{Open-Cycle Systems}

Almost all desiccant dehumidification for commercial and industrial applications uses open-cycle systems. Open-cycle systems can be subdivided into ventilation mode and recirculation mode. The ventilation mode uses $100 \%$ ambient air, which is suitable for those areas where large amounts of fresh air are essential, such as hospit..ls. In the open-cycle systems, either solid or liquid desiccants can be used. For solid desiccants, no corrosive fluid will be involved in system operation. Liquid desiccants, on the other hand, are easy to pump to the desired locations.

Figure 5.1 shows the schematic of a single-stage desiccant-integrated system for supermarkets [1]. Ref. [1] indicated that considerable energy savings can be achieved with this type of hybrid system.

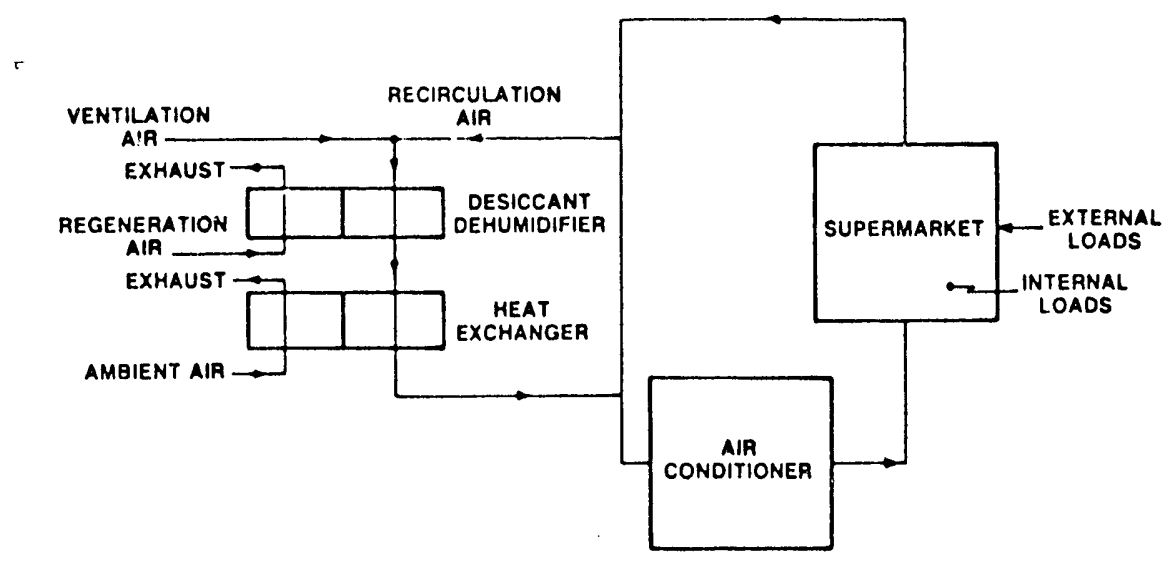

Figure 5.1 Hybrid space conditioning system*

*Source: Reprint by permission of the American Society of Heating, Refrigeration and Air-Conditioning Engineers from ASHRAE Trans. 198591 (pt. 1B). The view of the authors are not necessarily those of the Society, nor does their publication imply any recommendation or endorsement thereof by the Society.

Figure 5.2 shows the design of a two-stage desiccant-integrated HVAC system [2]. The first desiccant wheel is called the enthalpy exchanger; it handles $30 \%$ to $50 \%$ of the building's dehumidification with an external heat source for regeneration. This wheel absorbs both heat and moisture from the incoming airstream and transfers them to the drier exhaust airstream. Because the latent load is reduced, the second wheel needs to handle only $50 \%$ to $70 \%$ of dehumidification, and requires $30 \%$ 
to $50 \%$ less external heat for wheel regeneration. The COP of the two-wheel system is 1.2 to 1.5 at design conditions. The desiccant used in the first stage can be silica gel or molecular sieve. The desiccant for the second-stage wheel can be silica gel, molecular sieve, or lithium chloride, or a combination of two of them.

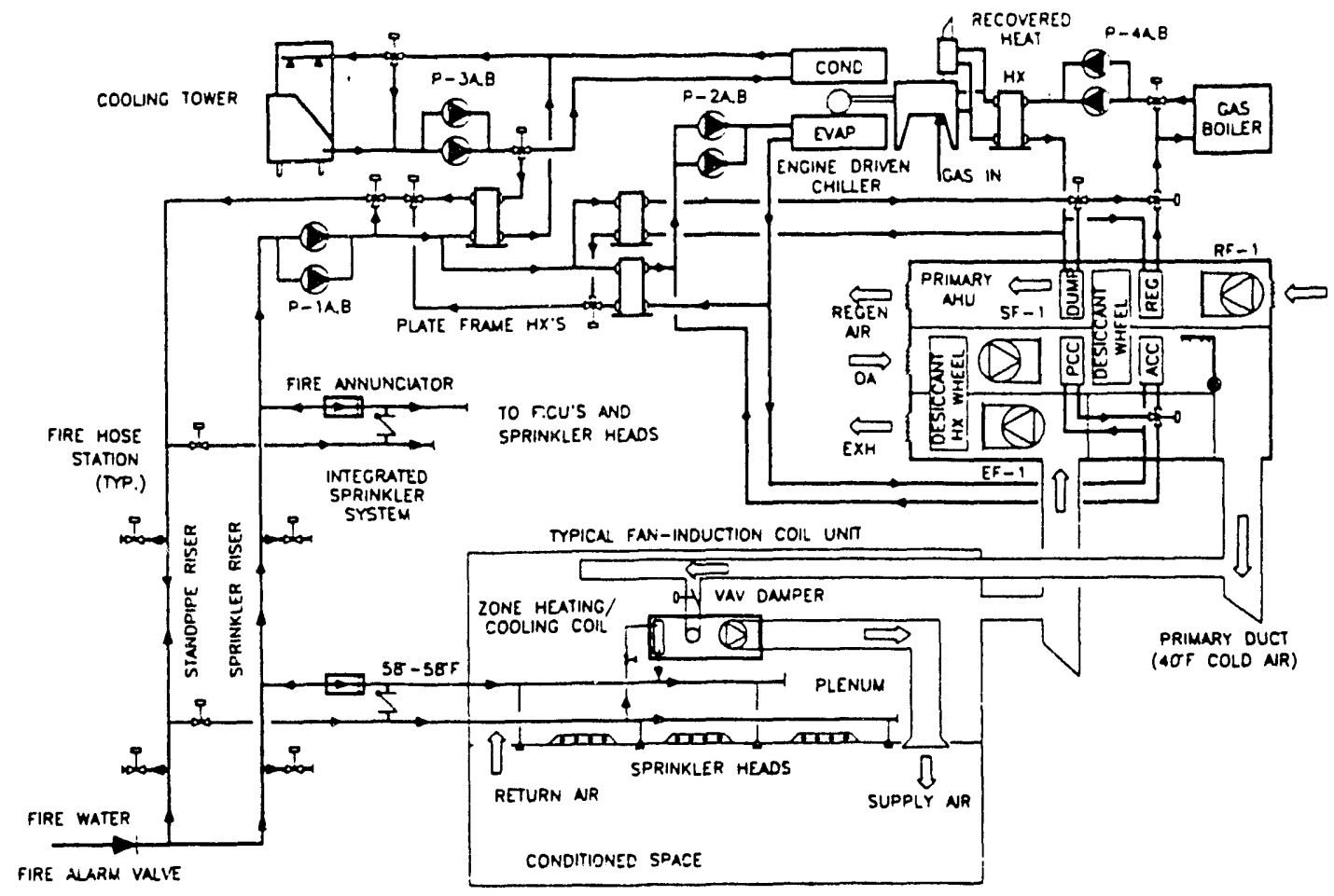

Figure 5.2 Two-stage desiccant dehumidifier integrated cold air VAV system

A two-wheel desiccant system has another performance advantage over a one-wheel system, in addition to its higher thermal efficiency: rain or very humid outdoor conditions do not cause supersaturation in the second wheel, while in a one-wheel system, such saturation can significantly impair performance and require regeneration heat to be at a much higher temperature. Reference [2] also discusses the two-stage gas energized, heat-pipe assisted, desiccant cold-air unit for small commercial buildings such as fast-food restaurants, and the two-stage gas-energized desiccant and cogeneration unit for supermarkets.

\subsubsection{Closed-Cycle Systems}

A closed-cycle system can be operated at an elevated pressure or in partial vacuum. It can achieve a cooling temperature low enough for refrigeration. Figure 5.3 shows a closed-cycle system with zeolite as the desiccant $[3,4]$. As shown in Figure 5.3, the zeolite is divided into at least two separate sealed containers so that one of the containers is always in the desorption part of the cycle while the other part is in the adsorption cycle. In the regeneration process (Figure 5.4), oil from the boiler is pumped into the zeolite tank to steam the moisture out. When the vapor contacts the cold wall, it 
condenses and drains down to the container at the bottom. For the adsorption process (Figure 5.5), the oil flow direction is reversed. The condensed moisture is pumped to the top of the tank and flows down along the tank wall. When zeolite starts adsorbing moisture, it creates low pressure in the tank and thus lowers the condensate temperature because part of the condensate is evaporated. This system has been theoretically analyzed [4]. Tchernev [3] claimed that in a 10 month operation period, a prototype unit achieved a cooling COP of 1.2 and a heating COP of 1.8.

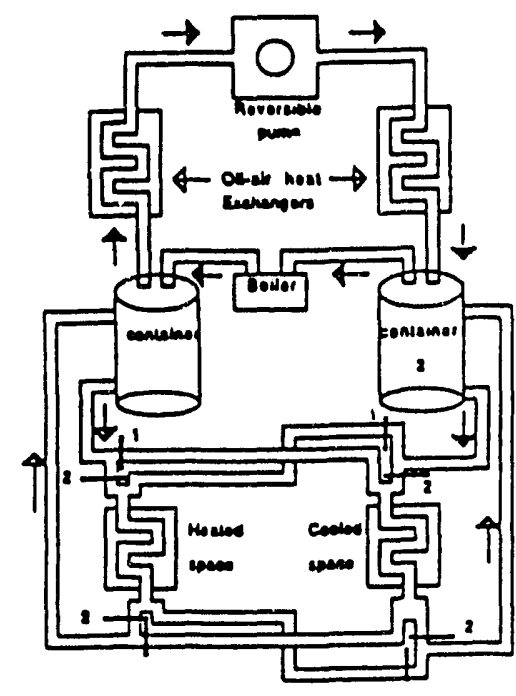

Figure 5.3 Closed-cycle desiccant cooling system

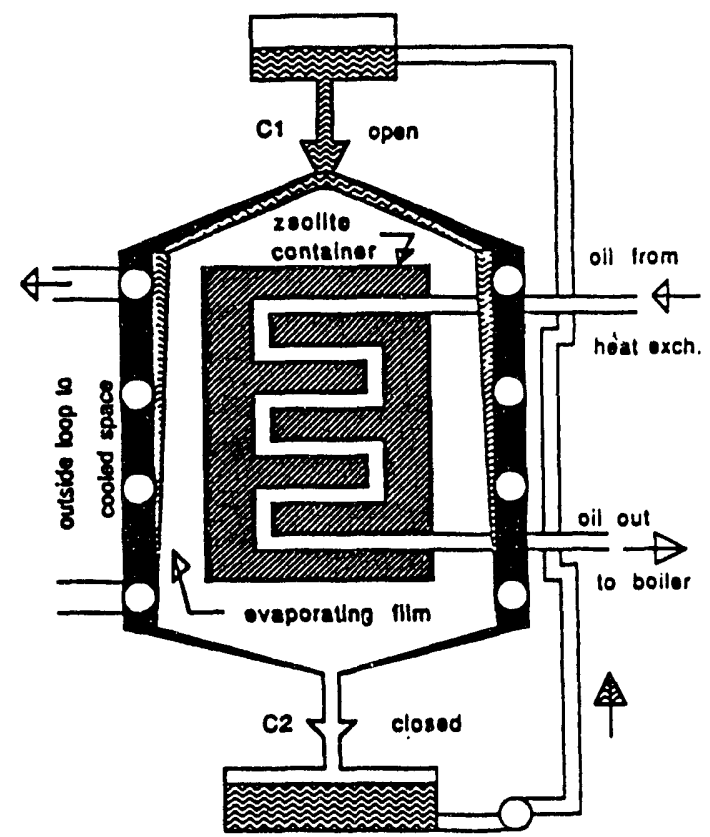

Figure 5.4 Regeneration phase: the walls of the container act as a condenser

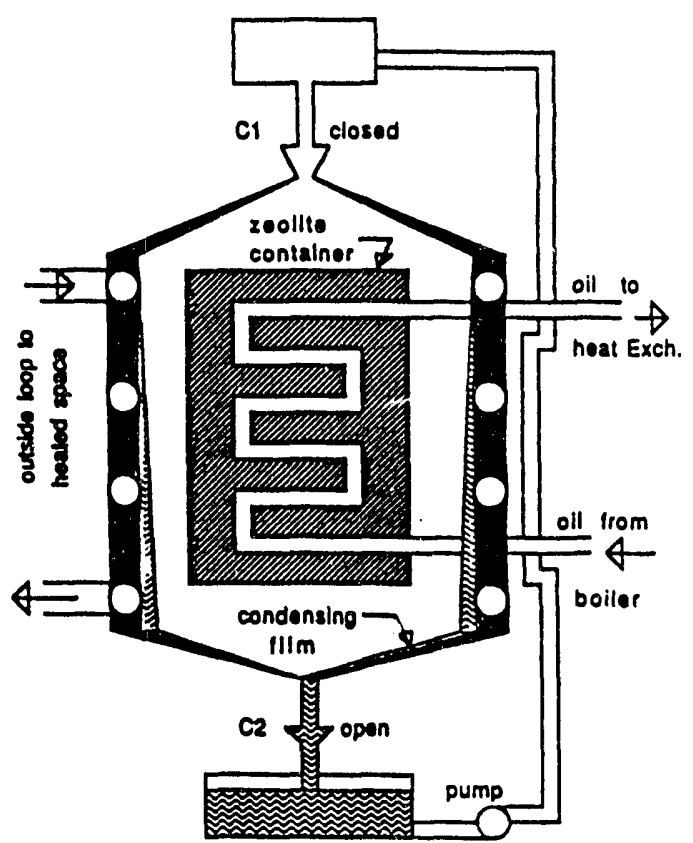

Figure 5.5 Adsorption phase: the walls of the container act as an evaporator 
Figure 5.6 shows the schematic of a basic closed-cycle system developed by Shelton et al. [5]. Ammonia/zeolite was 'used as the adsorption pair. The basic concept is simple, with no moving parts other than controls. When the system was actually built and tested, the cooling COP was about 0.4 . The researchers thought a great amount of heat was wasted, which resulted in the low COP. A modified cycle, as shown in Figure 5.7, was conceived to utiliz: the heat more efficiently. Their analysis indicated that the modified cycle could have a heating COP of 1.75 and a cooling COP of 0.75 for their base case study [5]. They also claimed that their system efficiency was not sensitive to the cycle's heat input and output temperatures. Other adsorption pairs have also been mentioned in the literature, such as zeolite/water, activated-carbon-methanol, activated-carbon-ethanol, and silica-gel-water [3,6-9]. Meunier has analyzed various combinations of cascading solid/adsorbent systems [10].

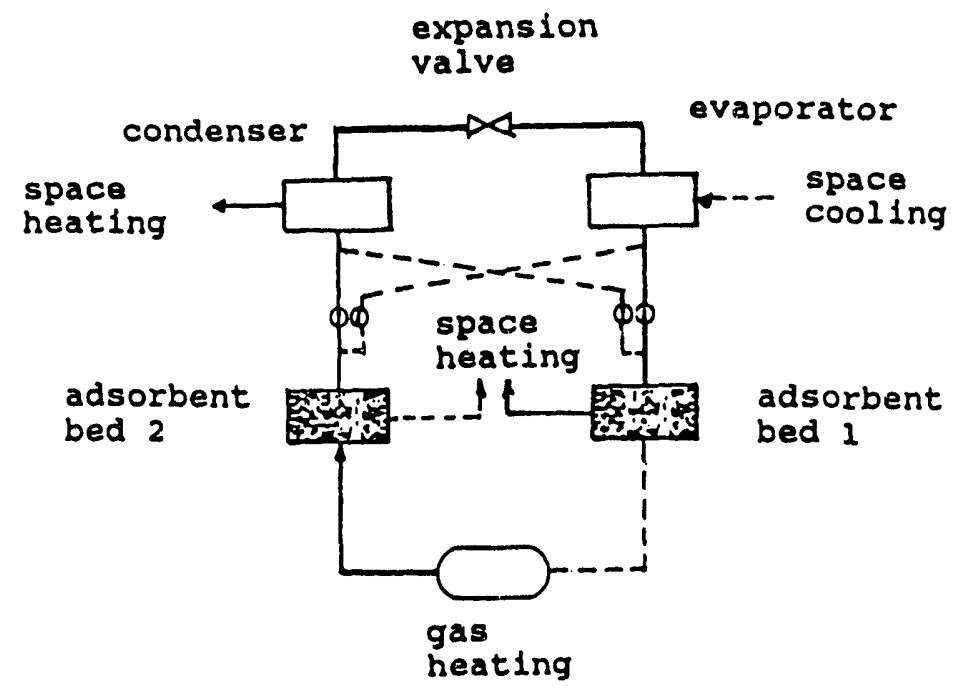

Figure 5.6 Basic solid/vapor adsorption system*

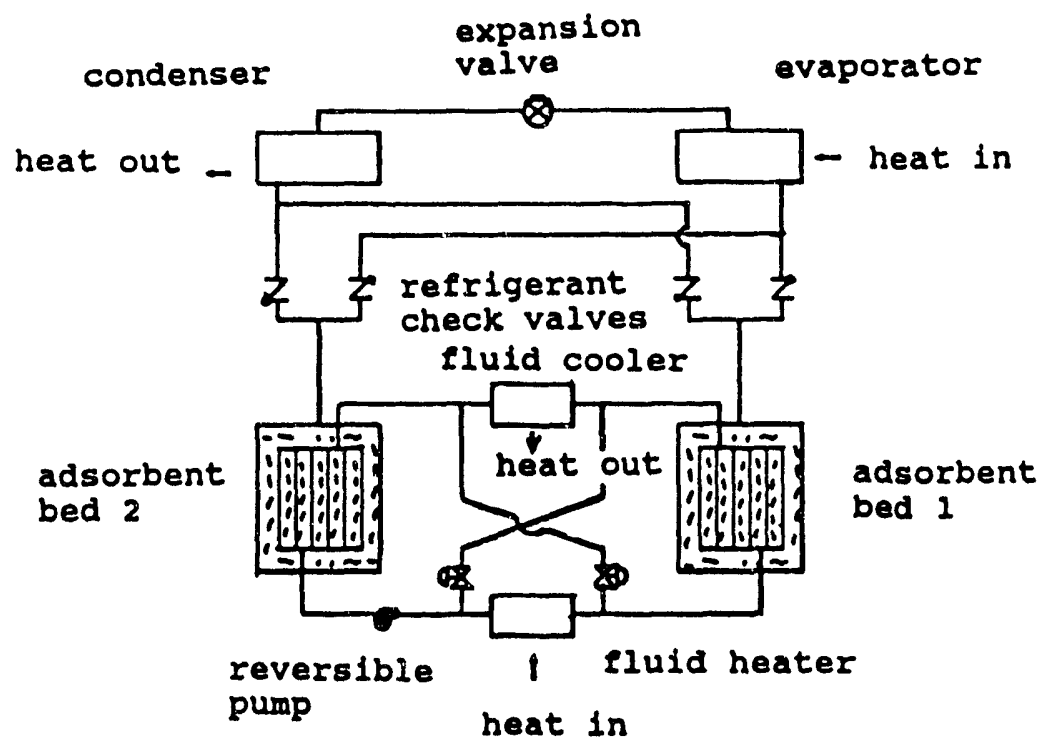

Figure 5.7 Thermal wave solid/vapor adsorption system*

*Source: Shelton, S.V., and Wepfer, W.J. "Ramp Wave Analysis of the Solid/Vapor Heat Pump," J. Energy Res. Technol.
$112(1), 69-78,1990$. 


\section{Components}

The most important component of a desiccant cooling system is the desiccant beds. Its structural configuration, thermal capacity and sorption characteristics largely control the operating economics of the desiccant device. Ideally, the bed should have infinitely low mass and infinitely high surface area. Low mass minimizes the amount of energy wasted in heating and cooling the desiccant, and high surface area maximizes the interaction between desiccant and the surrounding air. Developments in desiccant technology have been centered in the search for lower-cost, higher-efficiency, more durable desiccant bed configurations.

In solid desiccant systems, there are three basic bed configurations; static granular beds, rotating grnnular beds and rotating structured media. Static granular beds are arranged as their name suggests; tanks filled with granular solid desiccant dry air and are then regenerated by a second air stream. Rotating granular beds move the desiccant between the process and reactivation air streams continuously. Rotating structured media resembles corrugated cardboard rolled into a drum, so air can pass lengthwise down the flutes, which are lined with desiccant. Like the rotating granular bed, the structured media revolves continuously between process and reactivation air streams. Harriman [11] describes these different types of beds and their advantages and disadvantages in depth.

Structured media-type beds were introduced in the U.S. by Munters Cargocaire in the early 1960's. They have considerable performance advantages over other types of bed configurations. Their disadvantages are high cost and limited durability. Since some of the original patents protecting this design have now expired, other organizations are working on reducing the cost and improving the durability of such desiccant beds.

Barlow [12] has described several desiccant dehumidifier designs:

1. The AiResearch design has five major components: two evaporative coolers, a rotary thermal regenerator, a solar heater, and a rotary desiccant drum packed with silica gel [13]. See reference [13] for detailed information on the system.

- Advantages: A packed drum provides a large surface area per unit volume and a high fraction of desiccant in the dehumidifier matrix.

- Disadvantages: High air-pressure drop and high solid-side mass transfer resistance. Using large desiccant particles will decrease pressure drop but will increase the solid-side mass transfer resistance.

2. The Institute of Gas Technology (IGT) Solar-MEC design is a centrally supported wheel made of a corrugated fiber material impregnated with molecular sieve particles [14].

- Advantages: The corrugated wheel is very compact; it has a high ratio of surface area per unit volume, which in turn produces a relatively high heat transfer NTU (number of transfer unit). It has low pressure drop and high specific cooling capacity.

- Disadvantages: Data on the mass transfer characteristics of the dehumidifier are not available. Judging from high NTU yet low COP, the mass transfer resistance must be very high. The unit also needs a high regeneration temperature (above $400^{\circ} \mathrm{F}$ ), to be effective. 
3. The Illinois Institute of Technology (IIT) cross-cooled desiccant dehumidifier has two fixed desiccant beds. Silica-gel sheets were attached to the channel walls of the beds. The two beds work intermittently: one dehumidifies the process air and the other is regenerated by heated air [15].

- Advantages: It is a fixed-bed system with cross-cooling capability (desiccant is cooled while in the adsorption process). It has a very low design regeneration temperature and a high COP.

- Disadvantages: The system needs two bulky desiccant beds. Control of the IIT system is very complicated. Heat and mass transfer NTUs are relatively smail.

4. The University of California at Los Angeles (UCLA) design used fine grains of silica gel (average size: 0.12 and $0.25 \mathrm{~mm}$ ) that were bonded to one side of $0.76-\mathrm{mm}$-thick Lexan plastic sheets using a thin layer of silicone rubber adhesive to produce a sandpaper-like surface. The coated sheets were stacked, and spacers were used to form parallel-walled, laminar flow channels $[16,17]$.

- Advantages: The UCLA unit has a low pressure drop and a high heat transfer rate. Mass transfer resistance is reduced becausi of the small desiccant particles used.

- Disadvantages: Thick plastic sheets were used. The unit also has a structural problem.

5. The Solar Energy Research Institute (SERI) wheel design combines the UCLA concept of a sandpaper-like coating of silica gel and the heat exchanger construction concept developed by Dunkle [18]. It winds of a continuous thin polyester ribbon coated with silica gel onto a wheel.

- Advantages: It has a high ratio of Stanton number to friction factor (0.49) and a low solid-side resistance to mass transfer. It is relatively compact yet has a small pressure drop.

- Disadvantages: The plastic ribbon expands when it is heated and thus loses its structural rigidity.

Recently there have been other designs. Two of them are described below.

6. The Seibu Zeolite Ceramic Desiccant Rotor (Japan): The wheel consists of silica-gel/zeolite composite sheets. Seibu claimed that their design improved the wheel performance in the low-humidity range. However, the wheel is very expensive [19].

7. The Energy \& Resource Laboratory desiccant wheel design (Taiwan): Ceramic paper was used on the wheel. The paper was then burned, leaving only ceramic lines. Water glass was then used to chemically form silica gel on the ceramic line structure. The wheel has a high silica gel to wheel structural ratio, a low pressure drop, and a relatively compact size. The test results indicated a single-stage COP of close to 1.0. The wheel-making process is quite complicated and could be expensive [20].

8. Cohen et al. have experimentally compared desiccant wheels from various manufacturers [21]. A total of twelve wheels with four desiccants - silica gel, lithium chloride, molecular sieve, and activated carbon - were tested for their moisture removal performance.

9. SEMCO, under GRI contract [22], is currently developing a low cost solid-desiccant rotary dehumidifier and heat exchanger. 
In liquid desiccant systems, there are two basic types of desiccant beds; those with internal cooling and those where the desiccant is simply sprayed onto an extended surface which resembles cooling tower packing material.

Kathabar division of Somerset Technologies manufactures units of both types with lithium chloride as the primary desiccant. In recent years the company has made improvements in the packing material; reducing it's mass, increasing the surface area and reducing resistance to air flow.

Niagara Blower Co. uses triethylene glycol as a liquid desiccant. It is continuously sprayed on the evaporator coil to create a no-frost unit and to clean the process air. The weakened desiccant solution is then pumped out and regenerated [23].

\subsection{Desiccant Materials}

Recently, desiccants with optimum properties for air conditioning applications have been produced or tested or are undergoing development [24]. LaRoche Chemicals has developed a Type $1 \mathrm{M}$ desiccant that is based on hydratable salts and is capable of direct, gas-fired regeneration. They are currently developing an advanced desiccant matrix. Eaton Corp. is developing a Type $1 \mathrm{M}$ dcsiccant based on ionic gel polymers. They have initiated the study of polymers as liquid desiccants. Michigan Technical University is developing a Type $1 \mathrm{M}$ desiccant based on porous glass. Pennsylvania State University is studying the capabilities of nano-composite materials to perform as effective desiccants. They have identified Type $1 \mathrm{M}$ composites. The University of Pittsburgh is studying the capabilities of layered double-metal hydroxides to perform as effective desiccants. They have also identified type $1 \mathrm{M}$ materials.

\subsection{Computer Models}

As desiccant systems have been the subject of considerable research in recent years, there are a number of computer models which have been built to help investigators better understand the dynamic operation of desiccant systems. These models fall into four basic categories:

- Finite-difference solutions to the differential equations governing heat and mass transfer in a desiccant bed

- Finite-element solutions, and

- Analogy methods

- Commercial equipment performance approximations

Of the finite-difference approaches, the three most widely used computer codes are:

1. MOSHMX (I. Maclaine-cross [25])

2. University of Illinois at Chicago (UIC) (W. Worek [26])

3. Illinois Institute of Technology (IIT) (Z. Lavan [27])

In addition, a number of Ph.D. theses have been done on heat and mass transfer in desiccant structures. Computer models are usually developed as part of the work [28]. Most of these computer 
models fall into the finite-difference category. The vast majority of these models are not supported and cannot be recreated without great difficulty.

Only one finite-element solution is currently being used; the Florida Solar Energy Center (FSEC) computer model FEMALP [29]. This model is used primarily for predicting moisture transport throughout building structures, furnishings and HVAC systems rather than for predicting performance of desiccant equipment.

Of the analogy methods, there are two that are presently being used. These are:

- Analogy Method (Maclaine-cross and Banks [30])

- Enerscope, Inc. - (K. Collier [31])

The method used by Maclaine-cross and Banks is a heat exchanger analogy solution to the entire desiccation process. The Enerscope model is a heat and mass exchanger analogy to the individual water/desiccant processes within the desiccant matrix.

Equipment performance approximations are used primarily to model the performance of desiccant equipment in commercial building HVAC systems, analyzing their energy use over the course of one years operation. During 1991, two of the primary microcomputer-based building energy modeling programs were revised to incorporate desiccant equipment modeling:

- TRACE Release 11.05 (Trane Commercial Systems Group)

- DOE 2.1e (Lawrence Berkeley Laboratory Applied Science Division)

Both of these programs use similar algorithms. For solid desiccant equipment, performance characteristics are based on a state-of-the-art rotating desiccant wheel dehumidifier as configured for commercial buildings. The performance model assumes a commercially-available composite desiccant matrix, consisting of lithium chloride and silica gel. The liquid desiccant equipment model is based on a sprayed-media dehumidifier using lithium chloride as the desiccant.

These first three general classes of computer models can further be divided by the manner in which moisture transport within the desiccant particle is treated. There are currently two approaches to the problem of mass transport within the desiccant particle. They are the Lewis Number analogy and the solution of diffusion equations within the desiccant.

The Lewis Number analogy lumps the mass transport resistance within the desiccant particle with the mass transport resistance between the air and the desiccant. This single mass iransport resistance is used computationally as if all the resistance exists within the gas phase. The Maclaine-cross, UIC, and Enerscope models all use this approach.

Solving the diffusion equations within the desiccant is the most rigorous approach to the problem. Both the IIT and the FSEC computer models use this approach. The advantages and disadvantages of each approach are:

- Solution of diffusion equations is more rigorous, but data for internal diffusion constants are difficult to obtain. This limits the accuracy of the results. This method requires large amounts of computer time. 
- Lewis Number analogy can yield accurate results if the resistance factor is changed for changing conditions. It is difficult to determine the correct resistance factor a priori, but it requires only moderate amounts of computer time.

- Most practical applications of desiccants require that the internal mass transport resistance of the desiccant be small. Therefore, the need for an accurate representation of this phenomenon is minimal for those cases. There may be new applications, however, for which this conclusion is not true. They must be judged case-by-case.

A number of comparisons have been performed among many of these different computer models. Generally speaking, all of the models agree extremely well when only gas-side mass transfer resistance is involved. Disagreement is encountered only when the mass transfer resistance inside the desiccant particles is significant. Trying to determine which model is most accurate is very difficult because of the sparsity of reliable experimental data and the uncertainty of internal mass diffusion parameters. Whenever the internal mass transfer is negligible, all of the models will yield excellent agreemeni with available experimental data. Whenever the internal mass transfer is not negligible, all of the models will require some manipulation to match existing experimental data.

A detailed description of these models, together with a comparison of their results is included in this report as Appendix II.

\section{References for Section 5}

1. D.L. Manley, K.L. Bowlen, and B.M. Cohen, "Evaluation of Gas-Fired Desiccant-Based Space Conditioning for Supermarkets," ASHRAE Trans. 91 (pt. 1B), 447-456 (1985).

2. G. Meckler, Assessment of Opportunities for Introducing Desiccant HVAC Systems into the Commercial Building Market. Unpublished report to ORNL, Oak Ridge National Laboratory, Oak Ridge, Tenn. July 1990.

3. D.I. Tchernev, and D.T. Emerson, "High-Efficiency Regenerative Zeolite Heat Pump," ASHRAE Trans. 94 (pt. 2), 2024-2032, 1988.

4. A. Hajji, W.M. Worek, and Z. Lavan, "Numerical Simulation of a Regenerative Closed-Cycle Adsorption Cooling/Heating System," Presented at the ASME International Solar Energy Conference, San Diego, Calif. April 2-6, 1989.

5. S.V. Shelton, W.J. Wepfer, and D.J. Miles, "Ramp Wave Analysis of the Solid/Vapor Heat Pump," J. Energy Res. Technol., 112(1), 69-78, 1990.

6. R. Delgado, A. Choisier, P. Greiner, I. Ismail, F. Meunier, and M. Pons, Proceedings IIR, Jerusalem. Ed. IIR, 181-187, 1982.

7. R. Boussehain and M.L. Feidt, Proc. Journées Internationales sur les Transferts Héliothermiques, Rabat, 1985.

8. A. Sokoda, and M. Suzuki, J. Chem. Eng. Japan, 17, 52-57, 1984. 
9. A. Adell, Rev. Phys. Appl., 19, 1005-1011, 1984.

10. F. Meunier, "Theoretical Performances of solid Adsorbent Cascading Cycles using the Zeolite-water and Active Carbon-Methanol Pairs: Four Case Studies," Heat Recovery Systems, 6 (No. 6), 491-498, 1986.

11. Harriman, Lewis G. III, The Dehumidification Handbook - Munters Cargocaire, 79 Monroe St. Amesbury, MA 01913. 1990.

12. Barlow, R.S., An Assessment of Dehumidifier Geometries for Desiccant Cooling Systems, SERI/TR-252-1529, Solar Energy Research Institute, Golden, Colo. June 1983.

13. J. Rousseau, Development of a Solar Desiccant Dehumidifier. Phase II. Final Summary Report, DOE/CS/31591-T8, Washington, DC, Nov. 1982.

14. J. Wurm et al., Solar-MEC Development Program: Semi-Annual Progress Report, IGT COO-4495-23. Prepared for the U.S. Dept. of Energy, Washington DC, Nov. 1979.

15. J.B. Monnier, W.M. Worek, and Z. Lavan, Performance of a Cross-Cooled Solar Powered Desiccant Cooling System, IIT Report No. DES-81-1. Prepared for the U.S. Dept. of Energy, Jan. 1982.

16. S. Kim, "Development of a Laminar Flow Desiccant Bed for solar Air Conditioning Application," Master Thesis, Dept. of Mech. Eng., UCLA, 1981.

17. P. Biswas, "An Experimental Study of the Performance of a Laminar Flow Silica Gel Desiccant Packing Suitable for Solar Air Conditioning application," Master Thesis, Dept. of Mech. Eng., UCLA, 1981.

18. R.V. Dunkle, P.J. Banks, I.L. Maclaine-cross, "Wound Parallel Plate Exchangers for Air-Conditioning Applications," Compact Heat Exchangers - History, Technological Advancement and Mechanical Design Problems. American Society of Mechanical Engineers (ASME) HTD-Vol. 10; 65-71, Nov. 1980.

19. Private conversation with P. Lee of Energy and Resource Laboratory at 1989 ASME WAM at San Francisco, CA.

20. H. Lee, S. Lee, and Y. Cheng, "The Characteristics Analysis of a Desiccant Dehumidification Wheel Made by Energy and Mining Research Organization," Symposium Volume paper No. 3, Workshop on Solid Adsorption Dehumidification Air-Conditioning Technology, June, 1989, Taipei, Taiwan.

21. B. Cohen, R. Wysk, and R. Slosbery, Advanced Desiccant Cooling system Development : Desiccant Wheel Sample Performance Testing, GRI-89/0036.1, GRI, Chicago, March 1989.

22. GRI contract 5089-295-1791 to SEMCO for the development of low cost solid desiccant rotary dehumidifier and heat exchanger. GRI, Chicago, 1989. 
23. Research Bulletin RB-11-14-88 and Product Bulletin 162A, Niagara Blower Company, Buffalo, N.Y. 1988.

24. D. Kosar and D. Novosel, Summary of Desiccant Cooling Program, GRI, Chicago, Jan. 1990.

25. I.L. Maclaine-cross, "A Theory of Combined Heat and Mass Transfer in Regenerators",. Ph.D. Thesis, Monash University, Australia, 1974.

26. D. Charoensupaya and W.M. Worek, "Parametric Study of an Open Cycle Adiabatic Solid Desiccant Cooling System", The International J. of Energy, 13 (No. 9), 739-747, 1988.

27. Y.J. Ko, "Advanced Desiccani Cooling System with Staged Regeneration Including Solid Side Resistance", Ph.D. Thesis, Illinois Institute of Technology, Chicago, Illinois, 1989.

28. J. Jurinak, "Open-Cycle Solid Desiccant Cooling - Component Models and System Simulations", Ph.D. Thesis, University of Wisconsin, Madison, 1982.

29. A. Kerestecioglu, "The Detailed Mathematical Prediction of Simultaneous Heat and Mass Transfer in Cavities," Ph.D. Thesis, Florida Institute of Technology, Melbourne, Florida, 1986.

30. I.L. Maclaine-cross and P.J. Banks, "Coupled Heat and Mass Transfer in Regenerators Prediction Using an Analogy with Heat Transfer", International J. of Heat and Mass Transfer, 15, 1225-1242, 1972.

31. R.K. Collier, Advanced Desiccant Material Assessment, Phase II, Final Report, GRI-88/0125, GRI, Chicago, 1988. 


\section{RESEARCH AND DEVELOPMENT NEEDS}

Recent advances in state-of-the-art desiccant cooling are very encouraging. To those who are most knowledgeable in the field, it now appears that desiccant cooling systems can be cost effective as compared with conventional cooling systems in many applications. The problems with CFC fluids may further enhance the competitiveness of desiccant-based systems.

There is, however, a major obstacle preventing building owners from realizing the benefits of desiccant systems: the lack of effective technological aids to transfer knowledge of desiccant systems from laboratories and research reports to practicing architect and mechanical engineers.

\subsection{Recent Technological Advances}

There have been encouraging advances in the state of the art. Recent examples are described below.

\subsubsection{Open-Cycle Systems}

- Optimum desiccant properties, $1 \mathrm{M}$ type, have been identified for air conditioning applications.

- Several types of stable desiccants with the desired properties are being produced and tested.

- The staged regeneration concept was introduced.

- Low-cost designs of effective desiccant wheels have been suggested [1].

- The importance of optimum operation strategies have been identified.

- Indoor air quality has been considered in desiccant cooling systems [2].

\subsubsection{Closed-Cycle Systems}

- The principle of heat regeneration based on capture of the thermal wave has been recognized [3].

- Two- and three-container prototypes of regenerative systems have been produced and tested [4].

\subsubsection{Liquid Systems}

- Heat and mass transport from binary falling films of liquid desiccant solution have been studied $[5-7]$.

- Various cycle configurations have been built and studied. 


\subsubsection{Integrated Systems}

- Methods of integrating desiccant dehumidification with conventional cooling systems [8] and/or cogeneration systems $[9,10]$ have been designed.

- Several large-scale systems have been built and are successfully operating [11].

- Over 135 units introduced by Cargocaire Engineering Corp. have already been sold to supermarket chains through the SuperAire $\bullet$, and increased penetration is planned by Cargocaire [12].

\subsection{Future Research and Development Needs}

Recent advances in state-of-the-art desiccant systems should be the foundation for a vigorous research and development program aimed at establishing sorption systems and desiccant cooling as a mature and cost-effective alternative. Some suggested areas for future research and development are discussed in this section.

\subsubsection{Technology Transfer}

In the last five years, funds in excess of $\$ 20$ million has been expended by government, industry and institutions to research desiccant systems, and components. Very few resources have been devoted to transferring knowledge from research laboratories to practicing professionals. An organized approach to the problem of tech transfer is necessary to avoid the classic problem of wasted research investments. Two means of improving technology transfer are discussed below.

- Improved building energy models

In order to assess the costs and benefits of new technology, the engineering community relies on building energy models such as DOE 2.1e and TRACE. Unfortunately, neither of these programs was originally designed to accept new types of equipment and new system design concepts. In the case of desiccant technology, a substantial benefit is the improved humidity control and its effect on moisture problems in buildings. While extensive modeling of moisture behavior in buildings has been accomplished at considerable cost by GRI and FSEC, none of the research can be used in building energy programs because their basic structures are inadequate to the task.

Restructuring DOE 2 as an object-oriented, graphically-driven, modular program would be the most cost-effective means of removing a major obstacle to the assessment and introduction of new technology for building HVAC systems.

- Improved data access

For new technology to be useful, detailed information must be available, visible and affordable to the engineering community. Such is not yet the case with desiccant technology. A modest investment in publishing the full text, graphics and bibliographies from desiccant research on 
CD-ROM in ISO 9660 format would allow those who can best benefit from the research to access it quickly and economically.

\subsection{Desiccant Materials}

- Basic studies of sorption phenomena

- Prediction and determination of sorption dynamics

- Determination of optimum sorbent-sorbate pairs for specific applications such as air conditioning, medium- and low-temperature refrigeration, and heating

- Determination of desired optimum desiccant properties for respective applications, i.e., isotherm shape, heat of sorption, diffusivity, etc.

- Manufacture or synthesis of new stable sorbents with prescribed physical properties

- Development of safe and noncorrosive liquid desiccants

\subsubsection{Systems}

- Develop easy-to-use modular simulation models with different desiccant materials that can fit into conventional heating and cooling computer programs.

- Derive the general design guidelines for desiccant integrated HVAC systems, because most design engineers are not familiar with desiccant systems.

- Improve computer simulation of desiccant-integrated HVAC systems with flexible computer codes to suit the great variety of building designs and HVAC requirements.

- Investigate system designs that can maintain sharp concentration waves.

- Determine optimal operating strategies at various conditions and means of implementing the strategies.

- Investigate design and performance of systems undergoing chemisorption for low-temperature refrigeration purposes.

- Analyze the applications of using alternative fuels for desiccant systems.

- Study the possibilities of using waste heat for desiccant systems.

- Investigate hybrid desiccant systems.

\subsection{Components}

- Develop both regular and compact wheels with high desiccant fractions (over 80\%) which do not deliquesce or generate dust. 
- Develop high-performance sensible heat exchangers with effectiveness of 0.90 or better for both regular and compact sizes.

- Develop wheels with composite desiccants.

- Develop better evaporative coolers, in both regular and compact sizes.

- Develop easy-to-use system controls.

- Develop desiccant systems with indoor air quality improvement features.

- Design the airflow channels in wheels to yield the optimum ratio of heat and mass transfer over pressure drop.

\subsubsection{Theoretical Analysis}

- Study heat and mass transfer enhancement for desiccant systems.

- Investigate optimization of the regeneration temperature profile.

- Explore the possibility of continuously operating closed-cycle systems to minimize heat carry-over during switching.

- Analyze the performance of wheels with composite desiccants.

\section{References for Section 6}

1. SEMCO, under GRI contract 5089-295-1870, to develop low-cost rotary solid desiccant dehumidifier and heat exchanger. GRI, Chicago, 1989.

2. M. Meckler, "Integrated Desiccant Cold Air Distribution system," ASHRAE Trans. 95 (pt. 2), 1989.

3. S.V. Shelton, W.J. Wepfer, and D.J. Miles, "Ramp Wave Analysis of the Solid/Vapor Heat Pump," J. of Energy Resource Technology, 112 (No. 1), 69-78, 1990.

4. D.I. Tchernev, and D.T. Emerson, "High Efficiency Regenerative Zeolite Heat Pump," ASHRAE Trans. 94 (pt. 2), 2024-2032, 1988.

5. B.D. Wood, and G.A. Buck, "Natural Convection Heat and Mass Transfer from Falling Films in Vertical Channels," presented at ASME-JSME-JSES International Solar Energy Conference, Reno, Nevada, March 17-22, 1990.

6. B.D. Wood and H.M. Habib, "Effect of a Small Quantity of a Non-Absorbable Gas on the Heat and Mass Transfer for the Entrance Region of a Falling Film Absorber and Effect of the Mass Transfer for a Falling Film Absorber in Presence of a Non-Absorbable Gas," presented at ASME-JSME-JSES International Solar Energy Conference, Reno, Nevada, March 17-22, 1990. 
7. B.D. Wood, and T.A. Ameel, "Heat and Mass Transfer in Laminar Wavy Falling Film Absorption with the Presence of Low Concentrations of Non-Absorbable Gases," presented ASME-JSME-JSES International Solar Energy Conference, Reno, Nevada, March 17-22, 1990.

8. D.S. Calton, "Application of a Desiccant Cooling system to Supermarkets," ASHRAE Trans. 95 (pt. 1B), 441-446, 1985.

9. G. Meckler, "Two Stage Gas Energized Desiccant/Cogeneration Unit for Supermarkets," U.S. patents $4,577,471$ and $4,723,417$.

10. M. Meckler, "Cogeneration and Central Regeneration Multi-Contractor Air Conditioning system," U.S. patent 4,691,530.

11. G. Meckler, "Efficient Integration of Desiccant Cooling in Commercial HVAC Systems," ASHRAE Trans. 94 (pt. 2), 2033-2042, 1988.

12. D. Kosar, and D. Novosel, Summary of Desiccant Cooling Program, Gas Research Institute, Chicago. Jan. 1990. 


\section{ASSESSMENT OF OPPORTUNITIES FOR INTRODUCING DESICCANT HVAC SYSTEMS INTO THE COMMERCIAL BUILDING MARKET}

\subsection{Introduction}

\subsubsection{Existing Desiccant Market: Industrial and Military}

In recent decades there has been a small but viable, relatively stable market for desiccants in the military and industrial sectors. The approximate size of the annual desiccant market, based on information from knowledgeable sources in the industry, is $\$ 50$ to $\$ 60$ million. Desiccant dehumidification has been used in niche markets or specialty markets for which there was usually no practical alternative process to get the same result. Examples include moisture control for

- mothballing ships, armaments, and defense-related equipment,

- underground repositories of electronic systems and archives,

- photographic film manufacturing,

- clean rooms and laboratories for industrial manufacturing and research,

- oxygen production,

- multi-compound separation,

- gas purification,

- breweries, and

- water treatment plants.

An emerging opportunity for pollution control lies in the selective absorption of certain kinds of gas pollutants in industrial environments.

These specialty markets have not depended on energy efficiency or competitive pricing. There has been no mass market. Except for certain components, the equipment has been made-to-order for specific projects and clients.

Desiccant equipment manufacturers are not geared to mass marketing or creating new markets. They have always responded to perceived needs defined by a customer. They are interested in the prospect of expanding their market significantly into commercial HVAC systems. They lack the resources and confidence, however, in their ability to mount a successful national marketing effort to the HVAC building industry. The principal impetus for introducing desiccant HVAC systems into the commercial building market will not come from the existing desiccant equipment manufacturers. 


\subsubsection{Existing HVAC Market}

At least $95 \%$ of the air conditioning equipment in today's mass construction market is geared to electrically driven vapor- compression refrigerated-air systems. A large group of manufacturers of these components is led by Trane and Carrier.

These manufacturers communicate constantly with HVAC consulting engineers and design/building contractors. When it becomes evident to the manufacturers that these specifiers are interested in desiccant systems, they can be expected to respond to the new market. They have not yet seen evidence of such interest, in our opinion, because of the following impediments:

- Consulting engineers and design/building contractors are not familiar with and do not have ready access to techniques for using desiccants efficiently in commercial building HVAC systems.

- Consulting engineers and design/building contractors rarely have the luxury-the time and opportunity-tn do development work. In any case, they are rarely in a position to independently assume the added legal vulnerability that innovative work carries with it.

- Consulting engineers, building owners, and utilities need reassurance and education about the performance and cost-effectiveness of desiccant HVAC systems. A highly effective first step would be to make available for inspection in their community a desiccant system operating in a large government building. As explained subsequently, in large buildings, well-integrated desiccant HVAC systems are competitive in terms of first cost and also significantly reduce the ongoing energy costs. Demonstration and discussion about this performance within local communities is the most effective way to break through barriers and motivate designers and owners to want to learn more.

- Architects in most projects lead the design team and retain the consulting engineers. Architects resist mechanical innovation unless the owner is clearly interested in having a new approach evaluated. If government buildings lead the way and other owners begin to express interest in desiccant systems, architects and engineers will be responsive.

- In smaller facilities, although the life-cycle cost of desiccant systems is lower than that of conventional systems, the initial cost is higher. Utility subsidies may bridge the first-cost gap once the utilities observe desiccant performance in operating systems. Eventually, mass production of packaged units for small buildings can be expected to lower costs. A rise in electric utility costs would also favor desiccant units.

\subsubsection{GMAPC Experience with Desiccant HVAC Systems}

Gershon Meckler Associates, P.C. (GMAPC), has designed desiccant HVAC systems that are operating in large- and medium-size office buildings, a museum, and a hospital medical center. Their experience in designing, installing, and observing operating desiccant HVAC systems since the 1970s clearly indicates that desiccant equipment can be a reliable, practical component of HVAC systems and can significantly reduce an HVAC system's requirement for utility electricity. 
GMAPC has developed application techniques and has patented a series of desiccant HVAC system combinations. The application techniques involve new ways of integrating existing components and materials to improve the economics of desiccant HVAC systems in several ways.

We now see a number of factors converging that are creating a more favorable environment for the introduction of desiccant HVAC systems into commercial buildings. (More about this in the next section.) Government activities of several kinds could do a great deal to encourage this process.

\subsection{Commercial Desiccant HVAC: Benefits and Supporting Trends}

The beneficial effects of incorporating desiccant dehumidification into commercial building HVAC systems are as follows:

- In large buildings, it reduces the consumption of utility electricity for HVAC by more than $50 \%$, and the daytime peak demand for electricity by $65 \%$ to $70 \%$. Dehumidification/latent-cooling typically represents $20 \%$ to $40 \%$ of a building's total air conditioning load. In a desiccant HVAC system this portion of the load is shifted off the vapor compression refrigeration system and is handled by a moisture-absorbing/adsorbing desiccant. A gas-energized chiller/heater provides heat for desiccant regeneration and chilled water for sensible cooling.

- It reduces the use of refrigerants and chlorofluorocarbons (CFCs) by $20 \%$ to $30 \%$ in large buildings. It also reduces the environmentally harmful gases emitted by power plants by reducing air conditioning's need for utility electricity.

- For small commercial buildings, it eliminates entirely the use of CFCs and the consumption of utility electricity for air conditioning (except for fans and pumps) by eliminating vapor compression refrigeration from the air conditioning process. This is possible and practical when ventilation air is dried very deeply using a desiccant and then is evaporatively cooled to the supply temperature. (Given currently available components and desiccant materials, our experience indicates that an efficiently arranged two-stage process is necessary to dry deeply enough for adequate evaporative cooling yet remain practical in terms of the heat required for desiccant regeneration.)

- It uses heat instead of utility electricity to energize dehumidification. Heat is required to regenerate/dry the desiccant for reuse. Sources include solar energy and recovered heat as well as gas-produced heat (direct-fired or cogenerated). Off-peak electric resistance heaters or heat pumps can also be used.

- For building owners, it reduces energy operating costs significantly where peak electric utility demand charges are high and natural gas is available.

- For electric utilities, reduces peak demand and thus can cumulatively reduce the pressures on utilities' generating capacity.

- For gas utilities, it opens up a new opportunity for gas use in the summer-the annual low point for gas use. 
- It represents a more rational, efficient use of national energy resources shifting the load from the annual electric utility peak to the annual gas utility valley (summer) and to renewable (solar) or recovered sources.

Special-purpose industrial applications generally have been configured to use high-temperature heat (process steam) to regenerate the desiccant. The regeneration process has not been perceived as thermally efficient and there has been little reason or impetus to think of desiccants in the context of commercial building HVAC systems.

Several factors are converging to create a more favorable environment for the introduction of desiccants into HVAC systems. The most important is the strong pressure on many electric utilities to stem the growth of peak day demand. The result in many areas has been the imposition of high demand charges (geared to a user's peak demand), the development of other utility incentives to curb day demand or to shift it off-peak, and the appearance of new interest on the part of building owners, major developers, and consulting engineers in finding practical alternatives to conventional HVAC systems that reduce energy operating costs.

The primary beneficiary of this new interest thus far has been thermal storage (for example ice thermal storage), in which utility electricity is consumed off-peak to produce stored thermal energy that is then used during daytime operating hours. This solution is responsive to the needs of electric utilities and to the desires of users to reduce peak demand charges. However, it is not responsive to another of the factors converging to create a more favorable environment for wider use of desiccants: environmental concerns and the concurrent likelihood of increased regulation that will restrict use of CFCs as well as harmful gases emitted by power plants. Desiccants do not contain CFCs. Further, heat for desiccant regeneration can come entirely or primarily from sources other than utility electricity. In addition, as already indicated, for small commercial establishments a desiccant integrated with evaporative cooling can provide sensible cooling (temperature control) as well as latent cooling (dehumidification). There is no doubt, in our opinion, that desiccant HVAC systems have the potential to very significantly reduce the use of CFCs and utility electricity for air conditioning and would achieve that result if widely applied.

An additional factor favorable to desiccant dehumidification is the large availability of gas for summer cooling and of special gas price rates for gas cooling.

\subsection{Conditions Needed to Encourage the Spread in Use of Desiccant HVAC Systems}

The factors just cited are creating a more favorable environment for the introduction of desiccant HVAC systems, but alone they are not sufficient to propel many architects or engineers to install them. In our view, the following conditions are needed:

- Availability of guidance and techniques for reducing the first cost of desiccant HVAC systems. Much of our work has involved the integration of desiccant dehumidification in such a way that first cost savings in the air distribution system cover the cost of desiccant equipment for large buildings. In medium-size buildings, efficient integration techniques plus a utility incentive grant could eliminate any first-cost penalty for desiccant equipment. 
- Performance documentation and confirmation by a source such as the Department of Energy, and measures to encourage government facilities' people and their architects and engineers to objectively evaluate desiccant technology for their large building projects. For this, the following DOE activities would be extremely helpful:

- Study and document desiccant system performance in existing large office building applications.

- At the conceptual design stage for large government buildings, advocate and finance comparative HVAC system studies to encourage the particular government agency and its designers to evaluate desiccant technology.

- If the study supports a desiccant HVAC system, provide the necessary sponsorship to implement the design and installation of the desiccant system.

- Monitor and document the performance of desiccant HVAC systems in these government buildings.

- Disseminate results in the building industry.

- Development of design tools such as user-friendly computer programs or "expert systems" to enable designers to easily evaluate economic tradeoffs and design desiccant HVAC systems based on actual performance data.

- Availability of utility incentives such as equipment subsidies for the introduction of desiccant equipment. While these are not necessary for large buildings of $150,000 \mathrm{ft}^{2}$ and larger, they are needed to offset extra first costs for smaller office buildings, where the payback from energy savings may take five to seven years. An equipment subsidy is also needed to offset extra first costs for desiccant installations in small commercial establishments (e.g., fast food restaurants and shopping mall stores). In these buildings, even with an efficiently integrated two-stage unit that provides both sensible and latent cooling-such as the rooftop unit that GMAPC has developed-the payback from energy savings will take three to four years.

Utility advocates or potential advocates of desiccant cooling, such as gas utilities and many combined gas/electric utilities, would provide such assistance if they were educated about desiccants and assured about equipment reliability. (With desiccant systems installed, gas utilities sell more gas during their off-season, making more efficient use of their total resources, and gas/electric utilities can shift load from the annual electric peak to the annual gas nadir.) Giving government leverage assistance to these desiccant advocates to enable them to provide equipment subsidies would ease and speed the introduction of desiccant HVAC systems.

- Availability of solar incentives such as tax credits for the installation of solar collection systems. Solar energy is an excellent, practical heat source for desiccant regeneration, as has been proven to our satisfaction in two operating installations that GMAPC designed (the Monroe County Courthouse/Government Center, Stroudsburg, Pennsylvania; and the Veterans Administration Medical Center Addition, Washington, D.C.). However, it is unlikely that combined desiccantsolar HVAC systems will be installed to any extent until desiccants become more familiar and 
accepted as part of HVAC systems, and then only if solar tax credits or similar assistance is available.

- The development of desiccant materials that absorb more and are also inherently more efficient (require less heat for regeneration). Looking beyond the use of currently available components and materials, to helpful research and development, this would, in our opinion, significantly advance the practicality of desiccant HVAC systems for commercial applications.

A desiccant material with both a capacity to absorb close to 100 grains of moisture per pound of air processed (approximately double the current capacity) and a regeneration COP approaching 1.0 would have a strong impact on cost-effectiveness.

The COP of desiccant regeneration generally has been 0.4 or 0.5 , in its past industrial configurations. The two-stage arrangement with heat recovery that we have developed for HVAC applications increases the thermal COP to 1.0 on average. Further advances in inherent efficiency would be extremely helpful in every application.

\subsection{Appropriate Commercial Building Applications}

Desiccant HVAC systems can provide excellent environmental control and consume significantly less utility energy than conventional HVAC systems in large and medium-large office buildings, small commercial buildings such as strip-mall stores and fast-food restaurants, and supermarkets.

Office building application requires (1) efficient integration of the desiccant subsystem, (2) regeneration heat source(s), and (3) sensible cooling. When designed efficiently, in targe buildings desiccant HVAC systems are competitive with conventional HVAC systems in terms of first cost.

Prepackaged desiccant rooftop units are appropriate for small commercial buildings and supermarkets if utilities provide an equipment subsidy. The units for small commercial buildings can incorporate desiccant dehumidification and evaporative cooling to provide all of the required air conditioningboth latent and sensible cooling.

Supermarket units provide dehumidification only. Desiccant dehumidification is particularly appropriate for supermarkets, where conventional electric-driven air conditioning systems are not able to keep store air dry enough to absorb moisture that is generated in the space. This excess moisture is attracted to the frozen food cases, where it condenses, forms frost, and requires extra defrost cycles, a process that consumes a significant amount of energy unnecessarily.

A two-stage desiccant unit that GMAPC has developed for supermarkets maintains a space's relative humidity (RH) at $35 \%$ to $40 \%$ instead of the usual $50 \%$ to $55 \%$ RH. As a result, the supermarket's conditioned air is dry enough to absorb most of the moisture generated in the store as well as the moisture entering with the outside (ventilation) air.

The energy impacts in a typical supermarket are that condensation around frozen food cases is $80 \%$ less, and the two-stage desiccant system requires $30 \%$ to $45 \%$ less energy for refrigeration than the conventional system. The desiccant unit incorporates a cogenerator that provides regeneration heat cost-effectively by simultaneously generating electricity for store use. 


\subsection{Market Potential}

\subsubsection{Office Buildings}

GMAPC has assessed the potential for desiccant HVAC system applications in large and mediumlarge office buildings over a ten-year period. In these buildings, the first cost of well-integrated desiccant HVAC systems approximates the first cost of conventional all-air HVAC systems-without the aid of equipment subsidies from utilities. GMAPC has concluded that strong demonstration, educational, and marketing efforts are required to build confidence and transfer design skills to HVAC designers. Given such efforts, a reasonable projection of total potential ten-year application of desiccant HVAC systems in large and medium-large office buildings is 60 million $\mathrm{ft}^{2}$ : 333 projects averaging $180,000 \mathrm{ft}^{2}$ each. This represents almost $7 \%$ of the total ten-year office space market that GMAPC has projected.

Table 7.1 shows the basis for the estimate of the total office space market as well as a regional breakdown of potential applications. The regional breakdown of applications relates to the size of the respective markets, but is also based on a primary effort in the three east coast regions; secondary efforts in the Pacific, east north central, and west south central regions; and no effort in the west north central, east south central, and mountain regions (see Figure 7.1).

\subsubsection{Supermarkets and Small Commercial Buildings}

The rapid spread of desiccant units for supermarkets and small commercial buildings such as fast-food restaurants does not require an extensive educational program of design assistance, as is the case for large buildings. However, these units do require an equipment subsidy from the utility in order to be competitive in terms of first cost. The payback from energy-cost savings is approximately three to four years for the small commercial building unit and two years for the supermarket unit.

Therefore, at least in the case of small commercial buildings such as fast-food restaurants and stripmall stores, it is reasonable to assume that in most communities these will follow the introduction and demonstration of desiccant performance in large office buildings. In addition, the rapid spread in use of supermarket and small-commercial desiccant units requires the following:

- strong marketing to chain-store owners and others,

- $\quad$ equipment subsidies from advocate utilities,

- $\quad$ assistance from advocate utilities in securing demonstration projects within chains and within communities, and

- exponential growth in applications based on successful demonstration of performance to chain owners and others.

Tables 7.2 and 7.3 show the total number of applications GMAPC has concluded are possible over a 10-year period, given vigorous marketing, the availability of equipment subsidies, and thermally efficient prepackaged units such as those developed by GMAPC. 


\section{Table 7.1 Desiccant HVAC Systems Office Space Potential Market 10-Year Applications (Large Office Buildings - Average 180,000 $\mathrm{ft}^{2}$ )}

\begin{tabular}{|c|c|c|c|c|}
\hline \multirow[b]{2}{*}{ REGION } & \multicolumn{2}{|c|}{$\begin{array}{c}\text { OFFICE SPACE MARKET } \\
-10 \text { YEARS } \\
\left({\left.\text { Mil. } \mathrm{ft}^{2}\right)}\right. \\
\end{array}$} & \multicolumn{2}{|c|}{$\begin{array}{c}\text { POTENTIAL DESICCANT } \\
\text { HVAC APPLICATIONS - } 10 \\
\text { YEARS }\end{array}$} \\
\hline & $\begin{array}{l}\text { Retrofit } \\
\text { Market* }\end{array}$ & $\begin{array}{c}\text { New Construc- } \\
\text { tion Market, } \\
1989-99^{* *} \\
\end{array}$ & $\begin{array}{l}\text { Retrofit } \\
\text { Market, } \\
\text { Mil. ft }\end{array}$ & $\begin{array}{c}\text { New Construc- } \\
\text { tion Market, } \\
{\text { Mil. } \mathrm{ft}^{2}}^{2} \\
\end{array}$ \\
\hline \multicolumn{5}{|l|}{ Primary Markets } \\
\hline $\begin{array}{l}\text { Middle Atlantic } \\
\text { South Atlantic } \\
\text { New England } \\
\end{array}$ & $\begin{array}{r}107.5 \\
71.2 \\
31.5 \\
\end{array}$ & $\begin{array}{r}107.8 \\
87.7 \\
36.4 \\
\end{array}$ & $\begin{array}{l}8.1 \\
5.0 \\
2.2 \\
\end{array}$ & $\begin{array}{l}8.1 \\
6.1 \\
2.6 \\
\end{array}$ \\
\hline 10-year Market/Applic: & 210.2 & 231.9 & 15.3 & 16.8 \\
\hline \multicolumn{5}{|l|}{ Secondary Markets } \\
\hline $\begin{array}{l}\text { East North Central } \\
\text { West South Central } \\
\text { Pacific }\end{array}$ & $\begin{array}{l}91.1 \\
39.2 \\
63.8 \\
\end{array}$ & $\begin{array}{l}41.6 \\
46.1 \\
54.6 \\
\end{array}$ & $\begin{array}{l}7.6 \\
2.3 \\
4.2 \\
\end{array}$ & $\begin{array}{l}3.5 \\
2.8 \\
3.6\end{array}$ \\
\hline 10-year Market/Applic: & 194.1 & 142.3 & 14.1 & 9.9 \\
\hline \multicolumn{5}{|l|}{ Non-Targeted Markets } \\
\hline $\begin{array}{l}\text { West North Central } \\
\text { East South Central } \\
\text { Mountain }\end{array}$ & $\begin{array}{l}33.0 \\
21.2 \\
17.9 \\
\end{array}$ & $\begin{array}{l}16.2 \\
10.4 \\
15.6 \\
\end{array}$ & $\begin{array}{l}1.2 \\
0.8 \\
0.5\end{array}$ & $\begin{array}{l}0.6 \\
0.4 \\
0.4 \\
\end{array}$ \\
\hline 10-year Market/Applic: & 72.1 & 42.2 & 2.5 & 1.4 \\
\hline $\begin{array}{l}\text { TOTAL 10-YR MARKET/ } \\
\text { APPLICATIONS, } \mathrm{ft}^{2} / \$ \\
\end{array}$ & 476.4 & 416.4 & $\begin{array}{c}31.9 / \\
\$ 319 \text { mil. }\end{array}$ & $\begin{array}{c}28.1 / \\
\$ 281 \text { mil. }\end{array}$ \\
\hline
\end{tabular}

*Basis: $20 \%$ of existing office space built pre-1975.

** (a) Years 1989-95 based on "America's Office Needs: 1985-1995," an in-depth study by Dr. David Birch of MIT sponsored by the MIT Center for Real Estate Development and Arthur Anderson \& Co., which estimates the new space needed to reach a $6 \%$ vacancy rate by 1995 , taking into account 1985 vacancy rates, projected job growth, and other factors;

(b) Years 1996-99 based on a $2 \%$ annual growth in those years in the office space market.

\section{NOTES:}

1. Potential applications shown above represent close to $7 \%$ of the total construction market. Given strong demonstration, educational, and marketing efforts, this is a conservative projection.

2. These projections include only large buildings, where the first cost of well-integrated desiccant HVAC systems approximates the first cost of conventional all-air HVAC systems-without the aid of utility subsidies.

3. Applications can expand greatly, to medium-size buildings as well as retrofit projects, when desiccant system performance and design techniques become known and one of the following applies: (a) equipment subsidies are readily available, (b) CFC reduction is required, or (c) a reduction in peak-hour consumption of utility electricity is required. 


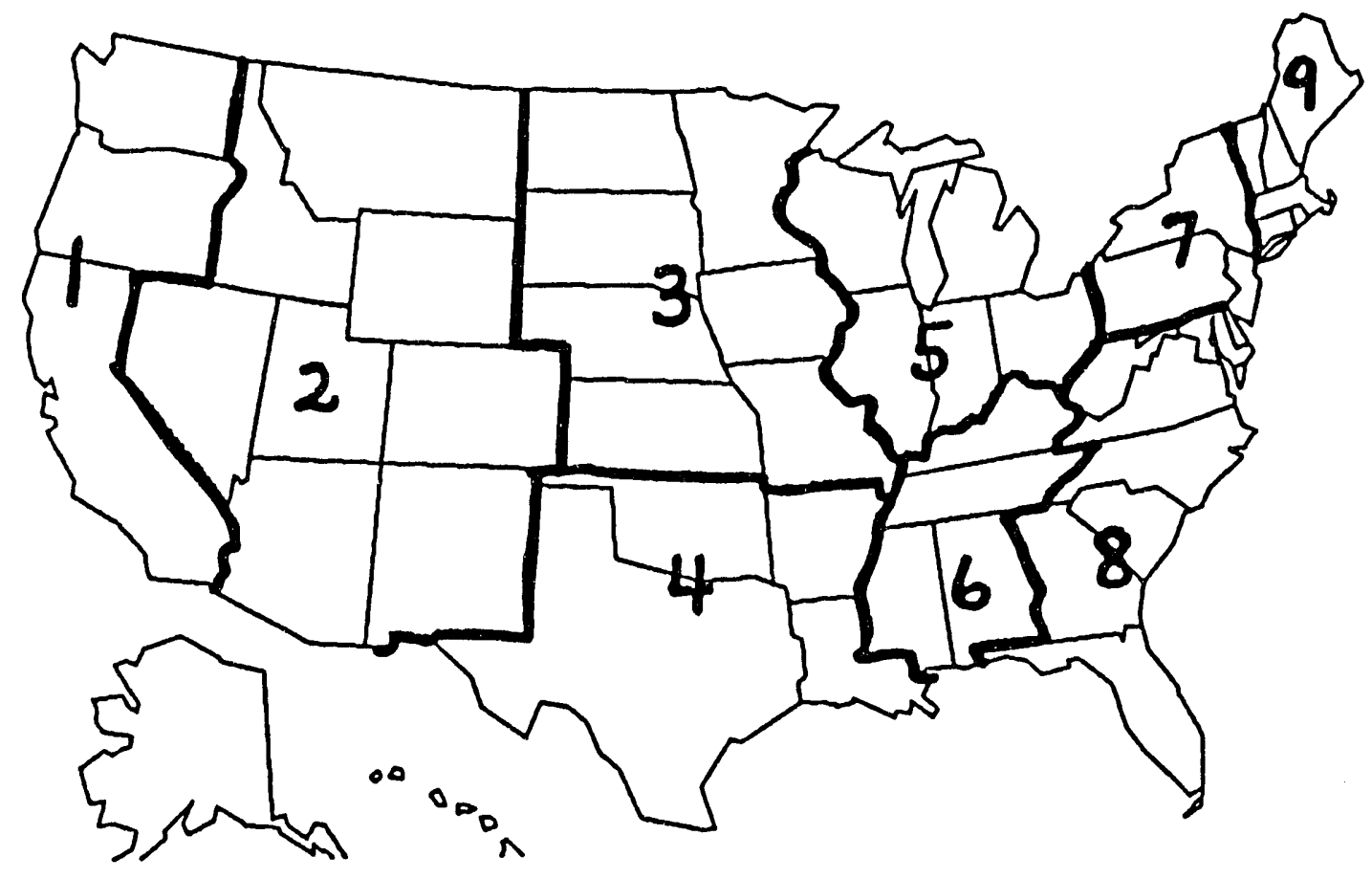

\section{REGION NO.}

1

2

3

4

5

6

7

8

9

\section{REGION NAME}

Pacific

Mountain

West North Central

West South Central

East North Central

East South Central

Middle Atlantic

South Atlantic

New England

Figure 7.1 Regions used in Table 7.1 (U.S. Census Regions)

In supermarkets, as shown in Table 7.2, the GMAPC estimate of potential 10-year applications exceeds 1,600 projects totaling more than 50 million $\mathrm{ft}^{2}$. The estimated 10 -year potential for small commercial buildings such as fast-food restaurants and strip-mall stores, shown in Table 7.3, is approximately 52,600 applications totaling 105.3 million $\mathrm{ft}^{2}$. 
Table 7.2 Supermarket Desiccant/Cogeneration Unit - Potential 10 Year Applications $\left(30,000 \mathrm{ft}^{2}\right.$ Average Store Size)

\begin{tabular}{ccc}
\hline Year & $\begin{array}{c}\text { Application } \\
\text { Per Year }\end{array}$ & $\begin{array}{c}\text { Square Feet } \\
\text { Per Year }\end{array}$ \\
\hline 1 & 5 & 153,766 \\
2 & 12 & 356,273 \\
3 & 20 & 602,571 \\
4 & 99 & $2,960,143$ \\
5 & 158 & $4,751,777$ \\
6 & 196 & $5,870,455$ \\
7 & 212 & $6,365,527$ \\
8 & 261 & $7,829,598$ \\
9 & 321 & $9,360,405$ \\
10 & 395 & $11,845,399$ \\
\hline 10 Year Total $\$$ & 1,679 & $50,365,914$ \\
& & $\$ 419.8$ million
\end{tabular}

Table 7.3 Small Commercial Building Desiccant Heating/Cooling Unit - Potential 10 Year Applications $\left(2,000 \mathrm{ft}^{2}\right.$ Average Store Size)

\begin{tabular}{ccc}
\hline Year & $\begin{array}{c}\text { Application } \\
\text { Per Year }\end{array}$ & $\begin{array}{c}\text { Square Feet } \\
\text { Per Year }\end{array}$ \\
\hline 1 & 5 & 10,000 \\
2 & 20 & 40,000 \\
3 & 40 & 80,000 \\
4 & 100 & 200,000 \\
5 & 500 & $1,000,000$ \\
6 & 2,000 & $4,000,000$ \\
7 & 5,000 & $10,000,000$ \\
8 & 10,000 & $20,000,000$ \\
9 & 15,000 & $30,000,000$ \\
10 & 20,000 & $40,000,000$ \\
\hline 10 Year Total $\$$ & 52,665 & $105,330,000$ \\
& & $\$ 1.053$ billion
\end{tabular}




\subsection{Cost Effective Design Techniques}

\subsubsection{Large Buildings}

To be competitive with conventional air conditioning systems in large and medium-large commercial buildings, desiccant systems must be integrated into the HVAC system in new ways that reduce first cost as well as energy operating cost.

Commercial building HVAC systems consist of two basic parts: a central plant and a distribution system. In small buildings, the central plant is the major cost; in large buildings, the major cost is the distribution system.

The central plant of a desiccant HVAC system is more expensive than that of a conventional HVAC system. In large buildings, however, a major reduction in the size and cost of the distribution system is possible when a desiccant is used instead of a conventional all-air system. This reduction covers the extra cost of the desiccant central-plant equipment.

The cost-effectiveness of desiccant HVAC systems that GMAPC has developed and applied in large and medium-large buildings is based on the following cost-saving techniques:

- Low-flow primary air. Distribute a very small quantity of desiccant dried primary air to reduce the size and cost of the primary ductwork and air handler as well as the fan energy required for air distribution. The size of the primary ducts and air handler can be reduced by $70 \%$ to $85 \%$ compared with a conventional electric VAV all-air system when the quantity of air distributed is 0.1 to $0.4 \mathrm{cfm} / \mathrm{ft}^{2}$. This quantity, dried to 33 to $40 \mathrm{gr} / \mathrm{b}$ (grains of moisture per pound of dry air), provides $100 \%$ of a facility's dehumidification requirement. (It is not practical to dry the air this deeply in a conventional vapor-compression refrigeration HVAC system.)

The dry air is distributed to terminals at a variable volume, determined by the humidity condition, to minimize fan energy. The temperature of the desiccant-dried air is approximately $75^{\circ} \mathrm{F}$.

Alternatively, the small quantity of desiccant-dried primary air can be distributed to mixing-box terminals at $40^{\circ} \mathrm{F}$, thus providing a portion of sensible cooling as well as $100 \%$ of latent cooling. The air temperature can be dropped to $40^{\circ} \mathrm{F}$ in a way that minimizes the use of refrigeration by drying the air more deeply, after-cooling with $50^{\circ} \mathrm{F}$ chilled water, and then cooling evaporatively with nonrefrigerated water.

For comparison, the figures include a schematic diagram and psychrometric process for three HVAC systems: a conventional all-air VAV system with vapor compression refrigeration (Figures 7.2 and 7.3), a two-stage solid desiccant HVAC system that includes evaporative cooling and distributes $40^{\circ} \mathrm{F}$ primary air (Figures 7.4 and 7.5), and a single-stage liquid desiccant HVAC system that distributes dry (not cold) primary air (Figures 7.6 and 7.7). These three HVAC systems are compared in detail in the section entitled 7.7, "Impact on Energy Consumption and Energy Cost." 


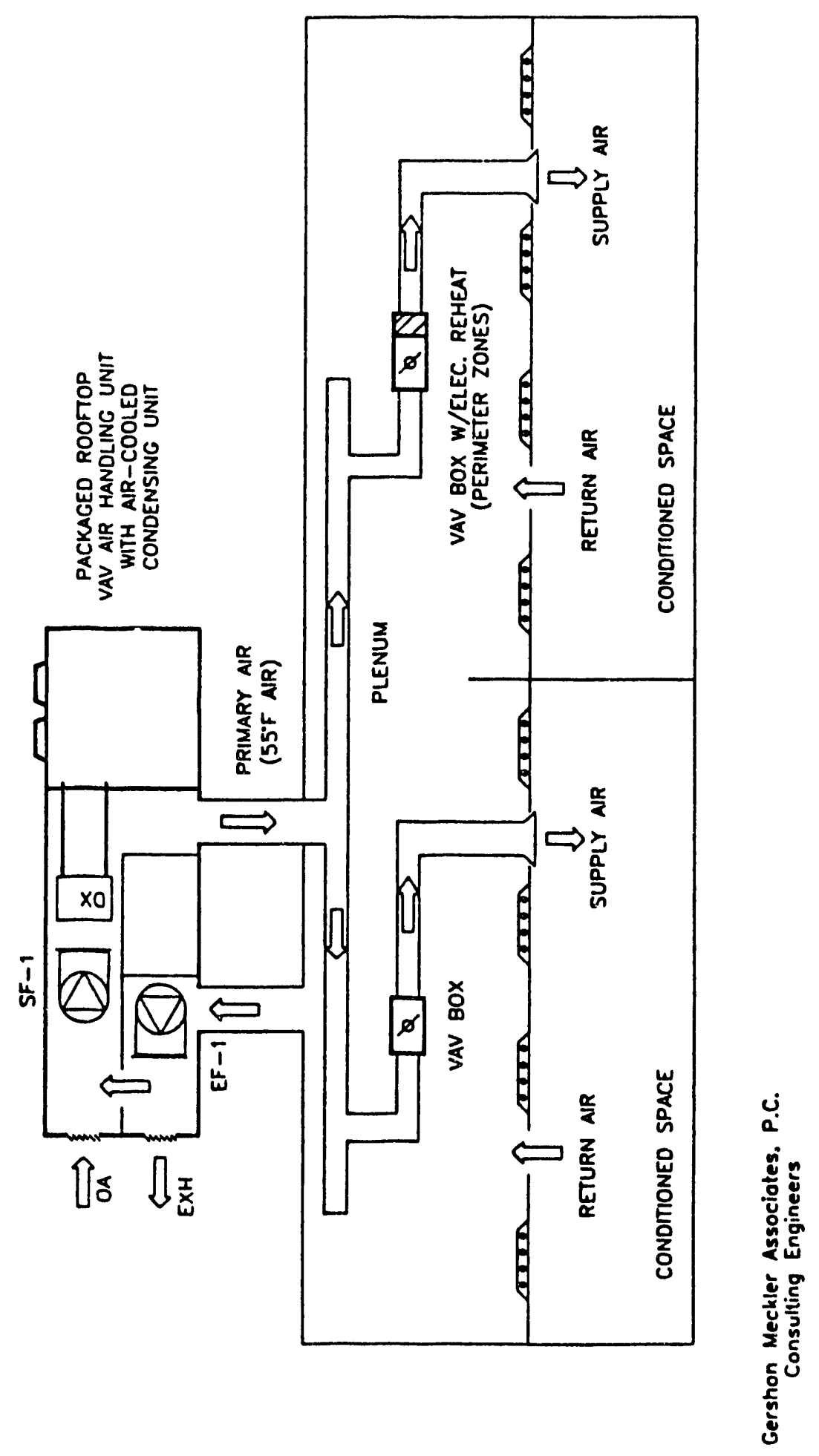

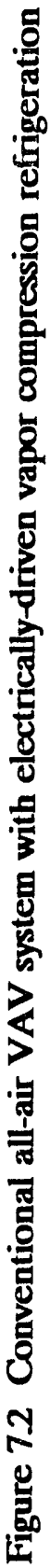



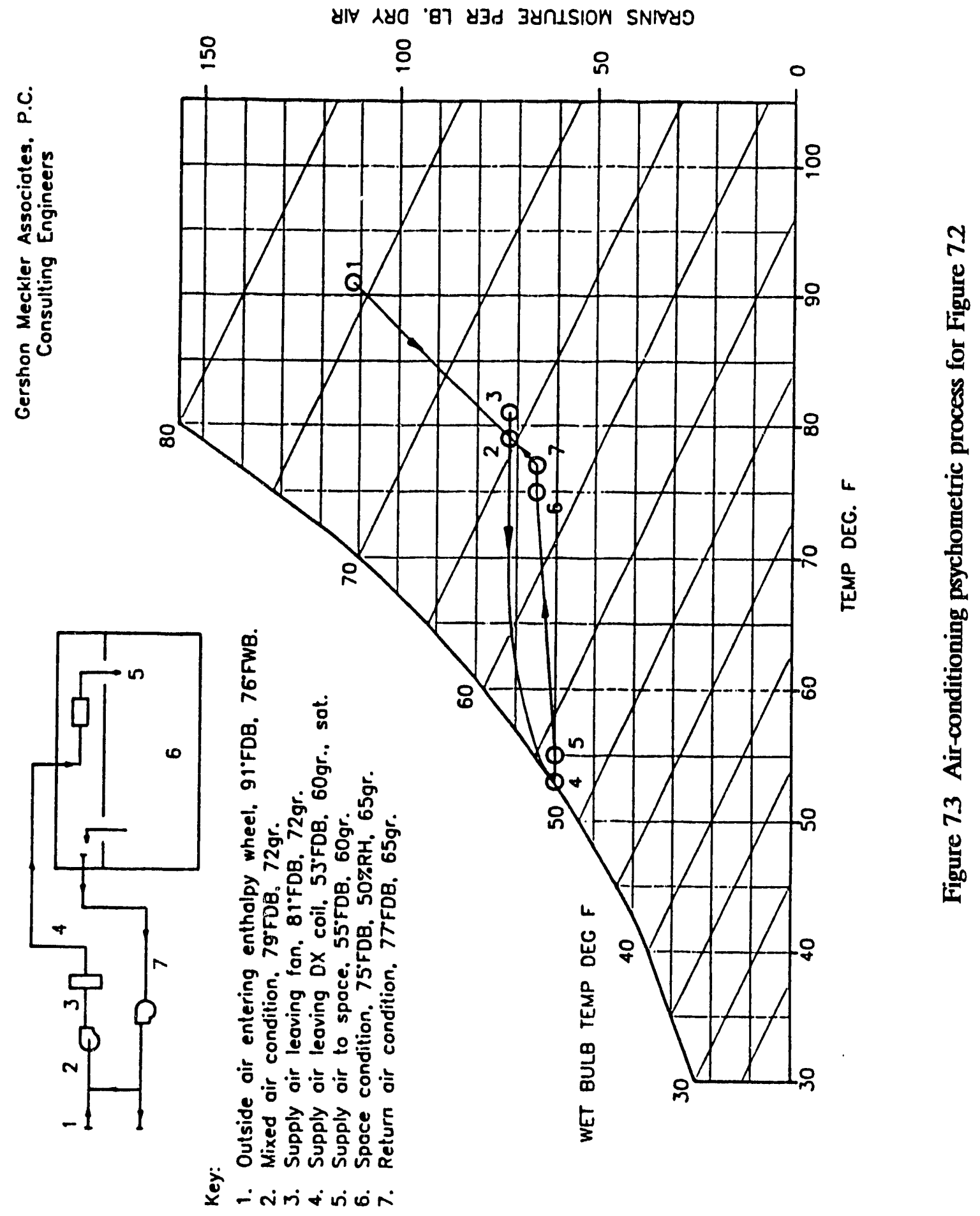

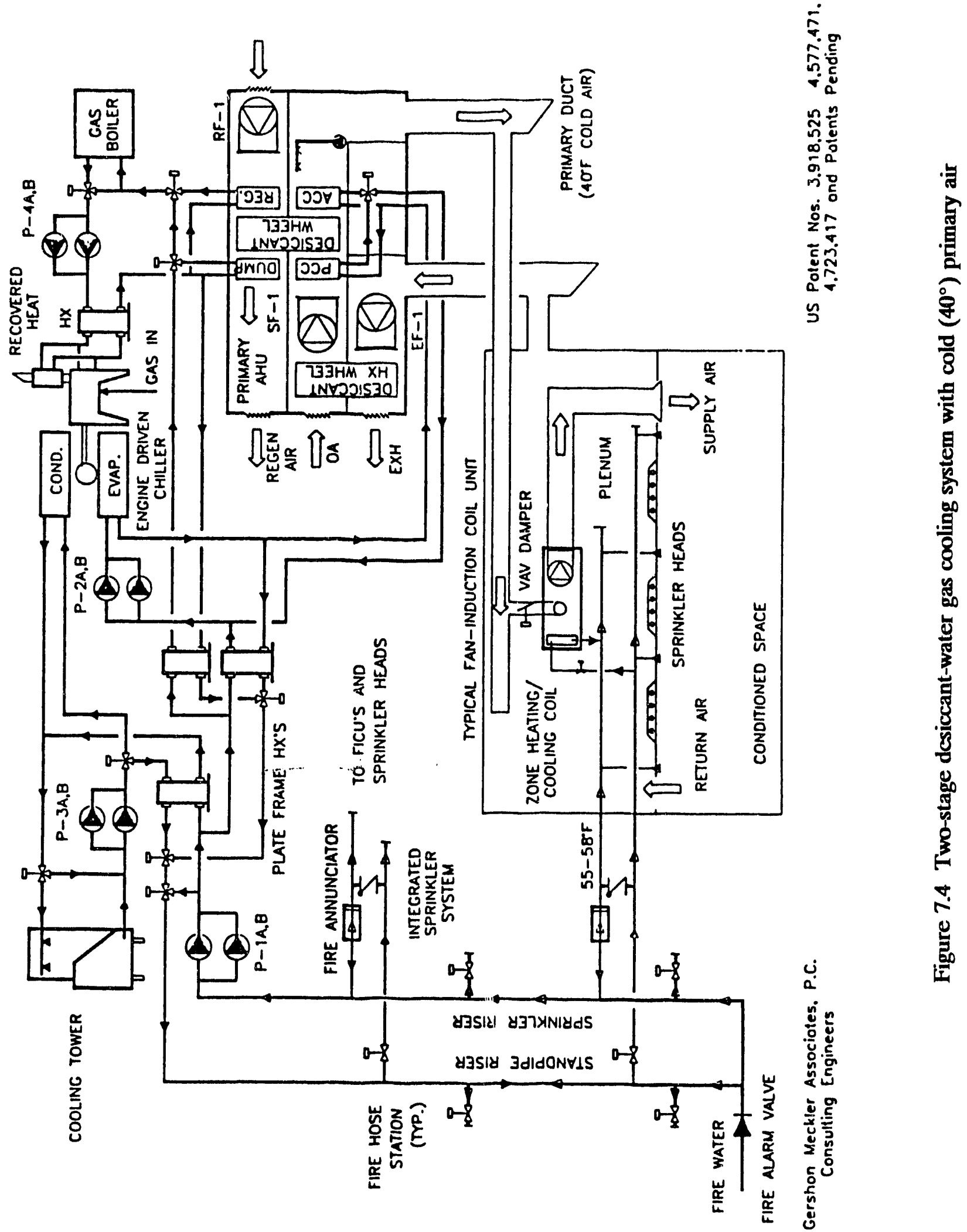


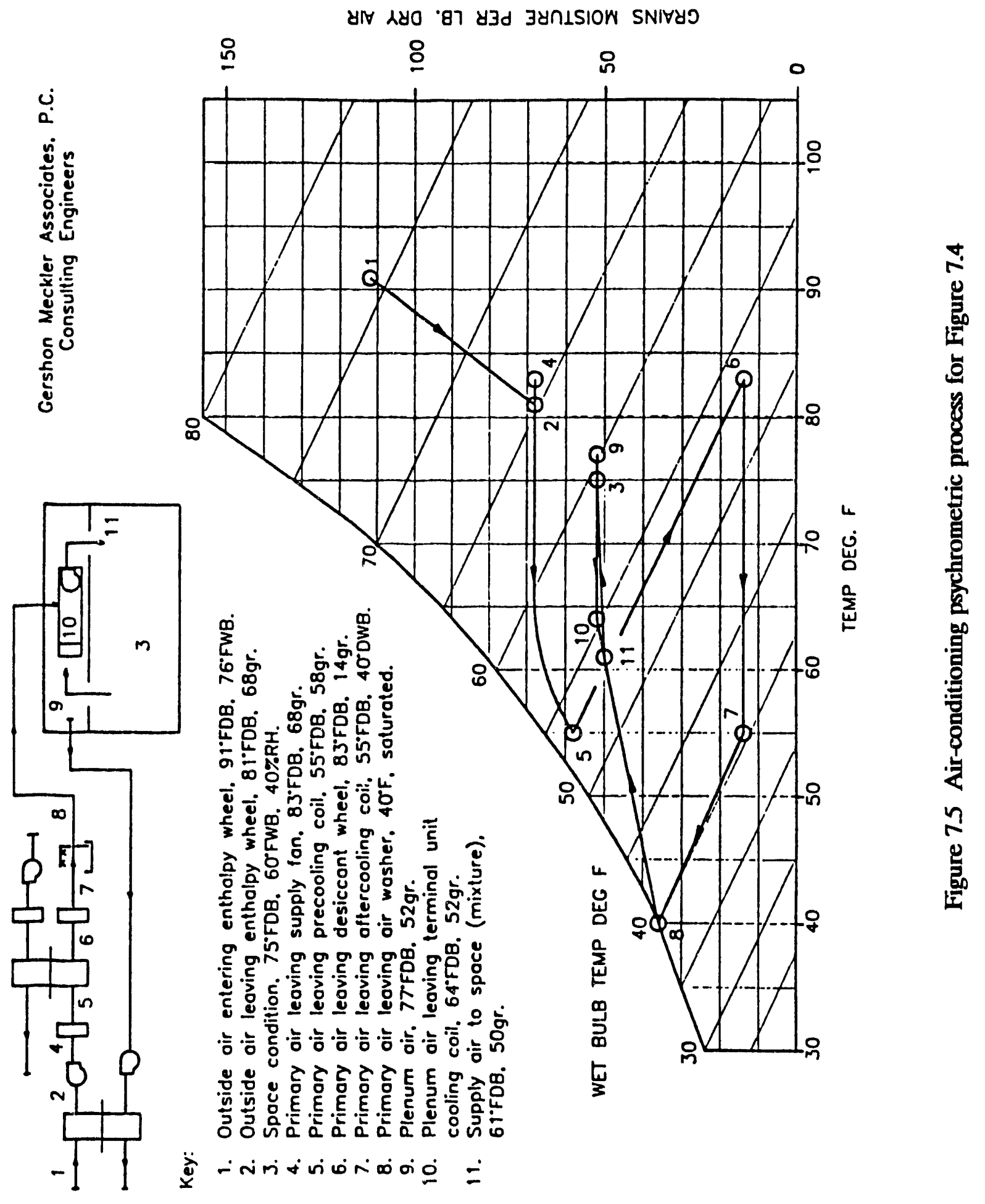


- Sensible cooling at efficient elevated temperature level. Provide sensible cooling separately at terminals at a higher-than-usual temperature level that is appropriate for the task. When a vapor compression chiller or absorption chiller is used, it produces $55^{\circ} \mathrm{F}$ chilled water; when unitary heat pumps are used, they operate at an evaporator coil temperature of $55^{\circ} \mathrm{F}$. (The air has already been dehumidified by desiccant absorption; therefore, there is no need to chill to $42^{\circ} \mathrm{F}$, as in a conventional system, to condense moisture.) Cooling at the higher temperature level increases the energy efficiency of sensible cooling, requiring less energy to do the work.

- Desiccant regeneration at $130^{\circ} \mathrm{F}$ to $200^{\circ} \mathrm{F}$. For efficient regeneration, incorporate one of the following, as appropriate:

- $130^{\circ} \mathrm{F}$ to $140^{\circ} \mathrm{F}$ hot water from one of the following sources:

- off-peak electric utility heating via thermal storage,

- heat pumped from an absorption machine that is gas-powered directly or indirectly (directfired or run by cogenerated heat),

- a combination of heat recovered from the regenerator exhaust and heat from a small heat pump dedicated to regeneration, or

- $\quad$ Flat plate solar collectors (with backup from another source).

- $\quad 160-180-200^{\circ} \mathrm{F}$ hot water from one of the following:

- Concentrating solar collectors or

- Cogenerated heat

- Integrated fire-sprinkler piping to distribute water to and remove heat from terminals. Save the cost of a separate piping network by distributing water for sensible cooling (chilled water for coils or condenser water for unitary heat pumps) from the central plant to terminals via the sprinkler piping. Such dual use of sprinkler piping has been permitted by the National Fire Protection Association code since 1978 (NFPA 13).

- Apprnpiate terminals to mix and cool primary and secondary air. Utilize mixing-box terminals that incorporate either a chilled water coil or unitary heat pump. Terminals receive a variable volume of desiccant-dried primary air $\left(0.1\right.$ to $\left.0.4 \mathrm{cfm} / \mathrm{ft}^{2}\right)$, determined by space conditions. (The minimum quantity is established by the ventilation-air requirement.) Terminals mix the dry air with a proportionate quantity of room air, cool the air as required, and distribute the mixed air at a constant volume. These terminals combine the benefits of a variable-air-volume (VAV) supply of primary air with the benefits of constant-volume (CV) distribution to occupied spaces:

- VAV primary air minimizes the fan energy required for air distribution.

- CV supply to occupied spaces maintains uniform air circulation for both comfort and health. 


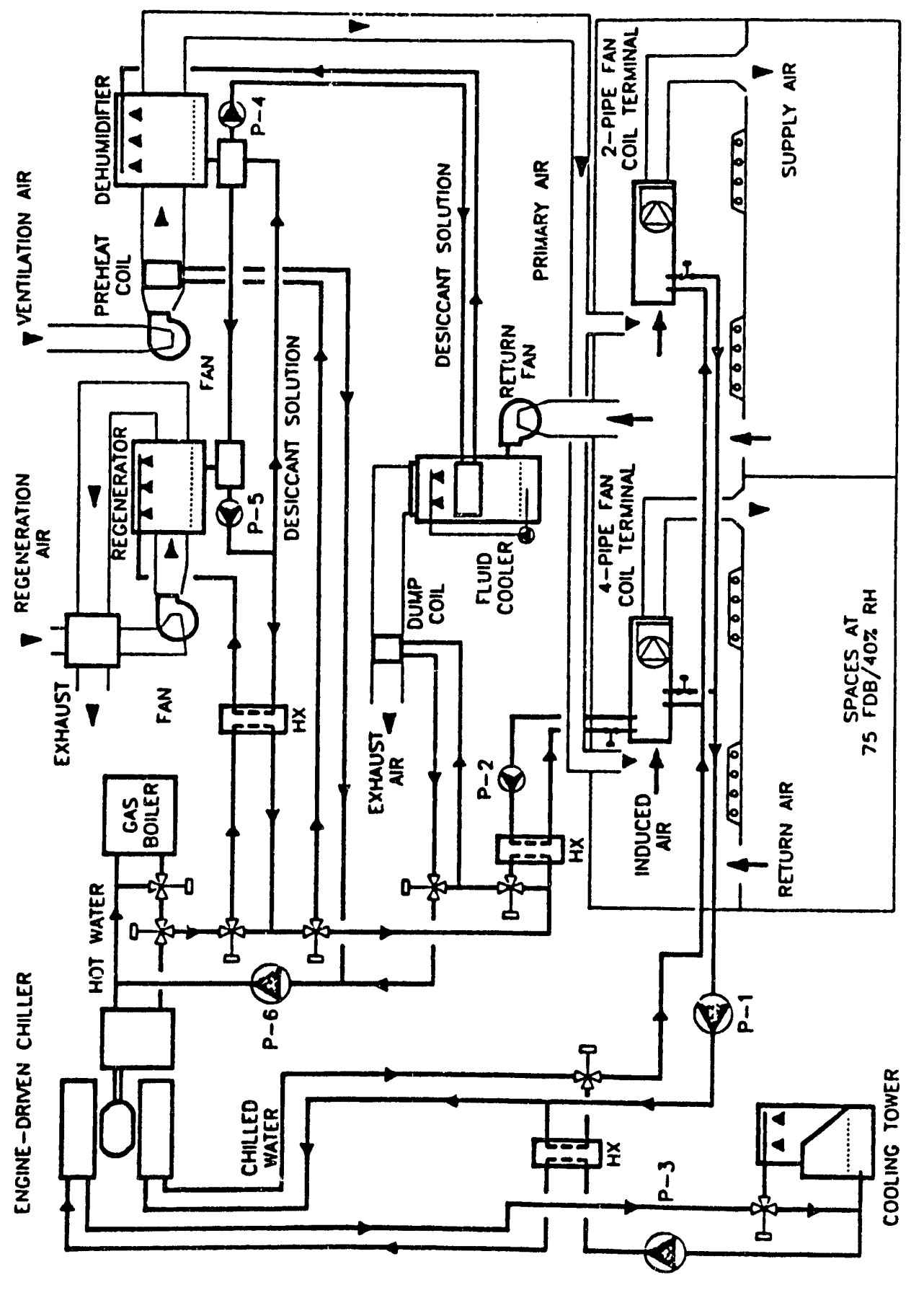

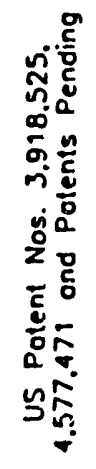

易

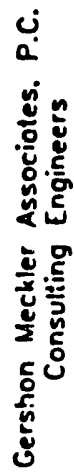




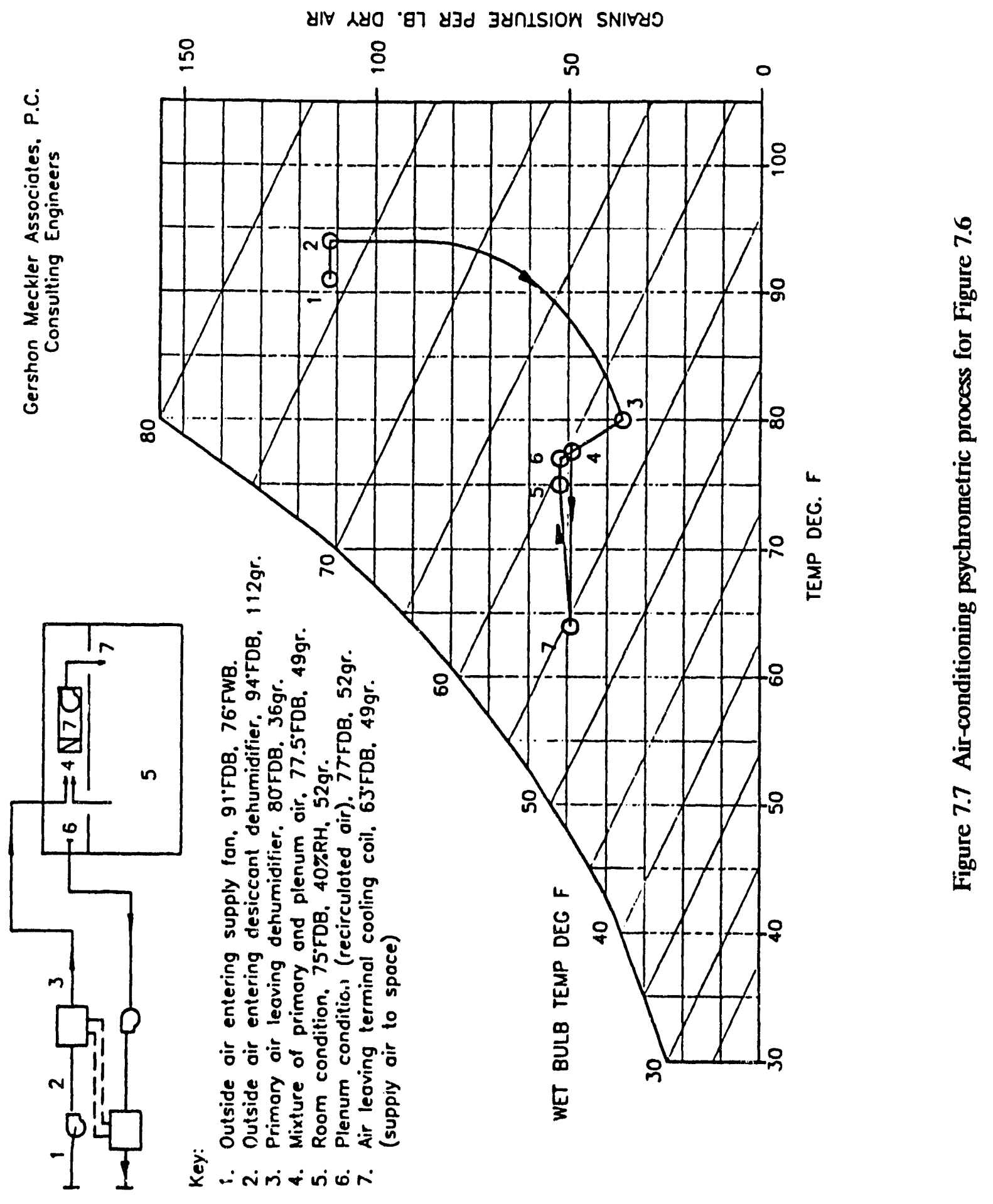


Mixing-box terminals that include a coil circulate chilled or hot water from the building's central plant, as needed. Mixing-box terminals that incorporate unitary heat pumps (UHPs) offer a separate, self-contained cooling and heating capability at each terminal. (UHPs are small air conditioners with a reversing valve that regulates the flow of hot and cold refrigerant gas to heat or cool as needed.)

Some UHPs can be in cooling mode while others are heating or are off. Where there are different tenants, diverse activities, or differing hours in a building, UHPs permit separate cooling without activating a central chiller.

When dehumidification is by condensation, a central refrigeration plant is more efficient than UHPs. However, when dehumidification is by desiccant absorption, and the heat pumps can operate at a higher, dry-coil temperature, their overall efficiency increases by about $35 \%$. As a result, they can be competitive with a central refrigeration system.

Terminal UHPs are joined by a closed water loop that is maintained at $70^{\circ} \mathrm{F}$ to $90^{\circ} \mathrm{F}$. UHPs draw heat from or reject heat to the water loop. When the temperature of the water loop exceeds $80^{\circ} \mathrm{F}$ to $90^{\circ} \mathrm{F}$, heat is rejected via the cooling tower. When the temperature drops below $70^{\circ} \mathrm{F}$, the water loop draws heat from the hot thermal storage tank. With a terminal unitary heat pump system, there is no need for both hot and chilled water piping.

- Incorporate other cost-saving, integrated-system options as appropriate, for example:

- Utilize cellular floor raceways (in place of separate ducts) to distribute the dry primary air. This is a very efficient option when primary air is a small quantity of desiccantdehumidified (not chilled) air. The vertical space required for the floor ceiling sandwich is reduced, and the first-cost saving from eliminated ductwork is considerable.

- Circulate the water used for sensible cooling through luminaries to remove lighting heat. Because of the high temperature level of the heat from lights, the cooling water does not require refrigeration. This technique reduces the sensible cooling load that must be handled at terminals. It is an efficient option for facilities such as shopping centers and industrial clean-rooms, where heat from light is a major component of the total cooling load.

\subsubsection{Small Commercial Buildings}

The most practical, cost-efficient way to use desiccant dehumidification in small commercial establishments such as fast-food restaurants and strip-mall stores is to use a prepackaged airconditioning unit that provides both heating and cooling. To provide air conditioning in such establishments without using vapor compression refrigeration with its CFCs, and to provide it at a significantly lower energy cost than that of a conventional vapor compression refrigeration unit, GMAPC has developed gas energized desiccant cold-air and heating units that incorporate evaporative cooling.

As shown schematically in Figure 7.8, the unit developed for fast-food restaurants, like a conventional refrigeration unit, conditions and supplies $100 \%$ outdoor air to the occupied space, to meet the ventilation requirement for people as well as for the kitchen exhaust hoods. The desiccant unit uses 
two stages of desiccant dehumidification, to dry the outside air deeply enough to achieve a sensible temperature of $55^{\circ} \mathrm{F}$ when the dry air passes through an evaporative air washer.

The unit includes two desiccant wheels that rotate continuously through two separate airstreams: the ventilation airstream, from which moisture is adsorbed by the silica-gel desiccant wheel, and the regeneration airstream, to which moisture is rejected from the wheel. Following second-stage dehumidification, the ventilation air is cooled by the evaporative air washer to the supply condition of $55^{\circ} \mathrm{F}, 60 \mathrm{gr} / \mathrm{hb}$.

As shown in Figure 7.8, regeneration occurs in parallel in the two stages. The outside-air regeneration airstream is first cooled in an evaporative air washer to enable it to absorb heat transferred from the dehumidification process by the heat recovery wheel. The regeneration airstream is then heated in series by (1) a heat-pipe heat exchanger that transfers heat from air exiting the regenerator and (2) a direct-fired gas heater. The heated air then regenerates (concentrates) the desiccant by picking up moisture as it passes through the regeneration side of the desiccant wheel. The thermal COP of this two-stage desiccant unit is 0.89 at design conditions.

In an analysis comparing energy use and cost of the desiccant unit with that of a conventional vapor compression air-to-air heat pump system in a typical 2,000 $\mathrm{ft}^{2}$ fast-food restaurant in Brooklyn, New York, results are as follows: Annual electric energy use by the desiccant unit is $60 \%$ less than that of the vapor compression unit; annual energy cost for the gas energized desiccant cold-air unit, based on Brooklyn utility rates, is $40 \%$ less than that of the conventional unit.

In the two-stage desiccant/cogeneration unit developed for supermarkets, as shown in Figure 7.9, a desiccant-impregnated enthalpy exchange wheel transfers both heat and moisture from the incoming outside air to the building exhaust air. Building return air is added to the partially dehumidified outside air before second-stage dehumidification. This configuration efficiently maintains the lower humidity desired in the supermarket $(35 \% \mathrm{RH})$.

In retrofit supermarket systems, the dehumidified air is supplied to the preexisting central air handler for sensible cooling; in new construction this configuration is changed by incorporating the vapor compression chiller or direct expansion refrigeration system into the dehumidification unit. In both retrofit and new construction, the dehumidified, sensibly cooled air is distributed at a constant volume through low-pressure ductwork to air outlets.

In the supermarket unit, integrated gas-energized cogeneration simultaneously provides the heat required for desiccant regeneration and electricity for store use.

\subsection{Impact on Energy Consumption and Energy Cost}

Desiccant HVAC systems reduce electric utility energy consumption in the following ways:

- They shift the dehumidification load from the refrigeration system to the desiccant system.

- They permit sensible cooling to be done at a more energy-efficient, elevated temperature level $\left(55^{\circ} \mathrm{F}\right.$ instead of $\left.42^{\circ} \mathrm{F}\right)$. This is possible because there is no longer a requirement to chill deeply in order to condense out moisture. 

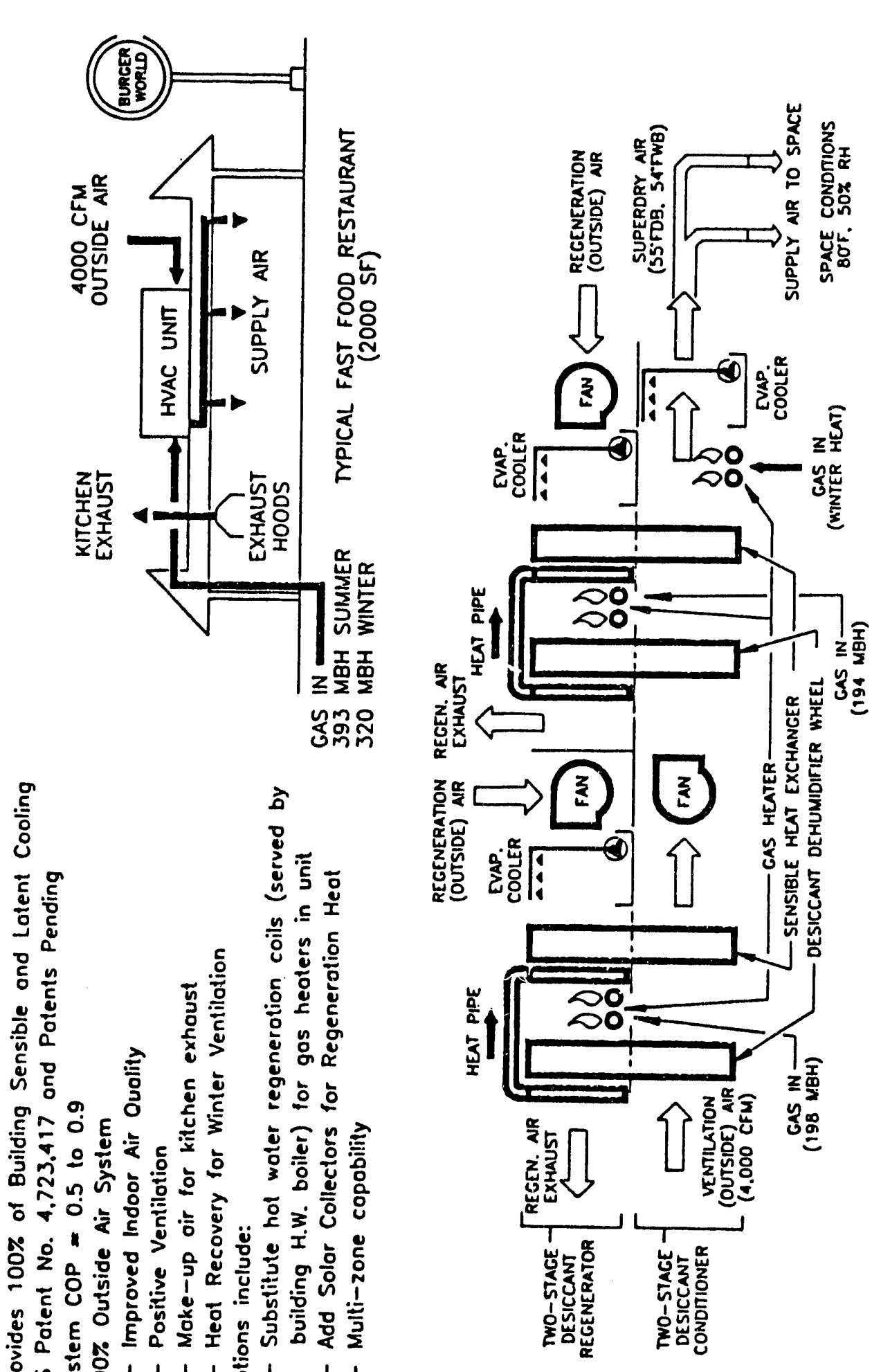

造

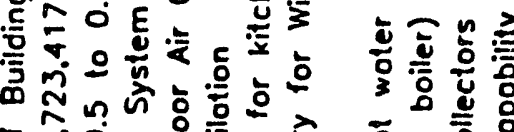

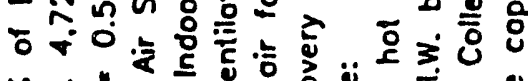

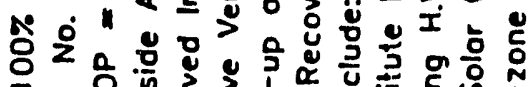

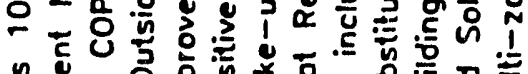

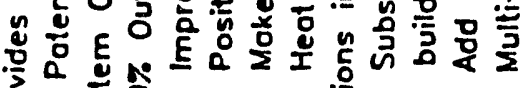

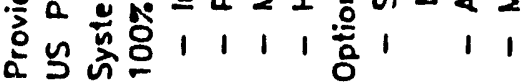




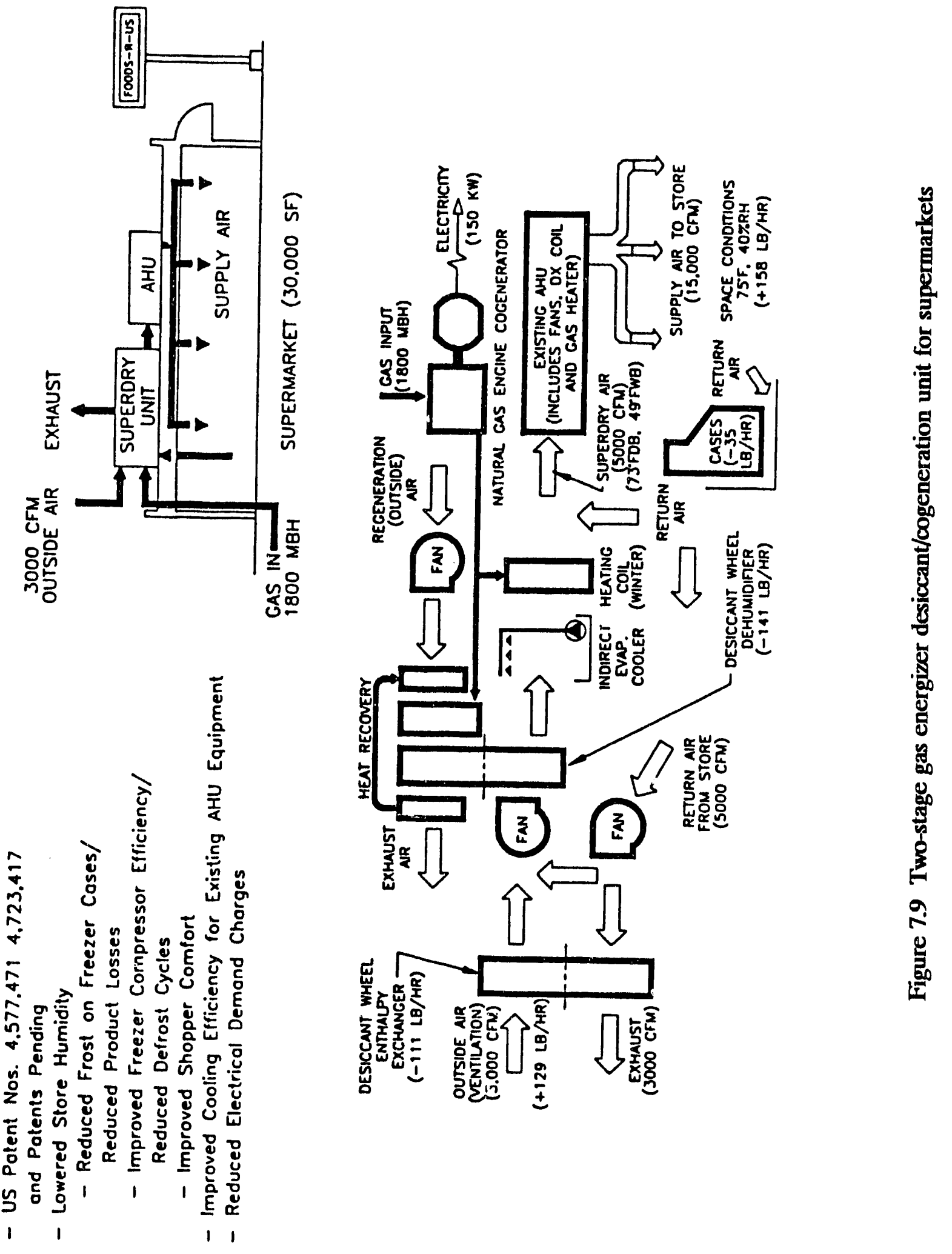


- They shift both latent cooling and sensible cooling off the refrigeration system in the rooftop unit that incorporates evaporative cooling (which GMAPC has developed for small commercial buildings such as fast-food restaurants and strip-mall stores). These multifunction units require more fan and pump energy than do conventional rooftop units, but the net reduction in the electric utility energy required is a major one.

In addition, in large office buildings using the GMAPC desiccant system configuration (described subsequently), there is a major reduction in air-distribution fan energy. The larger the building, the greater the reduction in fan energy (compared with a conventional all-air HVAC system).

In light of these energy factors, and based on GMAPC's experience over the last two decades, including innumerable comparative system energy analyses ( sample results of which are provided in the next section), we conclude that desiccant HVAC systems permit the following reductions in electric utility energy consumption:

\section{Desiccant HVAC System Application}

Office buildings, large

Office buildings, medium

Small commercial (fast-food restaurants, strip-mall stores)

Supermarkets

\section{Reduction in HVAC Electric Utility} Energy Requirement

$$
\begin{array}{r}
30 \%-60 \% \\
20 \%-35 \% \\
50 \% \\
25 \%-35 \% \text { (reduction in energy } \\
\text { required for refrigeration) }
\end{array}
$$

\subsection{Comparative Analyses of System Energy}

This section presents the results of a specific energy-use and energy-cost analysis (already mentioned in Section 7.6.1) that compared three HVAC systems: a conventional all-air VAV system and two desiccant systems.

The building studied is a $159,000 \mathrm{ft}^{2}$, six-story office building in northern New Jersey. The building characteristics, design

conditions, peak loads, and site utility rates are given in Table 7.4.

- System 1. Conventional $55^{\circ} \mathrm{F}$ all-air VAV system with electric utility powered vapor compression refrigeration and VAV terminal boxes (Figures 7.2 and 7.3). This has been the principal system used in commercial office buildings. Terminals incorporate electric heating coils for winter operation. In contrast with the desiccant system process, this system cools and dehumidifies simultaneously by chilling deeply to remove moisture by condensation.

- $\quad$ System 2. Two-stage solid-desiccant air/water system distributes cold primary air $\left(40^{\circ} \mathrm{F}\right)$ at a variable volume (VAV) to fan-induction coil terminals (Figures 7.4 and 7.5). Primary air provides $100 \%$ of the required dehumidification and a portion of sensible cooling. System 2 includes a gas e..gine driven chiller-heater and an evaporative air washer. The first-stage enthalpy wheel partially cools and dehumidifies incoming outside air. The air is then precooled to $55^{\circ} \mathrm{F}$, dehumidified in the second wheel, aftercooled to $55^{\circ} \mathrm{F}$ (to remove the heat released by the sorption process), and then saturated with nonrefrigerated water to drop the temperature 
to $40^{\circ} \mathrm{F}$. A small quantity of $40^{\circ} \mathrm{F}$ primary air is distributed to fan-induction coil terminals (FICU), which mix it with recirculated air. Terminal coils circulate $53^{\circ} \mathrm{F}$ to $58^{\circ} \mathrm{F}$ chilled water as required to sensibly cool recirculated air. Mixed air is supplied to the occupied space at a constant volume. The engine-driven chiller/heater provides both $50^{\circ} \mathrm{F}$ chilled water for precooling and aftercooling and heat for desiccant regeneration. Boiler provides backup heat for regeneration.

- $\quad$ System 3. One-stage liquid desiccant air/water system distributes a small quantity of dry (not cold) primary air at a constant volume to FICU terminals - or to the plenum (Figures 7.6 and 7.7). As in System 2, primary air provides $100 \%$ of the required dehumidification. Outside ventilation air is dried in the dehumidifier by a spray of cool desiccant. In this system, chilled water is not used to remove the heat of sorption released in the desiccant dehumidification chamber. Instead, evaporatively cooled exhaust air serves as a heat sink to draw the heat from the liquid desiccant by way of a heat exchanger.

In this dry-air system, all sen ible cooling is done at FICU terminals, which mix dry primary air with recirculated air and cool the mixed air with $53^{\circ} \mathrm{F}$ to $58^{\circ} \mathrm{F}$ chilled water. A gas-driven chiller/heater provides the chilled water as well as heat for desiccant regeneration. A boiler provides backup regeneration heat.

The three systems were compared in terms of air quantities circulated, peak electric demand (refrigeration, fans, and pump), electric and gas energy input, and annual energy costs (demand, electric use, and gas). Results of the study are summarized in Table 7.4. Principal results are as follows:

- The desiccant systems reduce the peak refrigeration load by $20 \%$ to $30 \%$.

- The desiccant systems, using gas-driven refrigeration equipment, reduce total peak electric demand by $65 \%$ to $70 \%$.

- The desiccant systems reduce peak fan demand by $35 \%$. Although secondary (terminal) fan demand is greater in the desiccant systems, the primary air distribution and fan energy is so much less that there is a significant net reduction in total fan demand compared with the conventional all-air system.

- The desiccant systems reduce total electricity use by $55 \%$ and substitute gas for a portion of that unused energy.

- Regarding annual energy cost, the desiccant systems reduce both electric demand charges and electric energy use charges by $52 \%$ to $54 \%$, add a gas charge, and end up with a total annual energy cost that is $24 \%$ to $27 \%$ less $\left(\$ 1.05 / \mathrm{ft}^{2}\right.$ and $\$ 1.09 / \mathrm{ft}^{2}$ compared with $\$ 1.44 / \mathrm{ft}^{2}$ for the conventional electricity driven all-air system).

\subsection{Conclusion}

Desiccant HVAC systems have the potential to make a major national contribution to the reduction of both CFCs and utility electricity used for air conditioning in commercial buildings. They also 
provide a practical way to increase the productivity of solar collection systems by using solar heat during the summer to energize part of the air conditioning load (to regenerate a desiccant that provides dehumidification).

Several operating examples exist in large buildings. They were designed from existing components and materials, are practical to operate, and reduce the use of CFCs and electric utility consumption and costs significantly compared with conventional HVAC systems. They are even cost-effective in first-cost terms in large buildings when efficiently integrated into the overall HVAC system. In smaller buildings the life-cycle cost is lower for desiccant systems, but an equipment subsidy is required to equalize the initial cost.

Desiccant HVAC systems will become more cost-effective for all commercial facilities if the inherent thermal efficiency of the desiccant regeneration process can be increased, i.e., if desiccant materials can be developed that simultaneously absorb more moisture and require less heat for regeneration. However, starting now and using existing technology, significant advances can be made in introducing desiccant HVAC systems into large commercial buildings.

Major impediments are the lack of familiarity with and confidence in the use of desiccants in HVAC systems on the part of building owners and their designers, the lack of knowledge about or ready access to the design techniques required to integrate the systems cost-effectively in large buildings, and the reticence of system designers to assume the added legal vulnerability that goes with innovative work.

Department of Energy strategies could have a major impact on educating HVAC designers and building owners, overcoming impediments to the introduction of these systems, and bringing desiccant systems into the HVAC design portfolio for commercial buildings decades sooner than would otherwise occur. The resulting benefits would be significant: a reduction in the CFCs and utility electricity used for air conditioning in commercial buildings, a shift of air conditioning load from utility electricity to gas and renewable energy sources, and a practical way to use solar energy yearround and thus significantly increase the cost-effectiveness of solar collection system

\section{Table 7.4 Building Characteristics, Design Conditions, Peak Loads, and Site Utility Rates}

\section{General Building Characteristics}

- Construction - Six-story steel structure with concrete slab, double-glazed perimeter windows, built-up roof deck, suspended acoustic tile ceiling.

$\begin{array}{llr}\text { - Gross floor area } & = & 159,000 \mathrm{ft}^{2} \\ \text { - Net leasable area } & = & 143,000 \mathrm{ft}^{2} \\ \text { - Perimeter zone area } & = & 67,000 \mathrm{ft}^{2} \\ \text { - Interior } r^{\prime} \text {, ne area } & = & 76,000 \mathrm{ft}^{2} \\ \text { - Common lobbies/corridors } & = & 8,000 \mathrm{ft}^{2} \\ \text { - Core area/support services } & = & 8,000 \mathrm{ft}^{2}\end{array}$


Table 7.4 (continued)

Estimate of Peak Cooling and Heating

- Summer outside design conditions

- Temperature

$91^{\circ} \mathrm{F} \mathrm{DB}$

- Mean daily range

$21^{\circ} \mathrm{F} \mathrm{DB}$

- Relative humidity

$53 \%$

- Summer sunshine

$65 \%$

- Winter outside design conditions

- Temperature

- Winter sunshine

$10^{\circ} \mathrm{F} \mathrm{DB}$

$45 \%$

- Summer/Winter occupied temperature

$75^{\circ} \mathrm{F} \mathrm{DB}$

Winter unoccupied temperature

$65^{\circ} \mathrm{F} \mathrm{DB}$

- Ventilation rate

$0.18 \mathrm{cfm} / \mathrm{ft}^{2}$

- Internal loads

- Number of people

$100 \mathrm{ft}^{2}$ per person

- Sensible heat per person

$250 \mathrm{Btu} / \mathrm{h}$

- Latent heat per person

$245 \mathrm{Btu} / \mathrm{h}$

- Average occupancy

$90 \%$

- Lighting load

$2 \mathrm{~W} / \mathrm{ft}^{2}$

- Equipment load

$1.5 \mathrm{~W} / \mathrm{ft}^{2}$

Peak Cooling Load Summary, tons

\begin{tabular}{lrcc}
\hline \multicolumn{1}{c}{ Load Item } & Sensible & Latent & Total \\
\hline Transmission & 174 & - & 174 \\
Internal & 169 & 27 & 196 \\
Ventilation & 37 & 70 & 107 \\
Fan Heat & 38 & - & 38 \\
\hline TOTAL TONS & 418 & 97 & 515
\end{tabular}

Site Utility Rates

Demand, summer

$\begin{array}{ll}- & \$ 10.76 / \mathrm{kW} \\ - & 9.78 / \mathrm{kW} \\ - & 0.0756 / \mathrm{kWh} \\ - & 0.0597 / \mathrm{kWh} \\ - & 5.30 / \mathrm{MBtu}\end{array}$




\section{ENERGY IMPACTS OF DESICCANT COOLING SYSTEMS}

\subsection{Introduction}

Two important and well-known advantages of desiccant cooling systems are that they are CFC free and they can reduce the electricity peak load. Another important but lesser known advantage of desiccant technology is its potential for energy conservation.

Desiccant systems are heat-actuated cooling technology with some electricity to power the motors. With the recent advances in desiccant technology, desiccant systems can now achieve a primary energy COP between 1.3 to 1.5 , with potential to go to 1.7 and higher. It is becoming one of the most promising alternatives to conventional cooling systems. In this section, the energy impact studies are mainly focused on residential and commercial sectors. The energy-saving potential for the industrial sector is also discussed.

Comparisons of the primary energy consumption of desiccant cooling systems and conventional cooling systems are based on the following assumptions:

- The COPs of conventional cooling systems are between 2.0 and 3.0, which was suggested by Blue et al. [1].

- The market penetration of desiccant systems is $30 \%$.

- Desiccant systems consume $77.5 \%$ primary energy and $22.5 \%$ electricity.

- The energy consumption of commercial and residential cooling is as taken from published data [1-5].

- For comparison, the desiccant system COPs are 1.0, 1.3, and 1.7.

- The conversion factor of primary energy to electricity is 3 .

- Natural gas is the alternative energy source for desiccant cooling.

\subsection{Residential Cooling}

A total of 0.4 quads of electrical energy is used on residential cooling, which is more than 1.2 quads of primary energy consumption. An energy impact study that compares the desiccant and sonventional cooling systems can indicate under what conditions desiccant cooling systems can be competitive with conventional systems, and most importantly, how much energy, if any, can be saved. Table 8.1 shows the estimated electrical energy used for residential cooling in different regions in the U.S. Not surprisingly, the south has the highest cooling load. 
Table 8.1 Estimated electrical energy used for residential cooling

\begin{tabular}{lcc}
\hline \multicolumn{1}{c}{ Region } & $\begin{array}{c}\text { Primary Energy } \\
\text { (quads) }\end{array}$ & $\begin{array}{c}\text { Electrical Energy } \\
\text { (quads) }\end{array}$ \\
\hline Northeast & 0.093 & 0.031 \\
North Central & 0.183 & 0.061 \\
South & 0.810 & 0.270 \\
West & 0.114 & 0.038 \\
TOTAL & 1.200 & 0.400 \\
\hline
\end{tabular}

Tables 8.2 and 8.3 show the energy impact of desiccant cooling systems if $30 \%$ of the conventional systems, with COPs of 2.0 and 3.0, respectively, are replaced by desiccant cooling systems.

Table 8.2 Estimated desiccant cooling system energy impact (in quads) for residential sector with COP of conventional cooling system assumed to be 2.0

\begin{tabular}{||l|c|c|c|c|c|c|c|c|c||}
\hline \multicolumn{1}{|c|}{ Region } & \multicolumn{9}{c|}{ Desiccant Systems COP } \\
\hline & \multicolumn{3}{|c|}{ COP $=1.0$} & \multicolumn{3}{c|}{ COP $=1.3$} & \multicolumn{3}{c|}{ COP = 1.7 } \\
\hline & Elec $^{\mathrm{a}}$ & $\mathrm{Gas}^{\mathrm{b}}$ & $\mathrm{Net}^{\mathrm{c}}$ & Elec. & Gas & Net & Elec. & Gas & Net \\
\hline Northeast & -0.015 & 0.013 & -0.001 & -0.018 & 0.009 & -0.007 & -0.021 & 0.007 & -0.012 \\
\hline Northcentral & -0.030 & 0.026 & -0.002 & -0.036 & 0.018 & -0.014 & -0.040 & 0.013 & -0.024 \\
\hline South & -0.134 & 0.113 & -0.008 & -0.159 & 0.082 & -0.062 & -0.179 & 0.057 & -0.105 \\
\hline West & -0.018 & 0.016 & -0.001 & -0.022 & 0.011 & -0.009 & -0.025 & 0.008 & -0.015 \\
\hline TOTAL & -0.198 & 0.167 & -0.012 & -0.830 & 0.620 & -0.110 & -0.930 & 0.430 & -0.190 \\
\hline
\end{tabular}

${ }^{a}$ Elec: the change in primary energy inputs to produce electric energy.

${ }^{b} \mathrm{Gas}$ : the net change in gas consumption, including both increased demand for desiccant cooling systems and decreased demand for primary gas inputs to produce electric energy.

'Net: the net change in total energy consumption. 
Table 8.3 Estimated desiccant cooling system energy impact (in quads) for residential sector with COP of conventional cooling system assumed to be 3.0 .

\begin{tabular}{||l|c|c|c|c|c|c|c|c|c||}
\hline \multicolumn{1}{|c|}{ Region } & \multicolumn{9}{c|}{ Desiccant Systems } \\
\hline & \multicolumn{3}{c|}{ COP $=1.0$} & \multicolumn{3}{c|}{ COP $=1.3$} & \multicolumn{3}{c||}{ COP = 1.7 } \\
\hline & Elec & Gas & Net & Elec. & Gas & Net & Elec. & Gas & Net \\
\hline Northeast & -0.009 & 0.021 & 0.013 & -0.013 & 0.015 & 0.003 & -0.017 & 0.011 & -0.004 \\
\hline Northcentral & -0.018 & 0.041 & 0.025 & -0.026 & 0.030 & 0.006 & -0.033 & 0.022 & -0.008 \\
\hline South & -0.079 & 0.181 & 0.109 & -0.117 & 0.134 & 0.028 & -0.147 & 0.097 & -0.036 \\
\hline West & -0.011 & 0.025 & 0.015 & -0.016 & 0.019 & 0.004 & -0.021 & 0.014 & -0.005 \\
\hline TOTAL & -0.117 & 0.268 & 0.162 & -0.173 & 0.198 & 0.042 & -0.217 & 0.144 & -0.053 \\
\hline \hline
\end{tabular}

Table 8.2 shows the energy saving potential of the desiccant system if the conventional electrical system COP is 2.0. The desiccant system primary energy COP of 1.0 can now be easily achieved. Even at this relatively low COP, desiccant systems can reduce the primary energy consumption by 0.012 quads, which represents savings of $1.0 \%$. When desiccant system COP increases to 1.3 and then 1.7 , the energy savings increases to $7.7 \%$ and $13.0 \%$, respectively.

When the conventional electrical cooling system COP is 3.0 , however, the desiccant system will have a net increase of primary energy consumption when the system primary energy COP is 1.0 or 1.3. When the COP increases to 1.7 , however, a $4.4 \%$ energy savings is achieved.

Because the existing conventional residential cooling systems usually have COPs of around 2.0, the desiccant systems can be very competitive as far as thermal efficiency is concerned. The reasons desiccant technology is not penetrating the residential market are that desiccant units are too bulky in size and their controls are probably too complicated.

\subsection{Commercial Cooling}

A total of 0.368 quads of electrical energy is used for commercial cooling, which translates into 1.102 quads of primary energy consumption, as shown in Table 8.4. However, for commercial applications, the desiccant system is more likely to be an integrated part of the whole HVAC system for latent load only. There is no direct competition with the existing commercial systems in most cases. The following comparison is, therefore, for reference only. More appropriately, the $30 \%$ market penetration can be interpreted as $30 \%$ of latent cooling load that is handled by the desiccant systems. 
Table 8.4 Estimated electrical energy used for commercial cooling

\begin{tabular}{lcc}
\hline \multicolumn{1}{c}{ Region } & $\begin{array}{c}\text { Primary Energy } \\
\text { (quads) }\end{array}$ & $\begin{array}{c}\text { Electrical Energy } \\
\text { (quads) }\end{array}$ \\
\hline Northeast & 0.160 & 0.053 \\
North Central & 0.338 & 0.113 \\
South & 0.458 & 0.153 \\
Northwest & 0.026 & 0.009 \\
Mountain & 0.010 & 0.003 \\
Far West & 0.110 & 0.037 \\
TOTAL & 1.102 & 0.368 \\
\hline
\end{tabular}

Tables 8.5 and 8.6 show the energy impact of desiccant cooling systems if $30 \%$ of the conventional systems, with COPs of 2.0 and 3.0 , respectively, are replaced by desiccant cooling systems.

Table 8.5 Estimated desiccant cooling system energy impact (in quads) for commercial sector with COP of conventional cooling system assumed to be 2.0

\begin{tabular}{||l|c|c|c|c|c|c|c|c|c||}
\hline \multicolumn{1}{|c|}{ Region } & \multicolumn{9}{c|}{ Desiccant Systems COP } \\
\hline & \multicolumn{3}{|c}{ COP $=1.0$} & \multicolumn{3}{c|}{ COP = 1.3 } & \multicolumn{3}{c||}{ COP = 1.7 } \\
\hline & Elec & Gas & Net & Elec. & Gas & Net & Elec. & Gas & Net \\
\hline Northeast & -0.017 & 0.014 & -0.001 & -0.002 & 0.010 & -0.008 & -0.022 & 0.007 & -0.013 \\
\hline Northcentral & -0.038 & 0.032 & -0.002 & -0.045 & 0.023 & -0.018 & -0.050 & 0.016 & -0.036 \\
\hline South & -0.045 & 0.038 & -0.003 & -0.054 & 0.028 & -0.021 & -0.061 & 0.019 & -0.036 \\
\hline Northwest & -0.001 & 0.001 & 0.000 & -0.001 & 0.001 & 0.000 & -0.001 & 0.000 & -0.001 \\
\hline Mountain & 0 & 0 & 0 & 0 & 0 & 0 & 0 & 0 & 0 \\
\hline West & -0.008 & 0.007 & 0.001 & -0.010 & 0.005 & -0.004 & -0.011 & 0.004 & -0.006 \\
\hline TOTAL & $-0.1 \% 9$ & 0.092 & -0.007 & -0.130 & 0.067 & -0.051 & -0.146 & 0.047 & -0.086 \\
\hline
\end{tabular}


Table 8.6 Estimated desiccant cooling system energy impact (in quads) for commercial sector with COP of conventional cooling system assumed to be $\mathbf{3 . 0}$

\begin{tabular}{||l|c|c|c|c|c|c|c|c|c||}
\hline \multicolumn{1}{|c|}{ Region } & \multicolumn{9}{c|}{ Desiccant Systems COP } \\
\hline & \multicolumn{3}{|c|}{ COP $=1.0$} & \multicolumn{3}{c|}{ COP = 1.3 } & \multicolumn{3}{c|}{ COP = 1.7} \\
\hline & Elec & Gas & Net & Elec. & Gas & Net & Elec. & Gas & Net \\
\hline Northeast & -0.010 & 0.023 & 0.014 & -0.015 & 0.017 & 0.004 & -0.019 & 0.012 & -0.005 \\
\hline Northcentral & -0.022 & 0.051 & 0.031 & -0.033 & 0.038 & 0.008 & -0.041 & 0.027 & -0.010 \\
\hline South & -0.027 & 0.061 & 0.037 & -0.040 & 0.045 & 0.010 & -0.050 & 0.033 & -0.012 \\
\hline Northwest & -0.001 & 0.001 & 0.000 & -0.001 & 0.001 & 0.000 & -0.001 & 0.000 & -0.001 \\
\hline Mountain & 0 & 0 & 0 & 0 & 0 & 0 & 0 & 0 & 0 \\
\hline West & -0.005 & 0.011 & 0.007 & -0.007 & 0.008 & 0.002 & -0.009 & 0.006 & -0.002 \\
\hline TOTAL & -0.064 & 0.147 & 0.089 & -0.095 & 0.109 & 0.023 & -0.420 & 0.410 & -0.040 \\
\hline
\end{tabular}

As these tables have shown, the energy savings is only $8 \%$ maximum for desiccant systems. There are some hidden savings, however. There is always a reduction of electricity usage, which means that the operating cost of desiccant systems will be lower because of the price difference between electricity and gas. Also, the equipment for conventional systems can be downsized because the latent load is now handled by the desiccant system. Because there is no direct competition with conventional HVAC systems, and the technology in this sector is relatively mature, future desiccant market growth will probably be in the commercial sector first.

\subsection{Industrial Dehumidification and Drying}

In the past, desiccant technology was applied in industry only when the required humidity could not be achieved economically by the conventional systems. Its high initial cost and relatively low thermal efficiencies have precluded wide acceptance. Because this is a niche market, there is no mass production of such equipment, nor there is any incentive for the few manufacturers involved to change the situation.

Desiccant systems can be excellent energy savers for industrial dehumidification and cooling, however, if waste heat can be used. In 1980, the waste heat streams from industry are estimated to total about 6.7 quads, of which approximately 5 quads are at temperatures of $500^{\circ} \mathrm{F}$ or below. This temperature is ideal for desiccant regeneration. Impressive energy savings would result if desiccant systems were coupled with this waste heat. 
In addition, large energy savings can be accomplished by using desiccant technology to:

- Prevent deterioration of buildings from mold and mildew damage (Energy is expended to manufacture replacement materials)[6],

- Prevent deterioration of stored farm crops and metal products (Energy is invested to increase production to offset storage losses, which can exceed 10 to $20 \%$ in many cases)[7],

- Reduce energy expended to heat warehouses and storage areas in winter for humidity control (European manufacturers and storage warehouses frequently reduce temperature in storage areas to $45^{\circ} \mathrm{F}$, using desiccant dehumidifiers to assure humidity control at a small fraction of the energy cost of heating to 60 or $65^{\circ} \mathrm{F}$ )[8], and

- Reduce energy expenditure to cool refrigerated warehouses by using a desiccant unit to remove latent load in the vapor phase more efficiently than it can be removed by periodic defrost cycles [8].

\subsection{Conclusion}

Besides being environmentally safe and able to reduce the electricity peak load, the energy impact studies of desiccant systems on residential and commercial markets indicated that energy savings of up to $13 \%$ for the residential sector and up to $8 \%$ for the commercial sector are possible. For the industrial sector, the great energy saving potential is in the coupling of waste heat with desiccant systems. Some hidden cost savings should be mentioned, such as the reduction of operating cost and the downsizing of conventional HVAC equipment.

\section{References for Section 8}

1. J.L. Blue et al. Building Enengy Use Data Book, ORNL-5552, 2nd ed. Oak Ridge National Laboratory, Oak Ridge, Tn., December 1979.

2. W. Fulkerson, D.B. Reister, and J.T. Miller, Energy R\&D: What Could Make a Difference? ORNL-6541/N2/P1, Oak Ridge National Laboratory, Oak Ridge, Tn., December 1989, p. 30.

3. Energy Information Administration, U.S. Department of Energy, Residential Buildings Energy Consumption Survey: Consumption and Expenditures, April 1984 Through March 1985, DOE/EIA0321(84), Washington, D.C., May 1987.

4. Energy Information Administration, U.S. Department of Energy, Nonresidential Buildings Energy Consumption survey: Commercial Buildings Consumption and Expenditures 1983, DOE/EIA-0318(83), Washington, D.C., September 1986.

5. U.S. Department of Energy, Regional Environment-Energy Data Book, DOE/TIC-10114/2-6, Washington, D.C., December 1978. 
6. Mold and Mildew in Hotels and Motels, Report of the Executive Engineer's Committec of the American Hotel \& Motel Association, Washington D.C., 1991.

7. Harriman, L.G. III, "Prevention of Metallic Corrosion in Storage Areas", Proceedings of the 1985 International Symposium on Moisture \& Humidity, Washington, D.C., Instrument Society of America, Research Triangle Park, N.C., 1985.

8. Harriman, L.G. III, The Dehumidification Handbook, Munters Cargocaire, Amesbury, Mass., 1990. 


\section{Appendix I - Optimizing Solid Desiccant Material Properties}

\section{A1.1. Introduction}

There is a wide variety of existing solid desiccant materials. Many more are under development. To determine which of these materials is likely to be useful for a given application, it is helpful to understand the influence of material properties on the performance of the desiccant system. Desiccant materials which may be ideal for deep-drying industrial applications may have limited usefulness for humidity control and cooling apparatus which operates in the human comfort zone.

Three basic goals for desiccant performance in a cooling application include:

- Maximize moisture removal given the constraints of the next two goals,

- Use the smallest amount (and lowest cost) of thermal energy to regenerate the desiccant, and

- Use the least-cost method of cooling to remove the sensible heat which results from the dehumidification process.

This appendix addresses these issues, discussing the effects of different desiccant sorption-desorption characteristics on system efficiency.

\section{A1.2. Significance of Desiccant Material Properties}

The effect that desiccant material properties have on the overall system performance of desiccant dehumidification systems can best be seen by examining psychrometrically the processes that occur within the dehumidifier. For both the dehumidification and the regeneration processes, there are two fundamental wavefronts that occur. The first and faster wave is primarily a thermal front that is most affected by the total amount of thermal heat capacity associated with the dehumidifier. The second and slower wave is the main concentration wavefront with strong associated thermal effects.

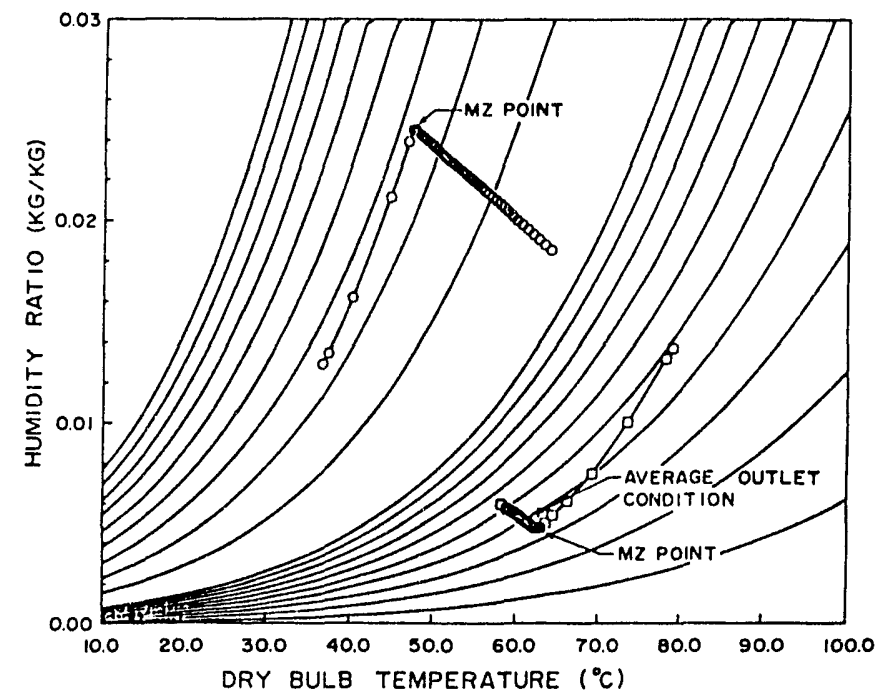

Figure A1.1 Outlet air conditions in process and reactivation air streams leaving a silica gel desiccant dehumidifier 
The outlet air conditions associated with these two waves are shown on the psychrometric chart in Figure A1.1. The locus of points show the time-dependent outlet air conditions for both the dehumidification and the regeneration processes. A constant elapsed time exists between each point plotted.

For the dehumidification process, the first wave is represented by the locus of points between the regeneration condition and a position of minimum absolute humidity. The outlet air remains at or near this condition for some time, and then experiences the gradual breakthrough of the main concentration wave, which creates a locus of points that connects this minimum absolute humidity point with the inlet air conditions. This point on the psychrometric chart has been called the $\mathrm{MZ}$ point or middle zone condition that exists between the two passing wavefronts.

A condition identical to that of the dehumidification process also exists for the regeneration process. The first and fastest wavefront creates a locus of points that begins at the dehumidifier inlet conditions and progresses quickly to a point of maximum outlet humidity. The air remains at this condition for a period of time and then experiences breakthrough of the main concentration front with the outlet conditions gradually approaching the inlet regeneration air conditions and progresses quickly to a point of maximum outlet humidity. The air remains at this condition for a period of time and then experiences breakthrough of the main concentration front, with the outlet conditions gradually approaching the inlet regeneration air conditions.

It is important to notice that the system performance is based on the average outlet air conditions that represent the time or position-averaged effects of both the first and second waves associated with the heat and mass transfer within the desiccant matrix. As will be shown later, the most thermodynamically advantageous conditions for optimal cycle operation are the two $\mathrm{MZ}$ points associated with both the dehumidification and regeneration processes.

On the dehumidification side, the position of the average outlet air condition on the psychrometric chart is critical to determining the ultimate performance of the system. The lower its absolute humidity, the higher the dehumidification capacity of the system. The higher its temperature, the higher the preheat temperature of the regeneration air will be. This reduces the amount of external thermal energy required to regenerate the desiccant and subsequently increases the thermal COP. The effect of the first wave is to increase both the average outlet humidity and the average outlet temperature. The effect of the second wave is to increase average outlet humidity and to decrease the average outlet temperature. In order to achieve the maximum possible performance, it is therefore necessary to avoid any significant breakthrough of the second wavefront and to increase the speed of the first wavefront. Then the average outlet air condition will be as close to the $\mathrm{MZ}$ point (the thermodynamic optimum) as possible.

On the regeneration side a similar situation exists, though the ramifications of the average outlet air conditions for system performance are not so widely appreciated. The average outlet air condition for the regeneration process hypothetically represents the minimum thermodynamic availability that is consistent with the Clausius-Clapeyron limits of the cycle. The air condition consistent with this hypothesis is the $\mathrm{MZ}$ point for regeneration, again indicating that avoiding breakthrough of the concentration wavefront is paramount for attaining maximum efficiency.

The preceding discussion has attempted to show that the primary function of the desiccant material in an energy-efficient dehumidification process should be to produce the sharpest possible 
concentration wavefronts for both the dehumidification and the regeneration processes. Just how sharp these wavefronts should be will be determined by the maximum allowable thickness of the desiccant matrix.

Difficulties with weight, manufacturability and pressure drop all limit the maximum possible length of the desiccant bed. Another important aspect is the geometry used to deploy the desiccant within the matrix. For example, a packed bed of spherical or nearly spherical desiccant particles would probably be the cheapest configuration to manufacture. However, because of the limit on the allowable pressure drop within the system, this configuration can be only two inches or so long. On the other hand, laminar-flow channel geometries with desiccant-laden walls could be up to two feet long without suffering from excessive pressure losses and the concomitant loss in energy efficiency ratio (EER). These designs suffer more from manufacturing limitations than from a pressure-drop limit. Manufacturing appears to limit bed length to eight or ten inches. These constraints dictate the degree of wavefront steepness required to meet the desired goal.

\section{A1.3. Sorption properties of desiccants}

The sorption properties of desiccants generally determines which materials are used. These sorption properties are usually depicted by a graph called an isotherm. Isotherms are generally plots of fractional loading (weight of water per unit weight desiccant) vs degree of saturation (i.e., relative humidity). Sorption isotherms have been categorized by Brunauer and his coworkers depending upon the sorption mechanisms that exist. The sorption mechanisms are defined as types 1 through 5 . These generic Brunauer types are shown in Figures A1.2 through A1.5. Some commercially available materials are shown in Figure A1.6. Generally speaking, molecular sieves are considered type 1 materials, silica gels are considered type 2 materials, and wool is considered a type 3 material. Hydratable salts vary between type 2 and type 3 .

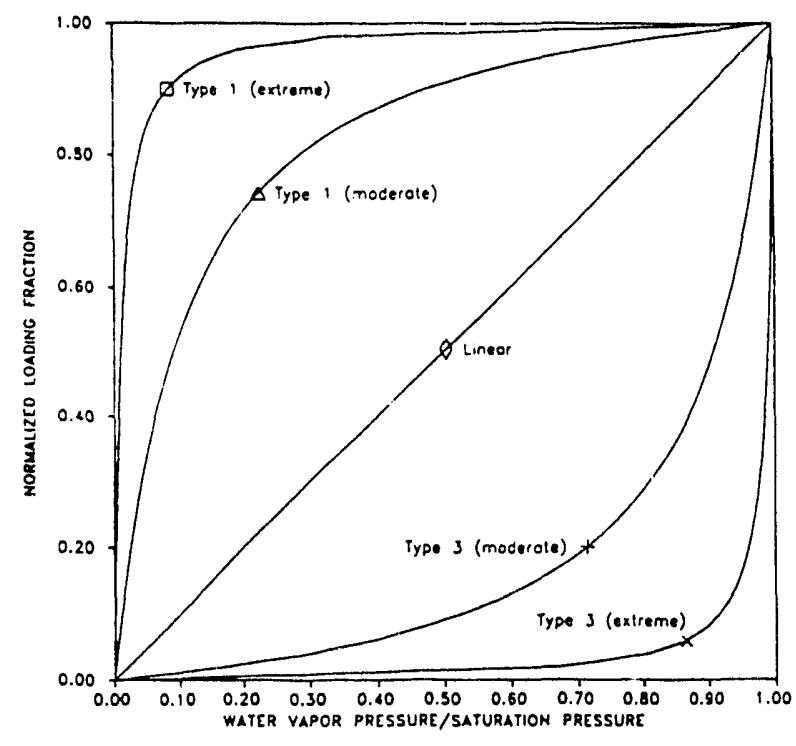

Figure A1.2 Brunauer isotherms of types 1 and 3 compared to a linear sorption isotherms

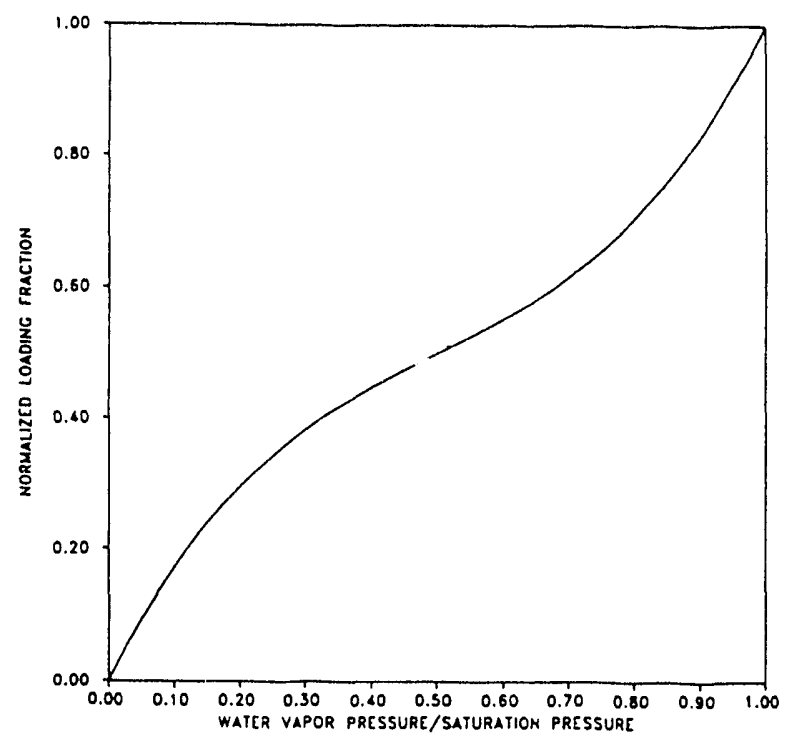

Figure A1.3 Brunauer type 2 isotherm 


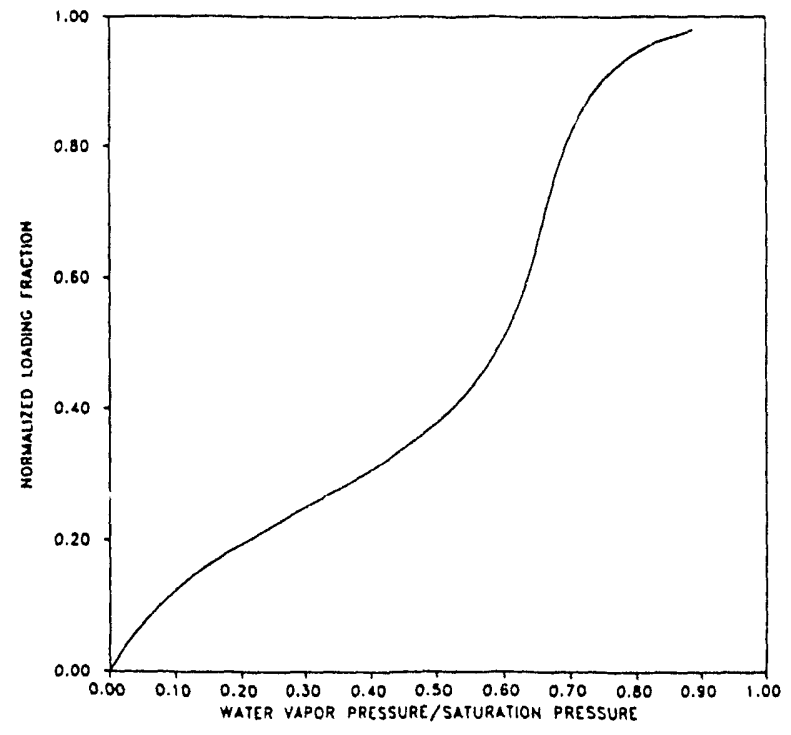

Figure A1.4 Brunauer type 4 isotherm

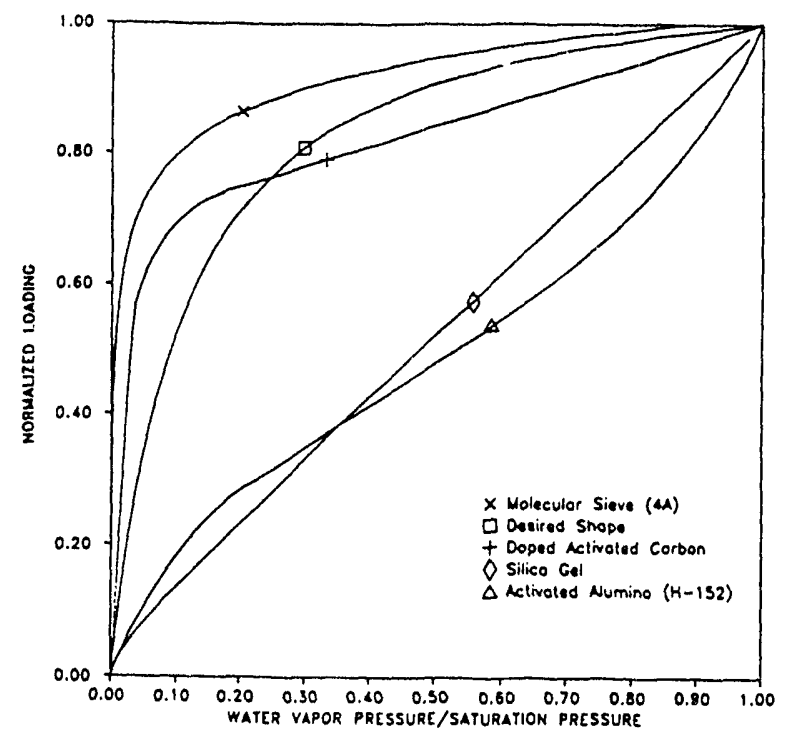

Figure A1.6 Adsorption isotherms of typical desiccants

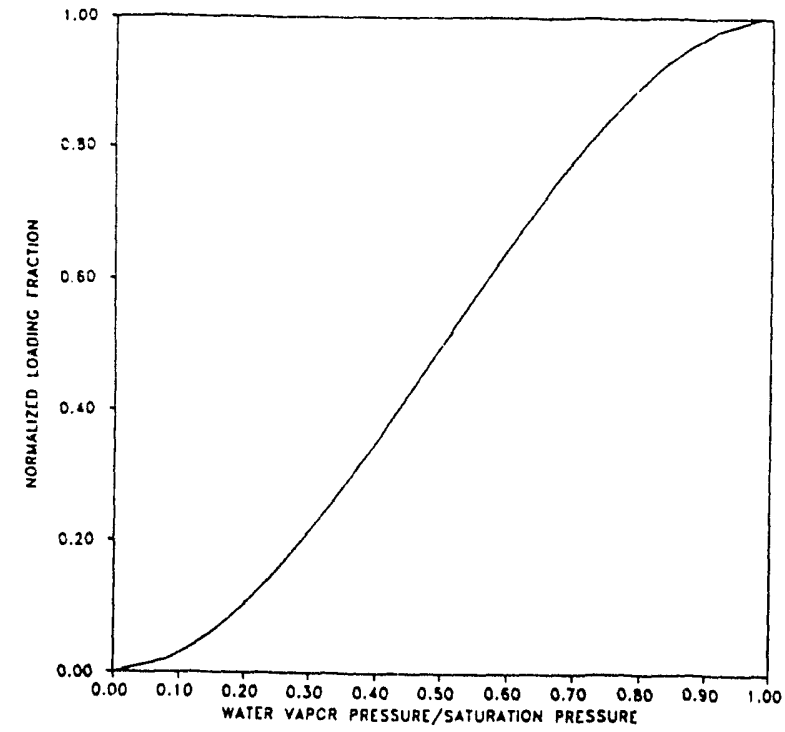

Figure A1.5 Brunauer type 5 isotherm

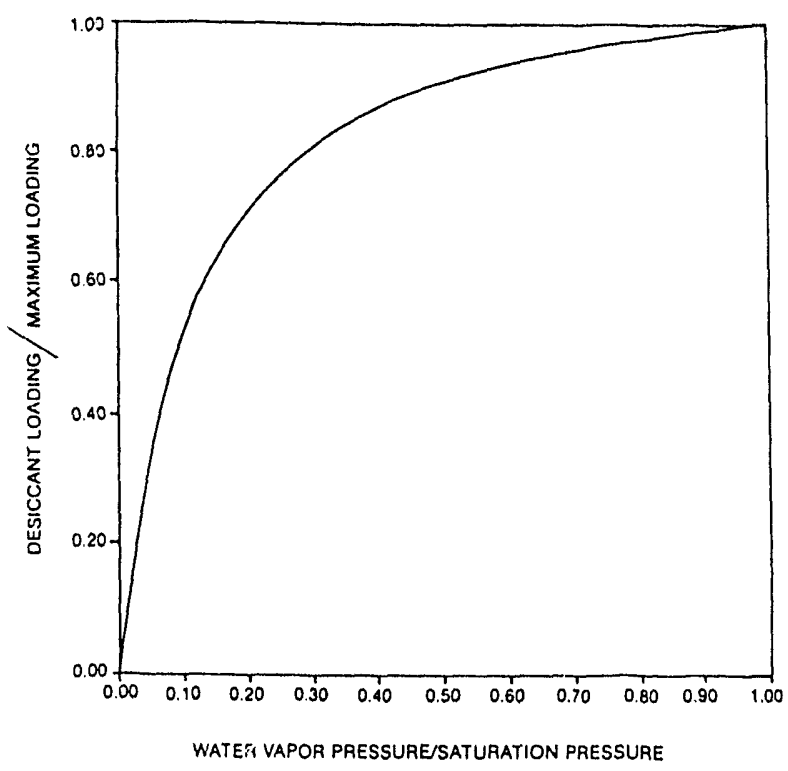

Figure A1.7 Ideal isotherm for desiccari cooling applications

\section{A1.4. Adsorption energy properties of desiccants}

The adsorption energy is the heat that is liberated or absorbed during the adsorption/desorption process. It is a very important material property whose role has been misrepresented in much of the literature concerning desiccant dehumidification cycles. It is very important to understand that the 
temperature dependence of the isotherm shape and the adsorption energy are not independent of one another. That is, any isotherm shape with any adsorption energy can be hypothesized at any given temperature. However, for any other temperature, the shape of the isotherm will be uniquely determined by the heat of adsorption at that temperature and loading. The physics that ties these properties together is defined by the Clausius-Clapeyron relationship, which is a consequence of the Second Law of Thermodynamics.

The nature of the adsorption process dictates that the heat of adsorption is not constant over the entire range of desiccant loadings. The very first molecules that attach themselves to the surface of a desiccant are bonded by the strongest forces available to the system. These molecules will, therefore, have the highest adsorption energies (strongest bonds) associated with them. As the available sites for bonding fill, i.e., the desiccant loading increases, the less energetic sites become occupied. As the desiccant approaches saturation conditions, the binding energies approach simple condensation. The heats of adsorption will then be highest at zero water loading and lowest (i.e., heat of condensation for water) at the maximum water loading. The rate at which this energy changes with water loading will vary depending upon the material.

The effect that the adsorption energy has on the shape of the isotherm is shown in Figure A1.7. The reference isotherm shape is at $80^{\circ} \mathrm{F}$. The reference material has a maximum heat of adsorption equal to 1.5 times the heat of vaporization/condensation of water. The other isotherms show the resultant behavior for the same material only at $175^{\circ} \mathrm{F}$. In one case, the adsorption energy quickly decreases from the maximum to the minimum value. Notice that the effect of the adsorption energy is to reduce the degree of type 1 behavior of the isotherm as the temperature increases. This is a universal consequence of the Second Law of Thermodynamics. The isotherm shapes of desiccant materials with adsorption energies higher than the heat of condensation for water become more like those of a type 3 material as the temperature increases. On the other hand, as the temperature decreases, the isotherm shapes become more like those of type 1 .

Most of the common desiccant materials have relatively low heats of adsorption that decay rapidly with loading. Their behavior would be similar to that shown by the curve in Figure A1.7 that is labeled "fast convergence." Notice that the isotherm shape did not change significantly with temperature. This is why the temperature dependence is generally not acknowledged on most isotherms.

\section{A1.5. Description of Desired Properties}

The desiccant material properties that most influence the ability to achieve the efficient cyclical dehumidification of air are:
- Isotherm shape
- Adsorption energy
- Maximum uptake
- Chemical and physical stability.

\section{A1.5.1. Isotherm shapes}

The desiccant isotherm shape is the single most important factor in determining the wavefront shapes within the desiccant matrix. One isotherm shape that will result in the steep wavefronts needed 
within the 3.8 to 3.10-in. length of the dehumidifier matrix is shown in Figure A1.8. This isotherm is characterized by the constant separation factor equation:

$$
S C=F C /(R+F C-R * F C),
$$

where $\quad \mathrm{SC}=$ relative solid concentration,

$\mathrm{FC}=$ relative fluid concentration,

$\mathrm{R}=$ separation factor.

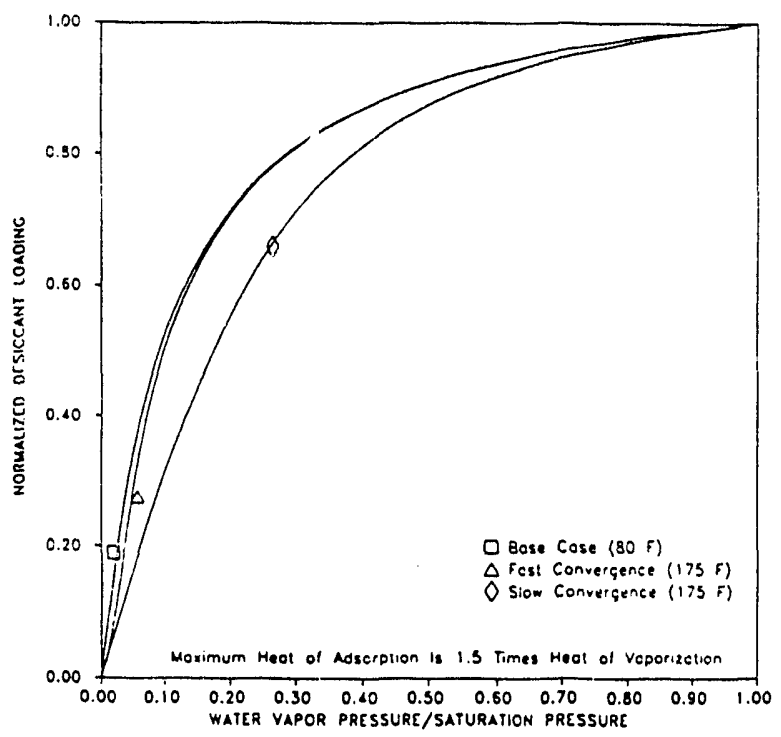

Figure A1.8 Type 1M isotherm, including the effects of heat of adsorption

The separation factor used for the isotherm in Figure A1.8 is 0.1 . It represents a compromise between the concentration wavefront behaviors of the dehumidification and the regeneration processes.

Separation factors less than 0.1 steepen wavefronts during the dehumidification process, but broaden wavefronts during the regeneration process. For separation factors greater than 0.1 the opposite effect results: wavefronts are broadened during the dehumidification process, but steepened during the regeneration process.

Regeneration temperature plays an important role in determining the compromise isotherm shape. High regeneration temperatures steepen the regeneration wavefronts as the value of the separation factor decreases and broaden the dehumidification wavefronts as the value of the separation factor increases. On the other hand, low regeneration temperatures broaden the regeneration wavefronts as the value of the separation factor decreases and steepen the dehumidification wavefronts as the value of the separation factor increases.

It is important to understand that the so-called "linear" isotherm $(R=1)$ does not produce symmetrical wavefronts between dehumidification and regeneration because the process is adiabatic and the 
The effect that regeneration temperature has on the performance of the system is very important in determining the proper isotherm shape for the desiccant. The dehumidification potential of the system increases with increasing regeneration temperature. There is a "point of diminishing returns," however, because the moisture in the air goes to zero asymptotically.

The net result is that we desire the highest possible regeneration temperature that is consistent with efficient heat transfer to the regeneration air stream and the chemical and physical stability of the desiccant matrix. The higher this regeneration temperature, the lower the value of the separation factor that yields optimal system performance.

\section{A1.5.2 Adsorption energy}

The second most important property of the desiccant is the adsorption energy. There are two aspects of adsorption energy that are important:

- The maximum value of adsorption energy that occurs at zero loading.

- The rate that the adsorption energy decreases to become the heat of vaporization for water at higher loadings.

The effect of high adsorption energies is generally bad from both a system standpoint and a wavefront standpoint. From a system standpoint, high adsorption energies decrease the outlet humidity for a given regeneration temperature. From a wavefront standpoint, high adsorption energies decrease the effective value of the separation factor for low temperatures and increase it for high temperatures.

The result of high absorption energy is that both the dehumidification and the regeneration wavefronts are broadened. The regeneration wavefront is most affected when the adsorption energy quickly decreases with loading. The dehumidification wavefront is most affected when the adsorption energy slowly decreases with loading. Generally speaking, the optimal value of the separation factor will decrease (become more like that of type 1) as the adsorption energy increases. Even though the system performance is decreasing, the decrease can be minimized by altering the isotherm shape slightly. Also, it is best to have the adsorption energy decrease as quickly as possible with loading. This will allow regeneration wavefronts to be steepened by increasing regeneration temperature.

The type 1 isotherm depicted in Fig. A1.8 is not the only possible isotherm shape that could produce the sheep wavefronts needed. Many applications of desiccant dehumidification will rarely expose the desiccant to relative humidities over $60 \%$, and when they do, the exposure may be for a short period of time, so the loss in system efficiency caused by an inappropriate isotherm shape would not seriously affect the seasonal performance. A type 2 or type 4 isotherm might then be appropriate as long as the second derivative of the isotherm is sufficiently negative over the range of relative humidities most encountered by the system. The word "sufficiently" should be emphasized here. The dehumidification wavefronts will quickly broaden if the second derivative is not sufficiently negative. It can be definitely stated that type 3 , type 5 , and linear isotherms will not satisfy the design conditions imposed.

\section{A15.3. Maximum uptake}

This desiccant property has historically been considered one of the most important cnes. This attitude was probably a carry-over from the large, static packed column applications where differences 
in the maximum uptake of the desiccant material could save hundreds or even thousands of dollars in material costs. The amount of desiccant in a rotating system is negligible by comparison.

The differences in wave speed (or breakthrough time) caused by differences in the uptake of the desiccant are handled by merely changing the rotational speed of the desiccant matrix. There are absolutely no inherent advantages in the concentration wavefront behavior associated with the slower wave speeds of desiccants with large maximum uptakes.

There can be a problem, however, with the thermal wavefront associated with the heat capacity of the system. For a given amount of heat capacity, the speed and magnitude of the first thermal wavefront will be almost independent of the maximum uptake of the desiccant. However, the speed and magnitude of the main concentration wave will be strongly affected by the maximum uptake of the desiccant. The result is that the outlet air conditions associated with the first wave make up a larger fraction of the total cycle's outlet air conditions as the maximum uptake of the desiccant decreases.

This causes the average outlet air conditions of the cycle to be further removed from the $\mathrm{MZ}$ conditions, with the concomitant reduction in system performance. Merely increasing the amount of desiccant per unit volume of matrix is not a solution, because the amount of heat capacity will also increase. This increase in heat capacity will slow the first wave, keeping its percentage of the total cycle time nearly the same.

Computer simulations have shown that the degradation in cooling system performance associated with the heat capacity of bulk desiccant materials (about $0.2 \mathrm{Btu} / \mathrm{lbm} /{ }^{\circ} \mathrm{F}$ ) and a desiccant maximum uptake of $0.4 \mathrm{lbm}$ water $/ \mathrm{lbm}$ is very small.

However, for the same uptake, increasing the heat capacity to $2 \mathrm{Btu} / \mathrm{bm} /{ }^{\circ} \mathrm{F}$ causes a severe performance loss. Not all of the heat capacity in a desiccant matrix is associated with the desiccant material itself. Many designs require a support structure to hold the desiccant in place. The heat capacity of this support structure adds to the heat capacity of the desiccant to result in sometimes very large overall heat capacities compared with that of the bulk desiccant material alone. It is possible, therefore, that a dehumidifier matrix made up entirely of self-supporting desiccant material with a relatively low maximum uptake would yield higher system performance than a desiccant with a relatively large uptake that required a significant supporting structure for deployment.

\section{A1.5.4. Chemical and physical stability}

It is intuitively obvious that chemical and physical stability are properties that any desiccant should possess. There are, however, two important aspects to this stability that deserve special attention:

- the ability to withstand high regeneration temperatures, and

- the ability to be reliably regenerated by ambient-source air.

Many desiccants rely on molecular sieve structures that are not stable at high temperatures. The requirements for desiccant dehumidification cycles dictate that desiccant sorption properties should be stable at temperatures between $300^{\circ} \mathrm{F}$ and $400^{\circ} \mathrm{F}$. Some desiccants are "fouled" by the presence of certain molecules that have a greater affinity for the active sites than water vapor does. Others change chemical composition in the presence of certain compounds that change the desiccants' water 
of certain molecules that have a greater affinity for the active sites than water vapor does. Others change chemical composition in the presence of certain compounds that change the desiccants' water sorption characteristics. Contaminants and pollutants are in the air used for processing, as are byproducts from the combustion of natural gas (oxides of carbon, nitrogen, and sulfur; particulates, etc.). Exposure to these substances must not inhibit or change the water sorption characteristics of the desiccant material.

\section{A1.6. Shortfalls in Current Desiccant Materials and Components}

It is not apparent whether any of the commercially available desiccant materials were developed for the specific purpose of providing dehumidification for buildings. In most present-day applications, the necessity of achieving efficient regeneration as well as achieving deep drying of the air has not been considered. The requirement for attaining the very sharp adsorption wavefronts associated with the molecular sieve:;, along with the more efficient regeneration characteristics of the silica-gels, makes this application truly unique commercially. It is not surprising, therefore, that none of the commercially available desiccants match the properties needed.

The simulated isotherms of various commercial and laboratory-developed desiccants are shown in Figure A1.9. The trend is to see linear or nearly linear (type 2) isotherms or extreme type 1 isotherms. The extreme type 1 isotherms almost always are associated with very high adsorption energies. This is because the type 1 behavior is often obtained by using ionic dopants. These dopants form a limited number of very favorable, high-energy adsorption sites. After these sites are filled, the less energetic parent-material sites are filled, with a concomitant change in the isotherm shape.

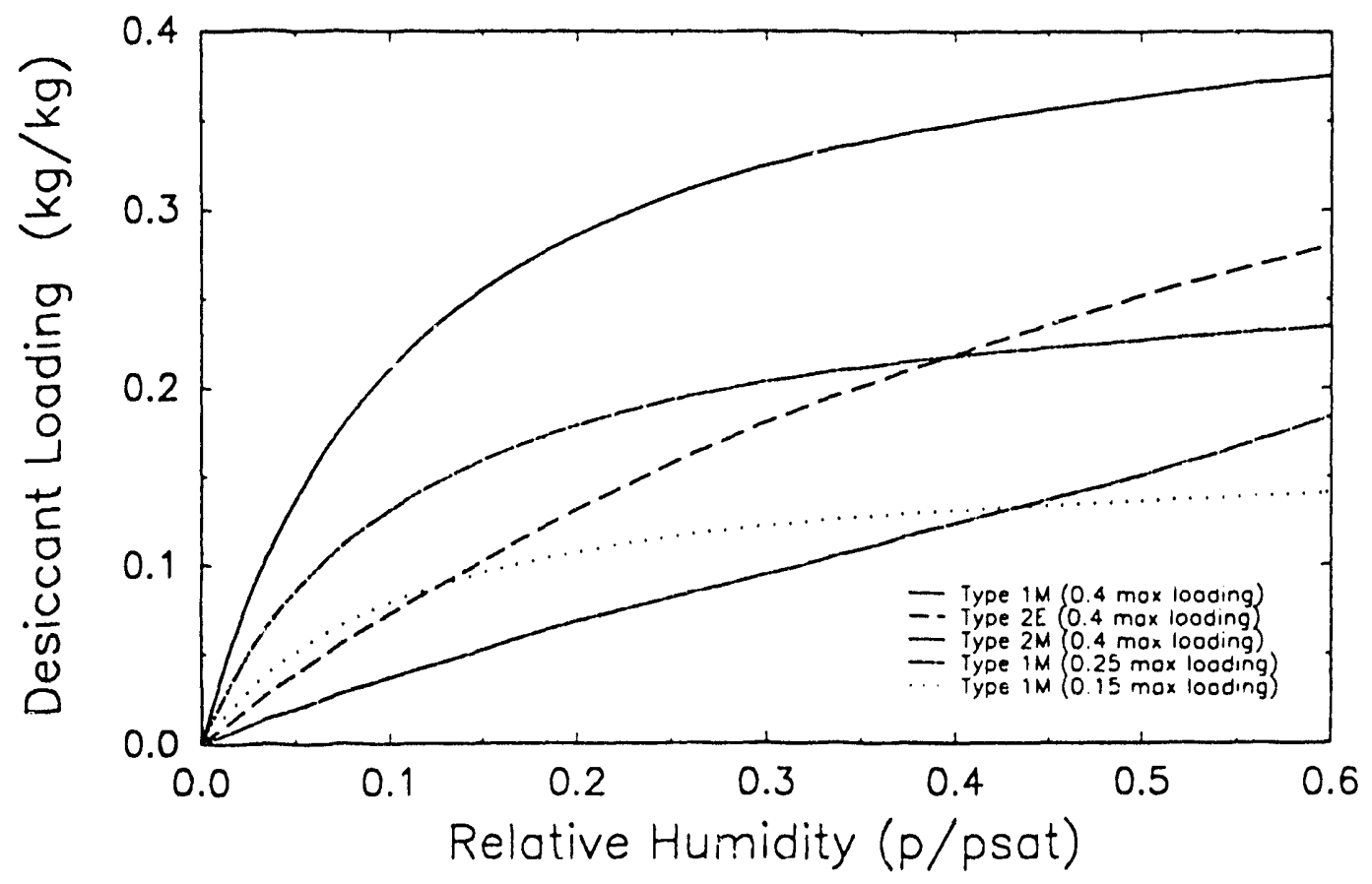

Figure A1.9 Simulated isotherms for various types of desiccants 


\section{Appendix II - Description and Comparison of Desiccant Computer Models}

This appendix describes and compares three thermodynamic models of desiccant equipment that are available outside of manufacturing companies.Each program is described individually, then comparisons are made between the programs when run with similar operating assumptions.

\section{A21. Model Descriptions}

\section{A2.1.1. MOSHMX (I. Maclaine-cross)}

This model uses a finite difference approach to the solution of the combined heat and mass transfer equations. Enthalpies are replaced with known temperature dependencies, and the equations are made nondimensional in axial position and rotational time. The resultant second order equations are similar in form to the set of equations used to solve rotary heat exchanger problems. There are several novel techniques employed to develop a computer code that strives for numerical stability while achieving rapid convergence. This computer code has gained acceptance, in large part, because the University of Wisconsin has adopted it for much of their work in the desiccant cociing area.

\section{A2.1.2. Enerscope}

This model is based philosophically on the computer code DESSIM developed at the SERI by Barlow [A2.1]. The code divides the desiccant matrix into a number of sections that each operate in series with a fixed quantity of air. The key to the program is the use of heat and mass exchanger equations (based on log mean temperature difference analogies) that predict the quantity of heat and mass transfer between the fixed quantity of air and the particular bed section being analyzed. It relies on characterizing the heat transfer process with a Nusselt number, the mass transfer process with a Sherwood number, and a relationship existing between the two processes with a Lewis number.

There are several important differences between the computer model developed by Enerscope and the original DESSIM model from SERI. The most significant of these differences include:

- The Enerscope model uses parallel-flow rather than counter-flow equations for the heat and mass exchanger analogies.

- The Enerscope model uses vapor pressure driving potentials in the mass exchanger rather than concentration potentials.

- The Enerscope model adds an iterative loop on the mass transfer process that converges to resultant vapor pressures that are consistent with the mass exchanger affectivities. This change allows the model to account for the temperature dependence of the mass transfer.

The resultant model is much more numerically stable and representative of physical reality than is the DESSIM model.

A second model was developed that combined the previously described model with the MOSHMX finite-difference model described earlier. The original DESSIM program was written to be able to 
analyze new concepts, both physically and thermodynamically. For this reason, it was developed with an extremely user-friendly interface. Changes to the model were straightforward because of the "building-block" nature of the program.

The MOSHMX program, on the other hand, is not nearly as straightforward to use. The major drawback of using the MOSHMX program is that one must examine a very detailed Ph.D. thesis to understand and use it. In addition, the code is structured to simulate only those geometries and desiccants investigated by its author. To model other geometries and desiccants, modifications would be required. The second Enerscope model combines the "building block" nature of the original program with the finite-difference algorithms from MOSHMX that model the heat and mass transfer within nodes.

Both programs assume that the resistance to mass transfer can be approximated by the heat transfer resistance times the nondimensional Lewis number. This technique, in essence, lumps the film resistance and the internal mass transfer resistance into a single parameter that is controlled by the equilibrium concentrations of water between the air stream and the desiccant. This procedure has been criticized, especially when the internal resistance is large. Previous work at SERI [A2.2], UCLA [A2.3], and Exxon [A2.4] has resulted in the following conclusions:

- For packed-bed geometries in which the internal resistance can be large, using different Lewis numbers between regeneration and dehumidification yields good agreement with experiments.

- For desiccant systems that use silica gel, particle sizes less than $0.25 \mathrm{~mm}$ in diameter can be adequately modeled with a Lewis number of approximately 1.

\section{A2.1.3. The University of Illinois at Chicago (W. Worek)}

The University of Illinois at Chicago has two desiccant system simulation programs: VENT1 and UIC Implicit.

The VENT1 desiccant system simulation program was developed in 1986/1987. In VENT1, an explicit finite-difference method was used to solve the governing equations. Because of the nature of explicit numerical method, very fine step sizes in both time and space had to be used to make the program converge and to be stable. For this reason, the VENT1 program is slow and was abandoned in 1988. To replace VENT1, a new desiccant simulation program was developed at UIC, UIC Implicit, which overcomes many of VENT1's shortcomings. The UIC Implicit program was made operational in 1988 and has been used since 1988 by researchers at UIC to simulate the performance of desiccant systems

In UIC Implicit, advanced numerical techniques have been used to make the program faster and more accurate. Some of techniques are:

- Quasi-linearization of the governing equations of desiccant wheel;

- Use of an implicit finite-difference method with second order accuracy to solve the governing equations;

- Use of variable step sizes in both time and space. 
By the nature of the implicit numerical method, UIC implicit is numerically stable. This enables more rapid calculation using larger step sizes. A run on a PC, which takes VENT1 383 seconds and requires only 6 seconds with UIC Implicit, as is shown in Table A2.1

The accuracy of UIC Implicit has been validated using two methods:

1. Compared to VENT1 and Enerscope, the results of all three programs agree well as seen in Table A2.1 and Figures A2.1 and A2.2;

2. Compared to the experimental results, the results of UIC Implicit simulation showed good agreement with single blow experiment as seen in Figure A2.3.

For last three years, UIC Implicit has been being intensively used for GRI sponsored projects in the area of desiccant materials development and the design of advanced solid desiccant cooling systems.

\section{A2.1.4. Illinois Institute of Technology ( $\mathrm{Z}$ Lavan)}

The equations that govern the dynamics of sorption in a channel with adsorbent walls are derived with the following assumptions.

- The axial heat conduction and mass diffusion in the channel are small compared with the convective heat and mass transfer, thus are neglected.

- There are no temperature and concentration gradients across the channel.

- The axial conduction and diffusion within the solid are neglected.

- The heat and mass transfer in the channel are approximated by constant transfer coefficients that can be calculated from Nusselt and Sherwood number correlations.

- Equilibrium exists at every point of the solid-fluid interface, because the kinetics of surface adsorption are fast and may be neglected.

During the adsorption process, moisture is transferred from the process air stream to the external surface of the desiccant. The moisture then diffuses through the pores of the desiccant and is simultaneously adsorbed on the pore surfaces. The diffusion of water molecules in the desiccant is expressed by considering both gas-phase diffusion and surface diffusion. The gas-phase diffusion and surface diffusion are parallel processes.

The heat and mass transfer processes within the desiccant material are governed by coupled nonlinear differential equations that must be solved subject to the appropriate initial and boundary conditions, together with the equilibrium relation of the desiccant and the heat of sorption. These equations are solved numerically using a finite-difference method in which central differences are used for space derivatives. The formulation is implicit, and an iterative scheme is used for the nonlinear terms to obtain more accurate results. The control volume approach is used at the boundary conditions for both heat and mass balances. The system of finite-difference equations is solved simultaneously using the Gauss elimination method. 
The solutions to the governing equations for the process air stream, which are of first order and are related to the diffusion equations within the desiccant, are obtained by using the forward finite-difference scheme. The numerical solutions are checked by integral heat and mass balances that are obtained by Simpson's integration method.

\section{A2.1.5. Florida Solar Energy Center}

This computer code, called FEMALP, is a finite-element approach to the problem of heat and mass transfer in solids. It is the most general of all the computer codes now actively used. It is capable of dealing with the following problems:

- $\quad$ one-, two-, or three-dimensional capabilities,

- steady-state and/or transient modes,

- thermal radiation capabilities,

- variable material properties, and

- variable boundary conditions.

At present, the FEMALP routines have been integrated into the building energy analysis program, FSEC 1.1. They are used to predict moisture transport within the building structure. FSEC

1.1 is supported by GRI. At this time, the FEMALP algorithms have not been adopted for the solution of specific desiccant problems.

\section{A2.1.6. Single Blow}

Figure A2.1 compares the single-blow outlet humidity curves of a Type $1 \mathrm{M}$ desiccant for the Enerscope and the MOSHMX models. Both algorithms show excellent agreement as far as minimum

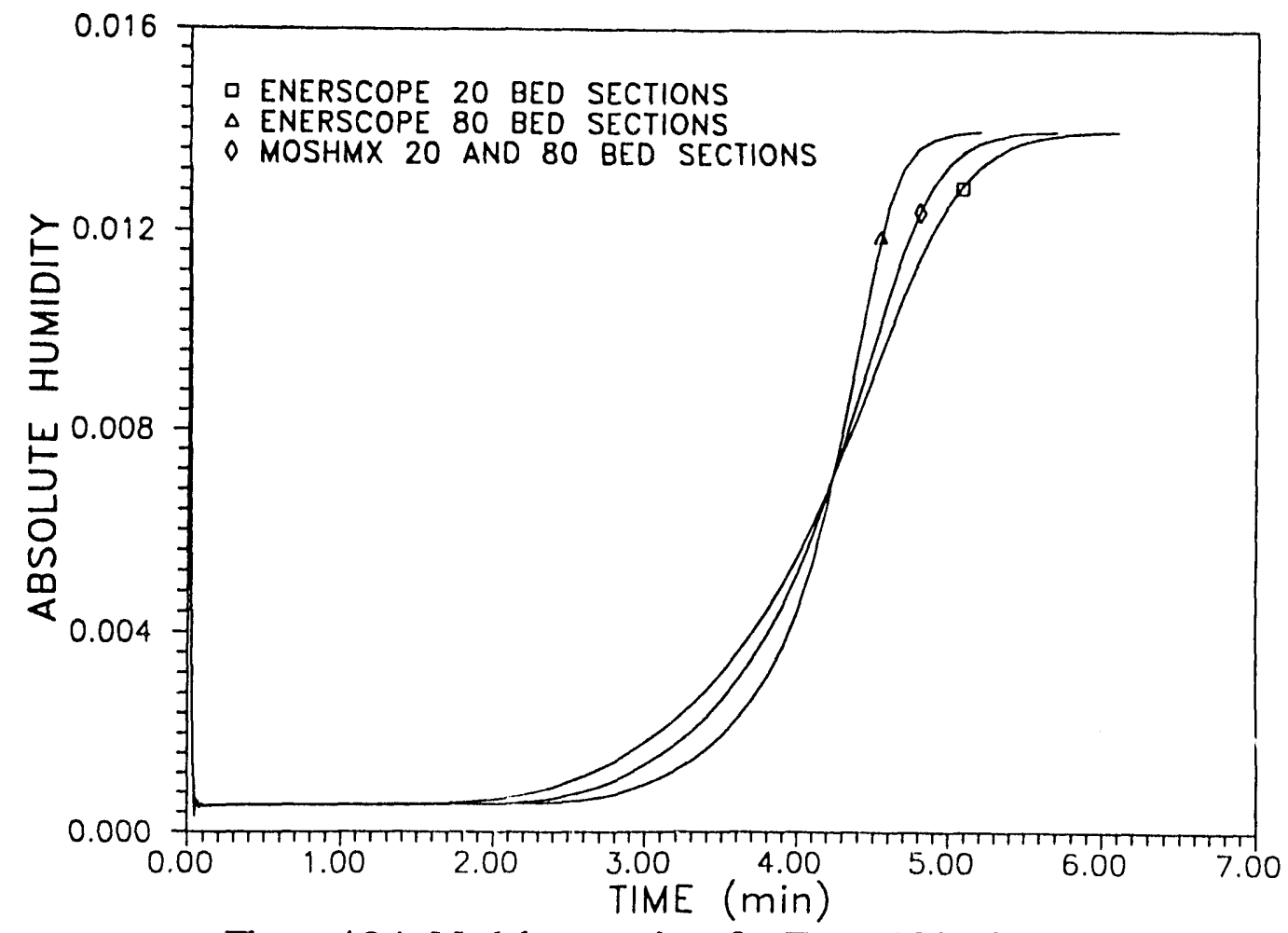

Figure A2.1 Model comparison for Type 1M isotherm 
outlet humidity and wavefront timing are concerned. The area of disagreement is the exact shape of the breakthrough curve. Notice the increased steepening of the wavefront with the Enerscope model as the number of bed sections increases. With the MOSHMX model, the same breakthrough curve is predicted regardless of the number of bed sections chosen. This demonstrates quite graphically the reasons for employing a finite-difference approach.

Figure A2.2 shows the same comparisons as Figure A2.1 except that the desiccant material has a linear isotherm. Exactly the same conclusions can be drawn from Figure A2.1. In this case, however, the differences are not as noticeable as with the type $1 \mathrm{M}$ desiccant. Notice the seemingly unstable behavior of the outlet humidity during breakthrough of the initial wavefront. Although this unstable behavior is not discernable from the graphic illustration, it is a predicted output of the MOSHMX model. This phenomenon is examined further in Figure A2.3. The time-frame of the results from Figure A2.2 has been expanded in order to see the results more closely. What is seen is the classic example of overshoot exhibited by under-damped dynamic systems. As is shown, this condition is remedied by decreasing the time-step used for the simulation. Figure A2.4 shows the same conditions, only modeled with the Enerscope program. Notice how much more stable the initial behavior of the system is when the analogy algorithms are used rather than finite difference.

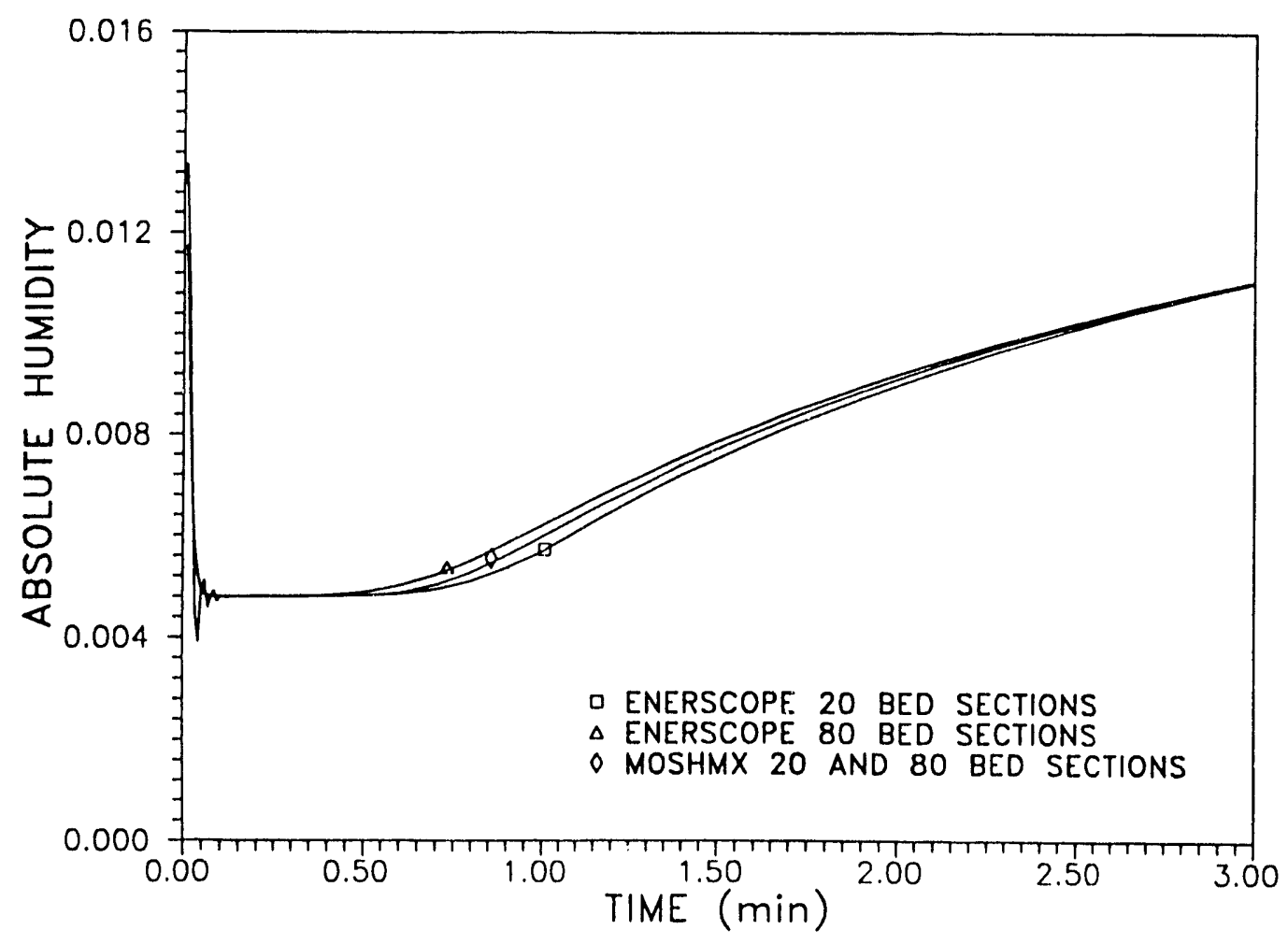

Figure A2.2 Model comparison for linear isotherm

This increase in stability is the reason that analogy-based algorithms continue to be used even though the finite-difference approaches are much more "elegant" and efficient. If they are properly written, the analogy-based algorithms seem to have much more numerical stability than do the finite difference approaches. This can be extremely useful when modeling different desiccant material properties and mechanical configurations. 


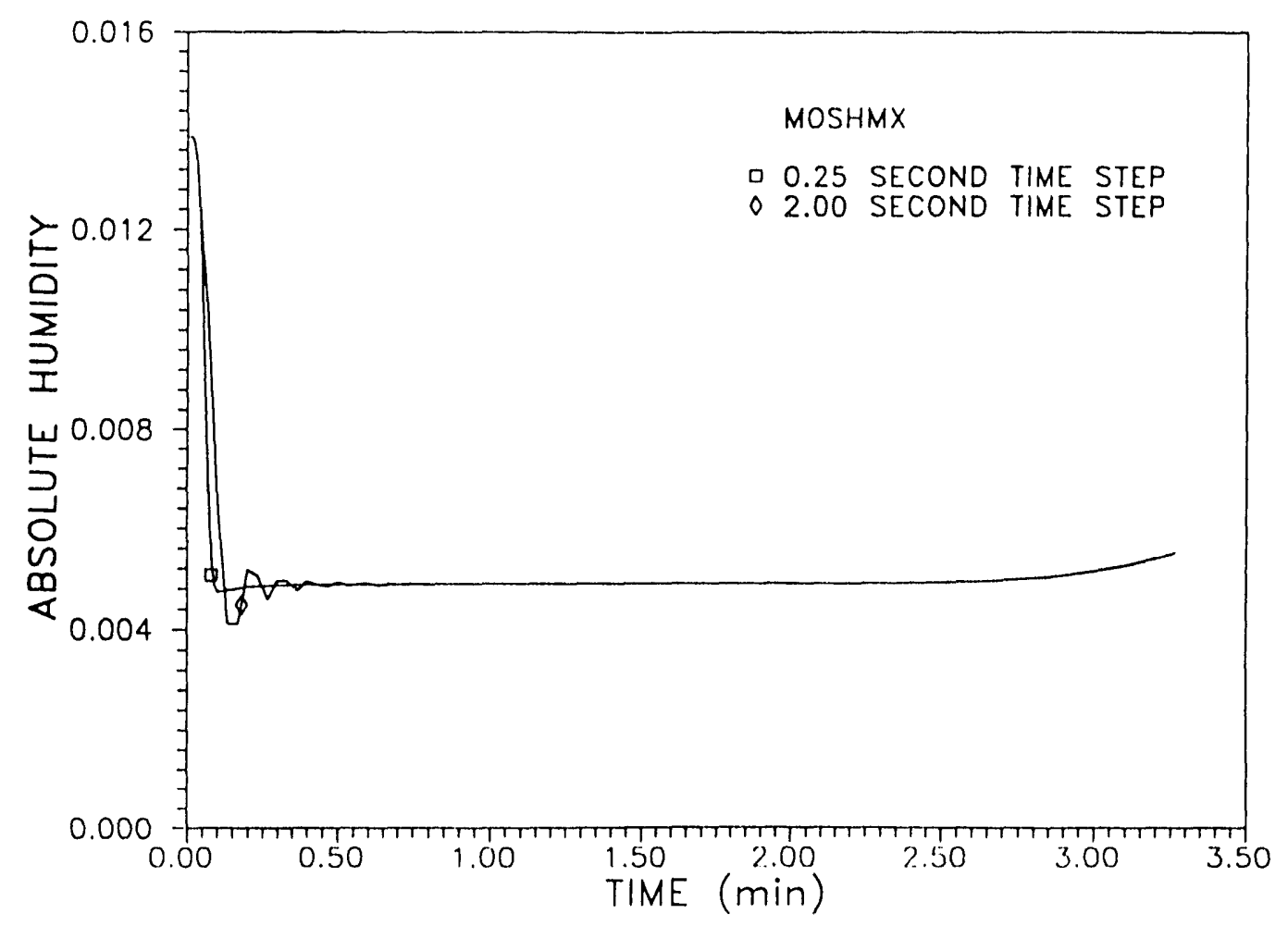

Figure A2.3 Model behavior for various time steps - MOSHMX

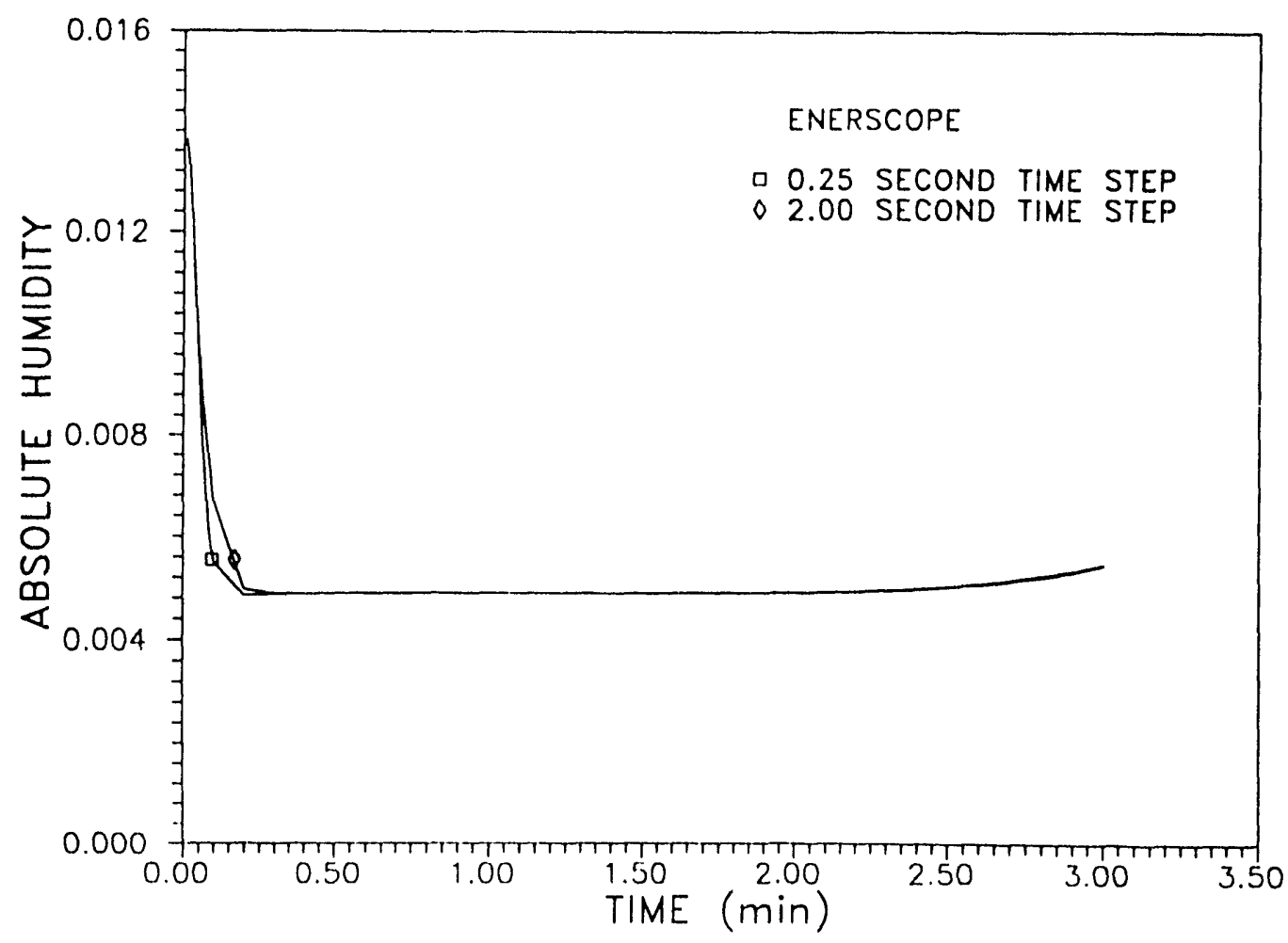

Figure A2.4 Model behavior for various time steps - Enerscope 


\section{A22. Comparison of Computer Models}

The performance of a typical open-cycle desiccant cooling system was compared using the UIC computer program, VENT1, and both versions of the Enerscope model. All the models used the same set of basic assumptions:

- All heat and mass transfer is one-dimensional in the direction perpendicular to air flow.

- Mass transfer resistance in the fluid film is directly proportional to the film-side heat transfer resistance. This proportionality constant is the Lewis Number.

- Heat transfer resistance within all solid materials is negligible (Biot number is small).

- Mass transfer resistance within the desiccant material is lumped with the film-side mass transfer resistance by manipulation of the Lewis Number.

- Axial dispersion is neglected.

Both MOSHMX and VENT1 are based on the differential conservation equations for energy and mass. Both use finite-difference approaches to solve these equations. The Enerscope model uses heat and mass exchange analogies to solve the energy and mass conservation problems.

The VENT1 program reviewed did not include the isotherm dependence on adsorption energy as required by the thermodynamics. It also required that a constant adsorption energy be input for all desiccant loadings. Initial comparisons are shown in Figures A2.5 and A2.6. An adsorption energy

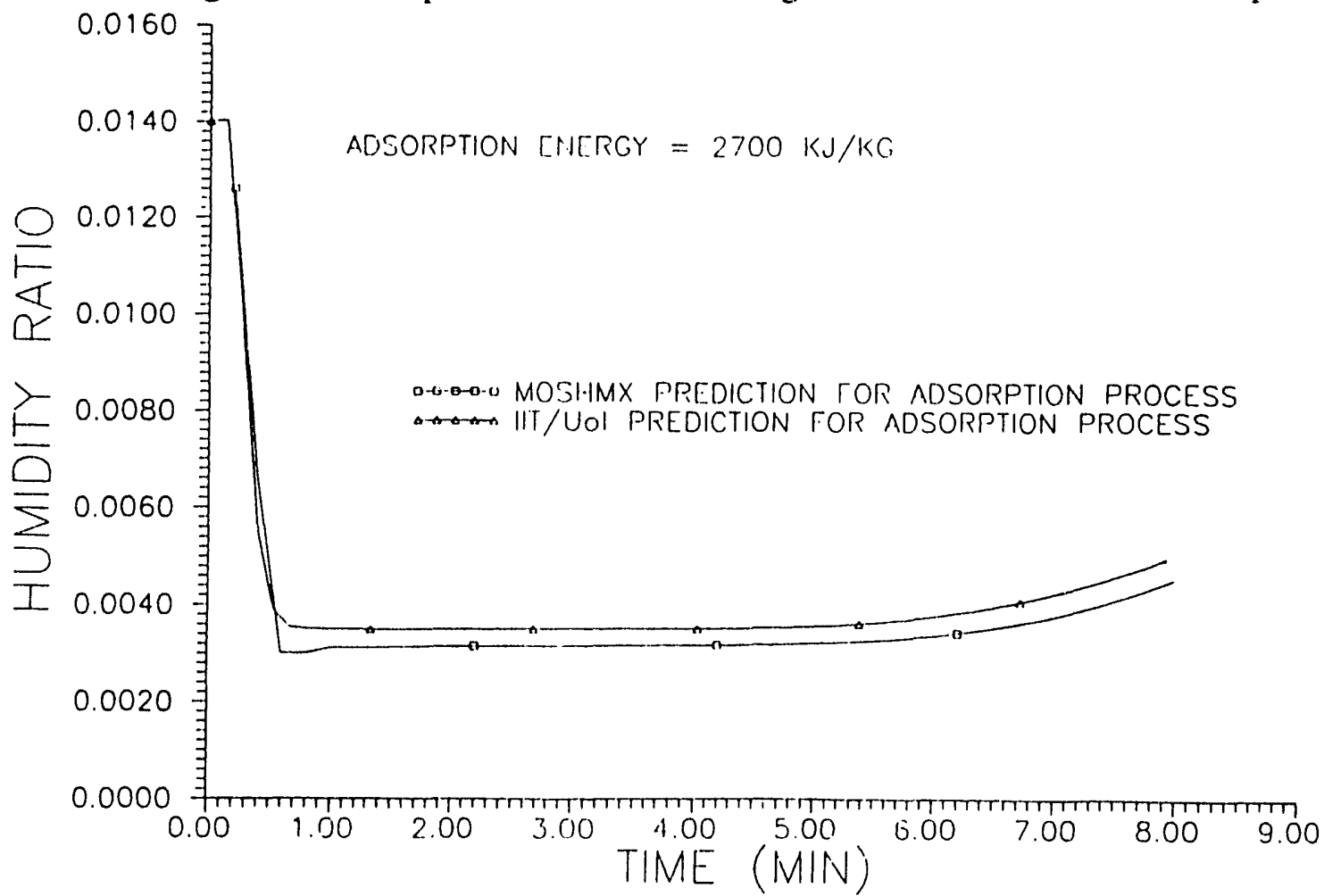

Figure A2.5 Comparison of adsorption process outlet humidities 
of $2700 \mathrm{~kJ} / \mathrm{kg}$ was chosen as the initial value in the VENT1 program. Figure A2.5 shows the desiccant outlet humidity as a function of time for the adsorption process. Figure A2.6 shows the same parameters for the regeneration process. Two problems become apparent when examining these two figures. One is the lack of agreement between the two programs, and the other is the instability of the VENT1 routine that occurs only during regeneration. Figures A2.7 and A2.8 show the same comparisons, only the adsorption energy is changed to $2300 \mathrm{~kJ} / \mathrm{kg}$. Notice that the agreement between MOSHMX and VENT1 is now quite good for both the adsorption and the regeneration processes. In addition, the instability exhibited by the VENT1 program in Figure A2.6 is missing in Figure A2.8. No changes were made in the various step sizes used to configure the program. Only the adsorption energy was changed.

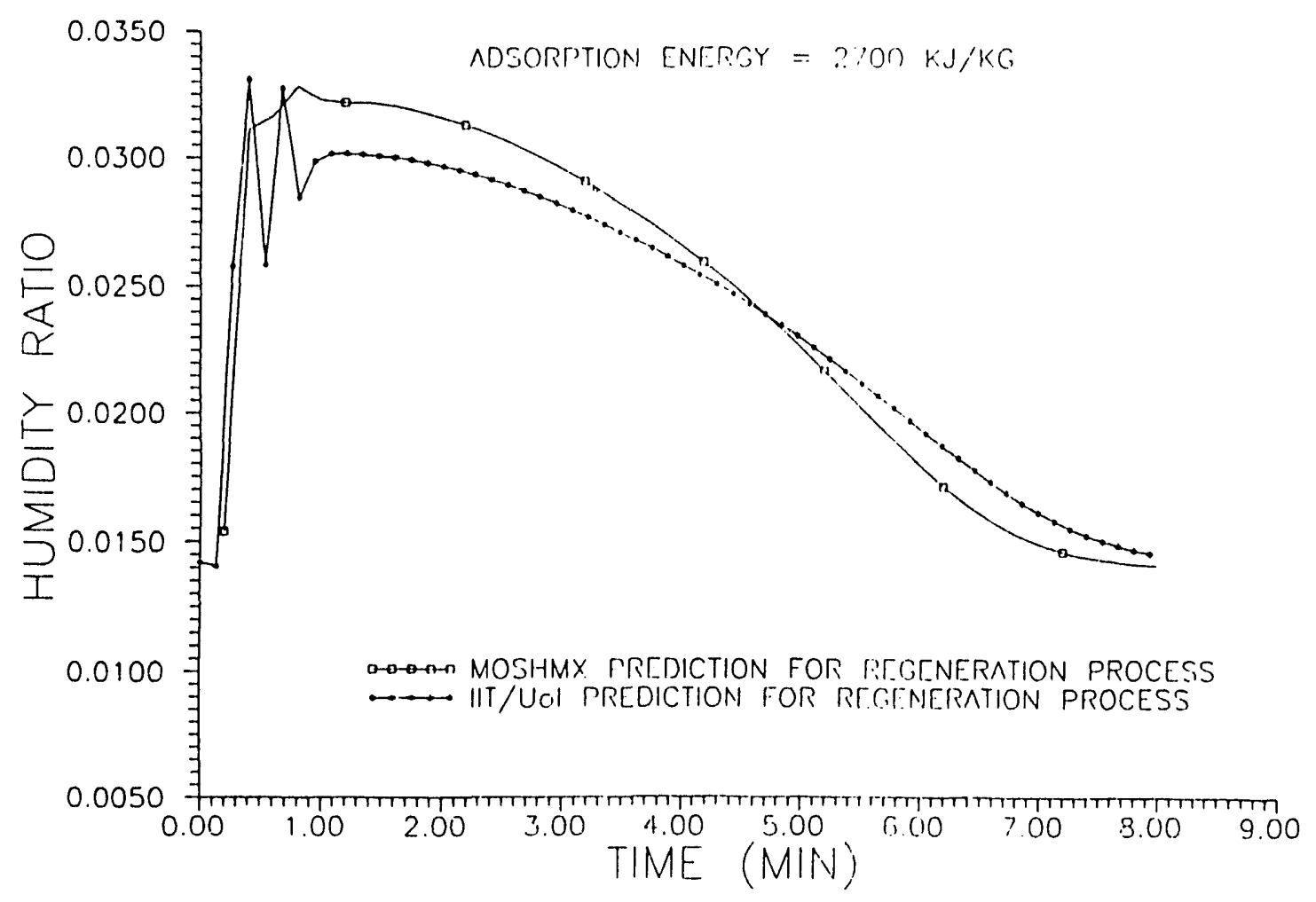

Figure A2.6 Comparison of reactivation outlet humidities

Further examination of Figures A2.1 through A2.8 shows that a slight amount of "overshoot" occurs with the MOSHMX program, that is, the humidity ratio changes rapidly during the initial stages of the cycle. Rather than smoothly progressing to the characteristic wave shape, it "overshoots" this wave and then returns much like an underdamped second-order mechanical system. The VENT1 results in Figure 5.12 also show this behavior.

Figures A2.9 and A2.10 show the effect of incorporating two time steps into the solution matrix. The first minute of the cycle incorporates a smaller time step than do the remaining seven minutes. Notice that the "overshoot" conditions exhibited in the previous figures are now missing. The reason for incorporating two time steps is to insure numerical stability during the initial phase of the cycle while reducing the total computer time required. The smaller time steps are used where the solution is most unstable, and the larger time steps are used where the solution is most stable. 


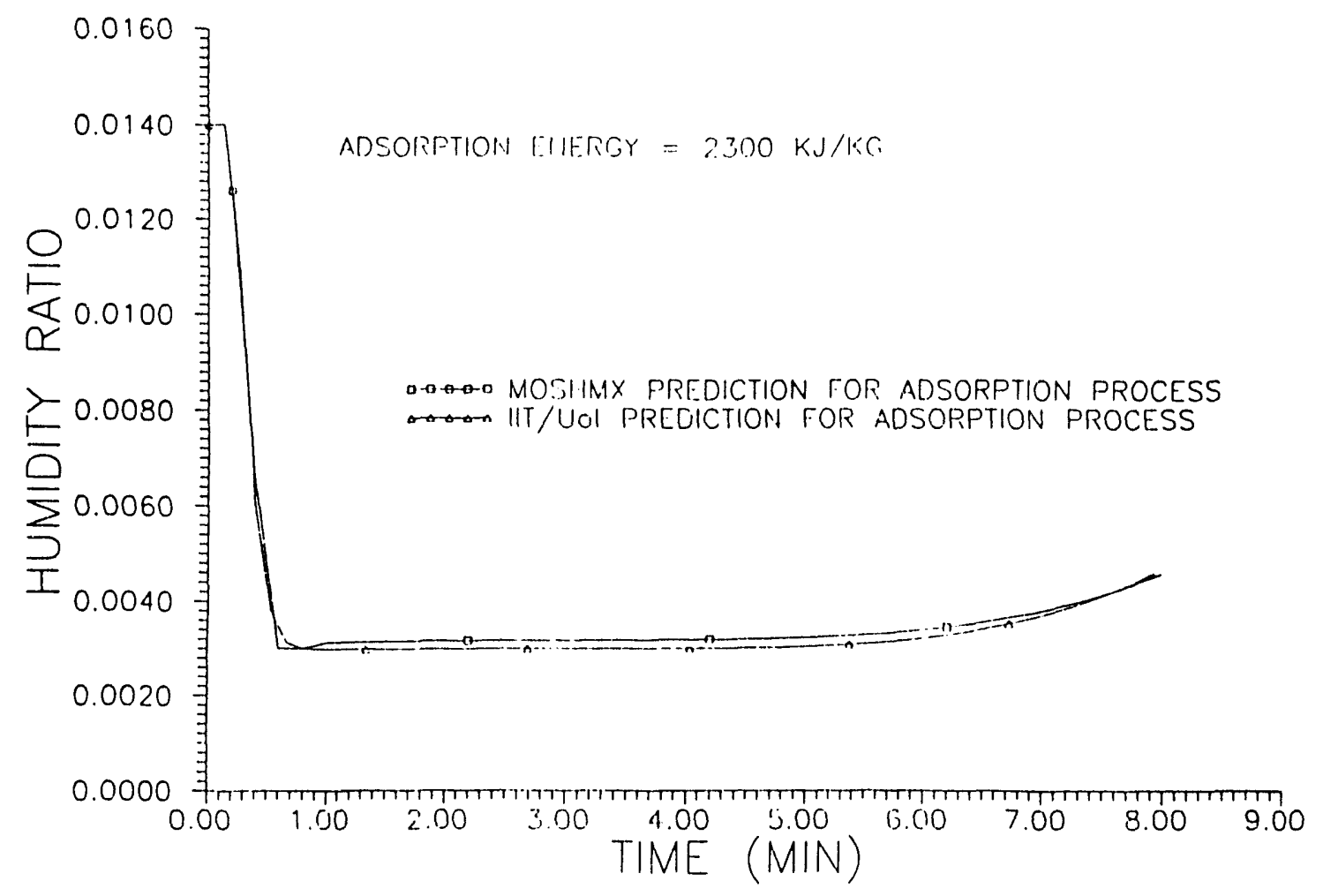

Figure A2.7 Comparison of adsorption outlet humidities

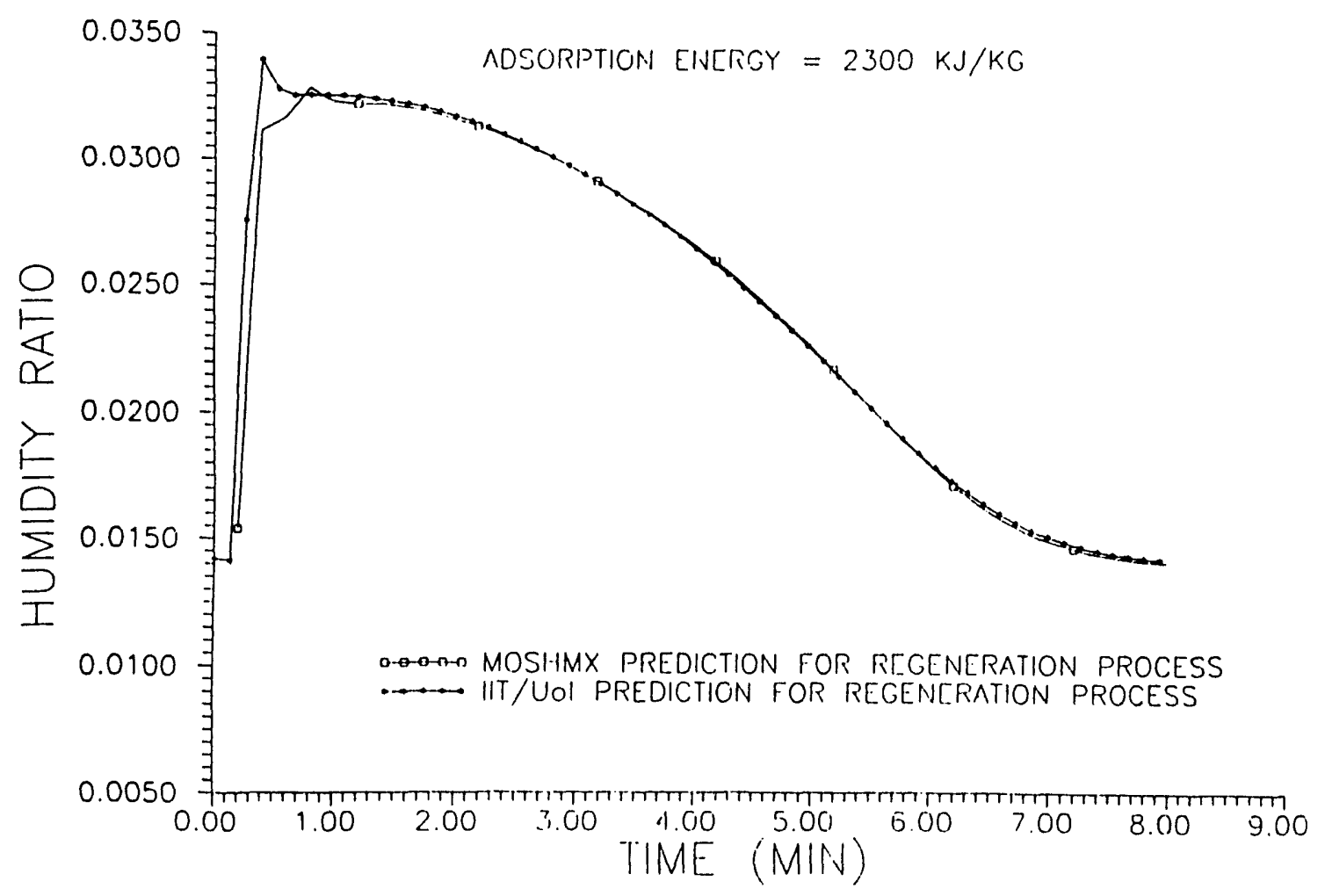

Figure A2.8 Comparison of reactivation outlet humidities 


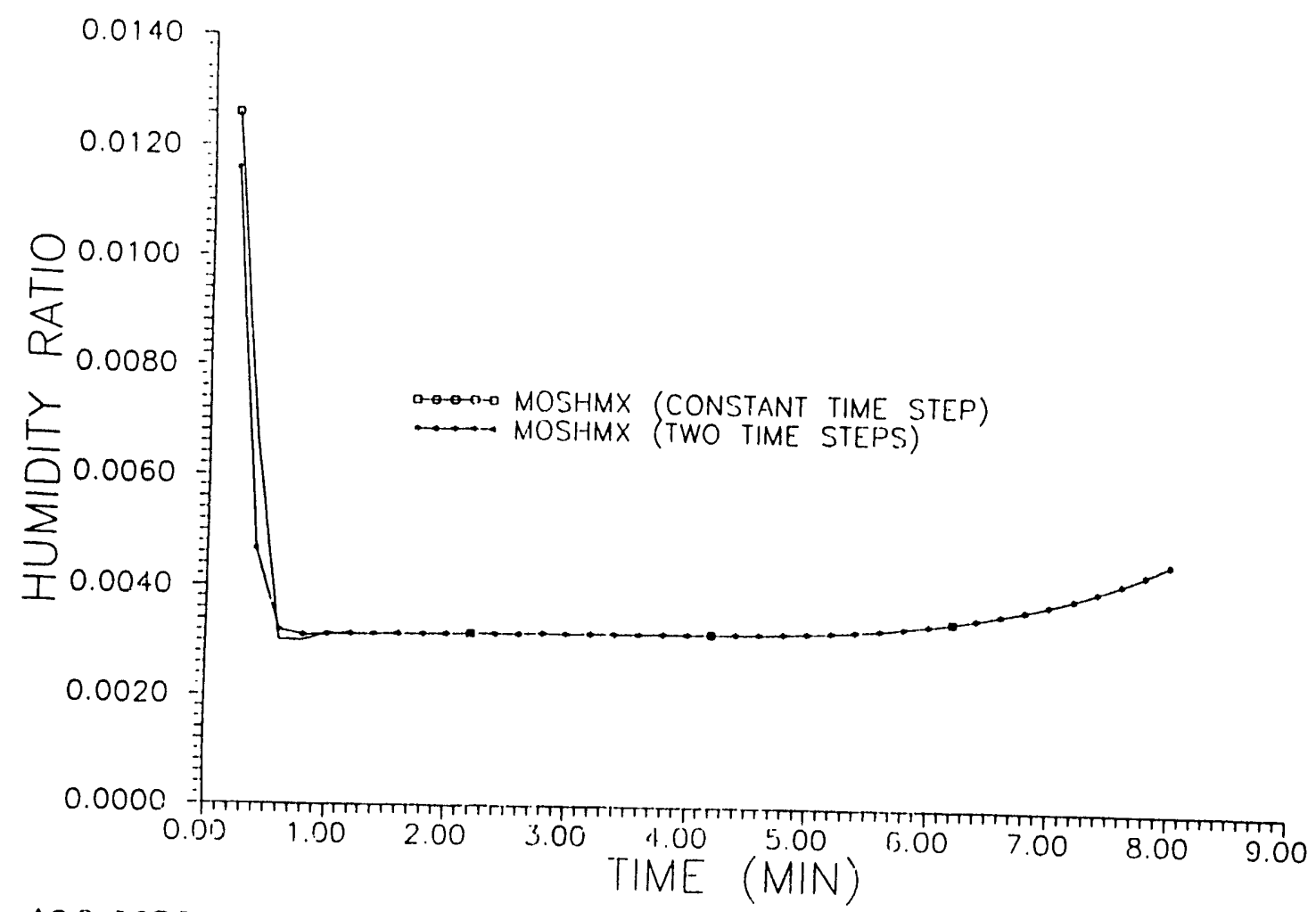

Figurc A2.9 MOSHMX adsorption process outlet humidities (constant time step vs. two time step)

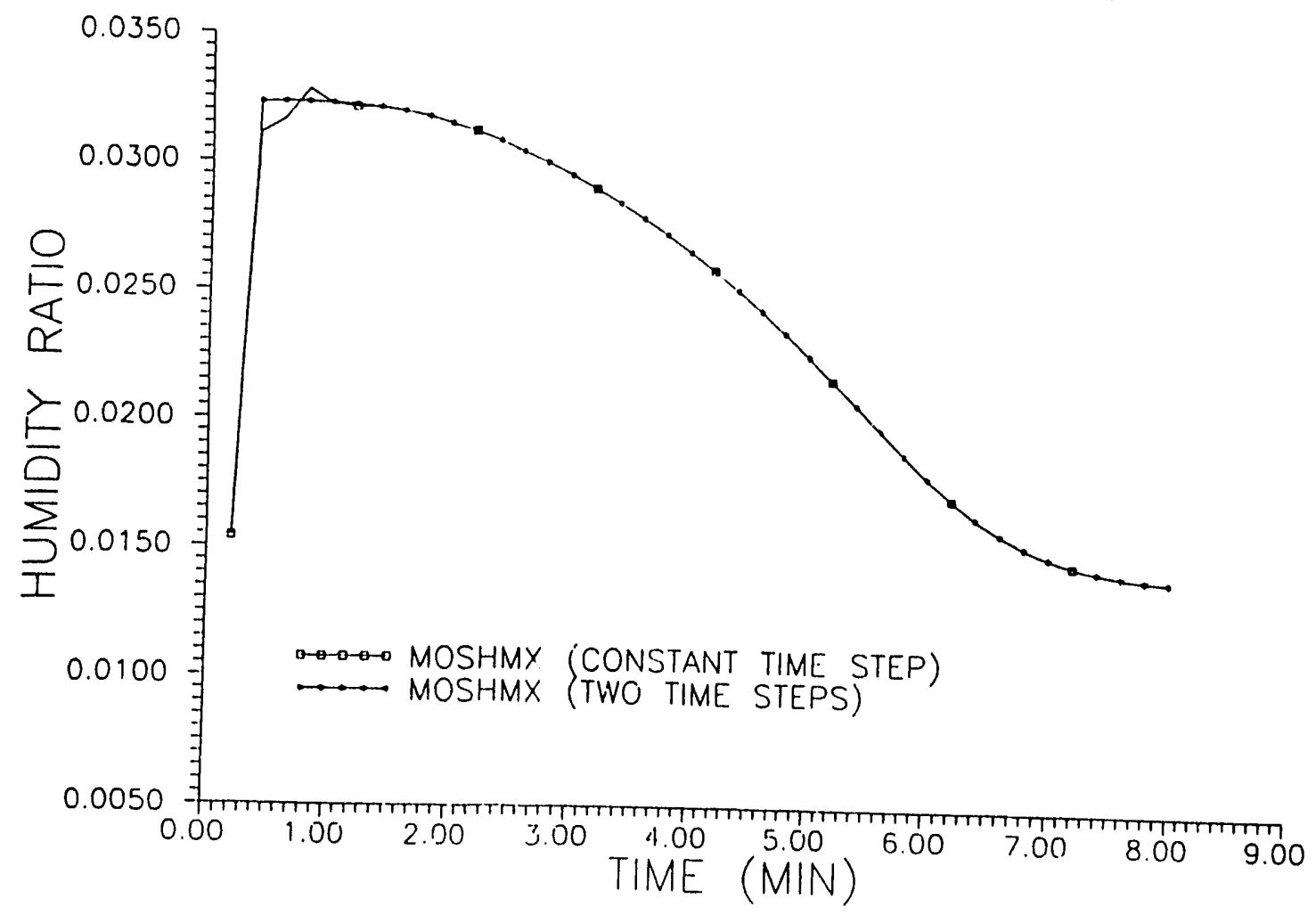

Figure A2.10 MOSHMX adsorption reactivation outlet humidities (constant time step vs. two time step) 
The amount of computer time used by competing models is an important criterion of evaluation. Unfortunately, the measurement of computer time, or run-time, for each model is not easy to determine. This is because the run-time for each code depends upon the size of the time and desiccant-bed steps chosen for the simulation. The limiting factors in reducing run-time by reducing the number of time and desiccant bed steps (making each individual step larger) are the accuracy and the numerical stability of the solution. Another factor affecting the run-time comparisons between models is the so-called convergence criterion that is, defining the error that will be tolerated before considering the problem solved.

Comparisons of the predicted performance of a candidate desiccant cooling machine are shown in Table A2.1. Listed are the cooling capacity, COP, and run-time associated with each model. The VENT1 program could not incorporate two time steps.

Table A2.1 Performance Comparison Among Various Models

\begin{tabular}{lccc} 
Model & Cooling Capacity (KW) & COP & Computer Time (sec) \\
\hline Single Time Step: & & & \\
MOSHMX & 22.38 & 0.64 & 42 \\
VENT1 & 22.73 & 0.66 & 383 \\
Enerscope & 22.16 & 0.56 & 47 \\
& & & \\
Two Time Steps: & & & 73 \\
MOSHMX & 22.339 & 0.605 & 76 \\
Enerscope & 22.107 & 0.594 & 6 \\
* MOSHMX & 22.289 & 0.603 & \\
& & & 45 \\
**Four Time Steps and Four Space Steps & & 5.5 \\
UIC IMPLICIT & 22.130 & 0.614 & \\
UIC IMPLICIT & 21.830 & 0.608 & \\
\hline
\end{tabular}

* Large step size chosen

** Information provided by W. Worek of UIC

Notice that for a single time step, the agreement among programs for cooling capacity and thermal COP is fairly good. Comparing these results with those shown in Figures A2.5 through A2.10 indicates that agreement on the minimum absolute humidity achieved by the cycle is more important than agreement on the shape of the breakthrough curve. This is because when a type $1 \mathrm{M}$ isotherm is modeled, the cycle outlet conditions are dominated by the "middle zone" region between wavefronts. For a more linear isotherm, such as silica gel, in which the outlet humidity is influenced more by the shape of the breakthrough curve, the comparisons may be different. 
Another difference between VENT1 and the others is the way in which cooling capacity is calculated. VENT1 calculates cooling capacity based on the difference between the enthalpy leaving the sensible heat exchanger and the room air enthalpy. The other models use the enthalpy leaving a second humidifier and the room air enthalpy. The difference is that adiabatic humidification is a constant wet-bulb temperature process rather than a constant enthalpy process. The magnitude of this discrepancy was not quantified.

The computer run-times of the two Enerscope models are about the same and yield similar results of system performance. As mentioned earlier, VENT1 takes considerably longer due to the more stringent convergeuce criterion. A new implicit UIC model (see Table A.21), however, has cut the computer time substantially. A very interesting point to notice is the speed of the MOSHMX code when very large steps are taken. A total run time of $6 \mathrm{sec}$ is remarkable for a full finite difference formulation of a desiccant bed simulation. Experience in the past, however, has been that relying on these models to remain stable as conditions change can be a risky proposition. The baseline step sizes chosen were developed from experience working with the MOSHMX algorithms.

Table A22 Comparison of Dehumidifier Performance Predictions - UIC and IIT Models

\begin{tabular}{lcc} 
& UIC Model & IYT Model \\
\hline Adsorption & & \\
Exit temperature, ${ }^{\circ} \mathrm{C}$ & 45.11 & 44.82 \\
Exit humidity ratio, & 0.01074 & 0.01071 \\
& & \\
Desorption & & \\
Exit temperature, ${ }^{\circ} \mathrm{C}$ & 54.98 & 55.71 \\
Exit humidity ratio, & 0.01766 & 0.01765 \\
\hline
\end{tabular}

\section{Conditions:}

Inlet adsorption air temperature $=35^{\circ} \mathrm{C}$

Inlet adsorption air humidity ratio $=0.0142$

Inlet desorption air temperature $=65^{\circ} \mathrm{C}$

Inlet desorption air humidity ratio $=0$

The IIT combined-resistances model is compared with the film resistance model used by UIC. The results of this comparison are shown in Table A2.2. The IIT model was also compared with the MOSHMX model of Maclaine-cross and the nonlinear analogy model of Maclaine-cross and Banks in Table A2.3. As can be seen, the results are in good agreement. The MOSHMX model predictions for a complete desiccant cooling system are listed in Table A2.4 and are again compared to the IIT system model. These results also appear to be in good agreement. Because solid-side resistances are considered in the IIT model, and because both heat transfer and mass transfer Biot numbers cannot be set to zero, very small values of heat transfer Biot number and mass transfer Biot number were used in the comparison to represent the film resistance model 
Table A2.3 Comparison of Dehumidifier Performance Predictions UIC, MOSHMX, and Nonlinear Analogy Models

Adsorption Air Adsorption Air

Exit Temp. $\left({ }^{\circ} \mathrm{C}\right) \quad$ Exit Humidity Ratio

\begin{tabular}{lll}
\hline UIC Model & 57.40 & 0.009752 \\
MOSHMX & 57.31 & 0.009759 \\
Nonlinear Analogy & 57.97 & 0.009076 \\
\hline
\end{tabular}

Conditions:

Inlet adsorption air temperature $=35^{\circ} \mathrm{C}$

Inlet adsorption air humidity ratio $=0.0142$

Inlet desorption air temperature $=85^{\circ} \mathrm{C}$

Inlet desorption air humidity ratio $=0.0142$

Table A2.4 Comparisons of Cooling System Performance Predictions

\begin{tabular}{lcc} 
& IIT & MOSHMX \\
\hline Adsorption & & \\
Exit temperature, ${ }^{\circ} \mathrm{C}$ & 61.0 & 62.2 \\
Exit humidity ratio, & 0.0050 & 0.0049 \\
& & \\
Desorption & & \\
Exit temperature, ${ }^{\circ} \mathrm{C}$ & 52.1 & 49.8 \\
Exit humidity ratio, & 0.0230 & 0.0230 \\
& & \\
COP & 1.040 & 1.036 \\
Cooling Capacity (KJ/KG of Air) & 19.68 & 19.46 \\
\hline
\end{tabular}

\section{Conditions:}

Inlet adsorption air temperature $=35^{\circ} \mathrm{C}$

Inlet adsorption air humidity ratio $=0.0142 \mathrm{~kg}$

Inlet desorption air temperature $=95^{\circ} \mathrm{C}$

Inlet desorption air humidity ratio $=0.0140$ 


\section{References for Appendix II}

1. R.S. Barlow, Analysis of the Adsorption Process and of Desiccant Cooling Systems - A Pseudo-Steady-State Model for Coupled Heat and Mass Transfer, SERI/TR631-1330, Solar Energy Research Institute, Golden, Colo. 1982.

2. C. Kutscher and R.S. Barlow, Dynamic Performance of a Packed Bed Dehumidifier: Experimental Results from the SERI Desiccant Test Loop, SERI/TR-253-1429, Solar Energy Research Inst. 1982.

3. S. Kim, P. Biswas, and A. F. Mills, "A compact, low pressure drop desiccant bed for solar air conditioning applications: bench scale tests," ASME J. of Solar Energy Engineering, 107, 120-127, 1985.

4. B. Husky et al., Advanced Solar/Gas Desiccant Cooling System, GRI 81/0064, GRI, Chicago, 1982. 
ORNL/CON-309

\section{INTERNAL DISTRIBUTION}

$\begin{aligned} 1 . & \text { P. R. Barnes } \\ 2 . & \text { V. D. Baxter } \\ 3 . & \text { J. B. Cannon } \\ 4 . & \text { R. S. Carlsmith } \\ 5-9 . & \text { F. C. Chen } \\ 10 . & \text { J. E. Christian } \\ 11 . & \text { G. E. Courville } \\ 12 . & \text { F. A. Creswick } \\ 13 . & \text { R. C. DeVault } \\ 14 . & \text { P. D. Fairchild } \\ 15 . & \text { S. K. Fischer } \\ 16 . & \text { W. Fulkerson } \\ 17 . & \text { G. R. Hadder } \\ 18 . & \text { E. L. Hillsman } \\ 19 . & \text { P. J. Hughes } \\ 20 . & \text { J. O. Kolb } \\ 21 . & \text { M. A. Kuliasha } \\ 22 . & \text { D. M. Kyle }\end{aligned}$

$\begin{aligned} 23 . & \text { H. A. McLain } \\ 24-48 . & \text { V. C. Mei } \\ 49 . & \text { W. R. Mixon } \\ 50 . & \text { N. C. Myers } \\ 51 . & \text { D. E. Reichle } \\ 52 . & \text { D. T. Rizy } \\ 53 . & \text { M. W. Rosenthal } \\ 54 . & \text { M. P. Ross } \\ 55 . & \text { J. R. Sand } \\ 56 . & \text { R. B. Shelton } \\ 57 . & \text { J. N. Stone } \\ 58 . & \text { A. W. Trivelpiece } \\ 59 . & \text { A. Zaltash } \\ 60-61 . & \text { Laboratory Records Dept. } \\ 62 . & \text { Laboratory Records - RC } \\ 63 . & \text { ORNL Patent Office } \\ 64 . & \text { ORNL Public Relations Office }\end{aligned}$

EXTERNAL DISTRIBUTION

65. N. M. Banks, Cargocaire, P. O. Box 640, 79 Monroe Street, Amesbury, MA 01913

66. W. W. Bassett, Senior Project Manager, Building Systems, Gas Research Institute, 8600 West Bryn Mawr Avenue, Chicago, IL 60631

67. B. G. Buchanan, Computer Science Department, University of Pittsburgh, 206 Mineral Industries Building, Pittsburgh, PA 15260

68-69. Y. K Chuah, Deputy Director, Thermal System, Energy and Resource Laboratory, ITRI, Building 64, \#195, Sec. 4, Chung Hsin Road, Chu-Tun, Hsin-Chu, TAIWAN 31015, ROC

70. B. M. Cohan, TECOGEN Inc., 45 First Avenue, P. O. Box 9046, Waltham, MA 02254-1456

71-75. R. K. Collier, Jr., Collier Engineering Services, 109 Tequesta Harbor Drive, Merritt Island, FL 32952

76. J. W. Cooke, DOE-OR, ORNL, Building 4500N, MS 6269

77. R. J. Denny, Air-Conditioning and Refrigeration Institute, 1815 North Fort Meyer Drive, Arlington, VA 22209

78. W. H. Dolan, Manager, Commercial Space Conditioning, Gas Research Institute, 8600 West Bryn Mawr Avenue, Chicago, IL 60631

79. R. J. Fiskum, Program Manager, Building Equipment Division, Office of Building Equipment Research, Department of Energy, CE-422, 5H-048/FORSTAL, 1000 Independence Avenue, SW, Washington, DC 20585 
80. A. A. Frank, Professor, Department of Mechanical Engineering, Room 111, Everson Hall, University of California at Davis, Davis, CA 95618

81. P. Gandhidasan, Professor, Mechanical Engineering Department, King Fahd University of Petroleum and Minerals, Dhahran 31216, SAUDIA ARABIA

82. R. V. Gemmer, Senior Project Manager, Combustion, Gas Research Institute, 8600 West Bryn Mawr Avenue, Chicago, IL 60631

83. L. G. Harriman, Mason-Grant Company, P. O. Box 6547, Portsmouth, NH $03802-$ 6547

84. R. J. Hassett, Program Manager, Building Equipment Division, Office of Building Equipment Research, Department of Energy, CE-422, 5H-048/FORSTAL, 1000 Independence Avenue, SW, Washington, DC 20585

85. A. Hirsch, Vice President, Environmental Sciences and Director, Washington Operations, Midwest Research Institute, 5109 Leesburg Pike, Suite 414, Falls Church, VA 22041

86. H. M. Ingram, Director, Udall Center for Studies in Public Policy, The University of Arizona, 803/811 East First Street, Tucson, AZ 85719

87-98. E. R. Kweller, Program Manager, Building Equipment Division, Office of Building Equipment Research, Department of Energy, CE-422, 5H-048/FORSTAL, 1000 Independence Avenue, SW, Washington, DC 20585

99. C. S. Laurent, Munter Cargocaire, 79 Monroe Street, P. O. Box 640, Amesbury, MA 01913

100-104. Z. Lavan, Professor Emeritus, Department of Mechanical Engineering, Illinois Institute of Technology, 3110 South State Street, Chicago, IL 60616

105. A. Lowenstein, President, AIL Research, Inc., 18 Cameron Court, Princeton, NJ 08540

106. C. D. MacCracken, President, Calmac Manufacturing Corporation, 101 West Sheffield Avenue, P. O. Box 710, Englewood, NJ 07631

107. J. Marsala, Senior Project Manager, Desiccant and Absorption Technologies, Gas Research Institute, 8600 West Bryn Mawr Avenue, Chicago, IL 60631

108-117. G. Meckler, Gershon Meckler Associates, P.C., 590 Herndon Parkway, Suite 100, Herndon, VA 22070

118. J. W. Mitchell, Professor, Solar Energy Laboratory, The University of Wisconsin at Madison, Madison, WI 53706

119. J. P. Murphy, Director of Education and Training, Oasis Energy Systems, 4425 North High Street, Columbus, OH 43214

120. G. H. Myers, Director, Gas Research Institute, 8600 West Bryn Mawr Avenue, Chicago, IL 60631

121. N. L. Nagda, GEOMET Technologies, Inc., 20251 Century Boulevard, Germantown, MD 20874-1192

122. D. Novosel, Project Manager, Gas Cooling, Gas Research Institute, 8600 West Bryn Mawr Avenue, Chicago, IL 60631

123-132. Office of Scientific and Technical Information, P.O. Box 62, Oak Ridge, TN 37831

133. R. A. O'Neal, Niagara Mohawk Power Co., 300 Erie Boulevard West, Syracuse, NY 13202

134. J. L. Peterson, Professor, Center for Energy Studies, The University of Texas at Austin, Balcones Research Center, 10100 Burnet Road, Austin, TX 78758

135. C. A. Redman, Battelle Pacific Northwest Laboratory, Battelle Blvd., Richland, WA 99352 
136. J. D. Ryan, Director, Building Equipment Division, Office of Building Energy Research and Conservation Renewable Energy, Department of Energy, CE-422, 5H-048/FORSTAL, 1000 Independence Avenue SW, Washington, DC 20585

137. Y. Saito, Professor, Department of Mechanical Engineering, Osaka Institute of Technology, 5-16-1, Omiya, Asahi-ku, Osaka 535, JAPAN

138. J. B. Shrago, Director, Office of Technology Transfer, 405 Kirkland Hall, Vanderbilt University, Nashville, TN 37240

139. S. V. Shelton, Associate Professor, Department of Mechanical Engineering, Georgia Institute of Technology, Atlanta, GA 30332-0405

140. H. Singh, Professor, Architectural Engineering, School of Engineering, North Carolina A \& T University, Greensboro, NC 27411

141. T. Statt, Program Manager, Building Equipment Division, Office of Building Equipment Research, Department of Energy, CE-422, 5H-048/FORSTAL, 1000 Independence Avenue, SW, Washington, DC 20585

142. R. Sullivan, Program Manager, Advanced Propulsion Division, Department of Energy, CE-322, 5G-046/FORSTAL, 1000 Independence Avenue, SW, Washington, DC 20585

143. D. L. Tchernev, The Zeopower Company, 75 Middlesex Avenue, Natick, MA 01760

144. A. K. Trehan, GEOMET Technologies, Inc., 20251 Century Boulevard, Germantown, MD 20874-1192

145. R. H. Turner, Professor, Department of Mechanical Engineering, University of Nevada at Reno, Reno, NV 89557-0030

146. W. J. Wepfer, Associate Professor, Department of Mechanical Engineering, Georgia Institute of Technology, Atlanta, GA 30332-0405

147. W. H. Wilkinson, Senior Research Scientist, Battelle Columbus Division, Battelle Corporation, Columbus, $\mathrm{OH} 43201$

148. M. Williams, Professor, Department of Economics, Northern Illinois University, DeKalb, IL 60115 

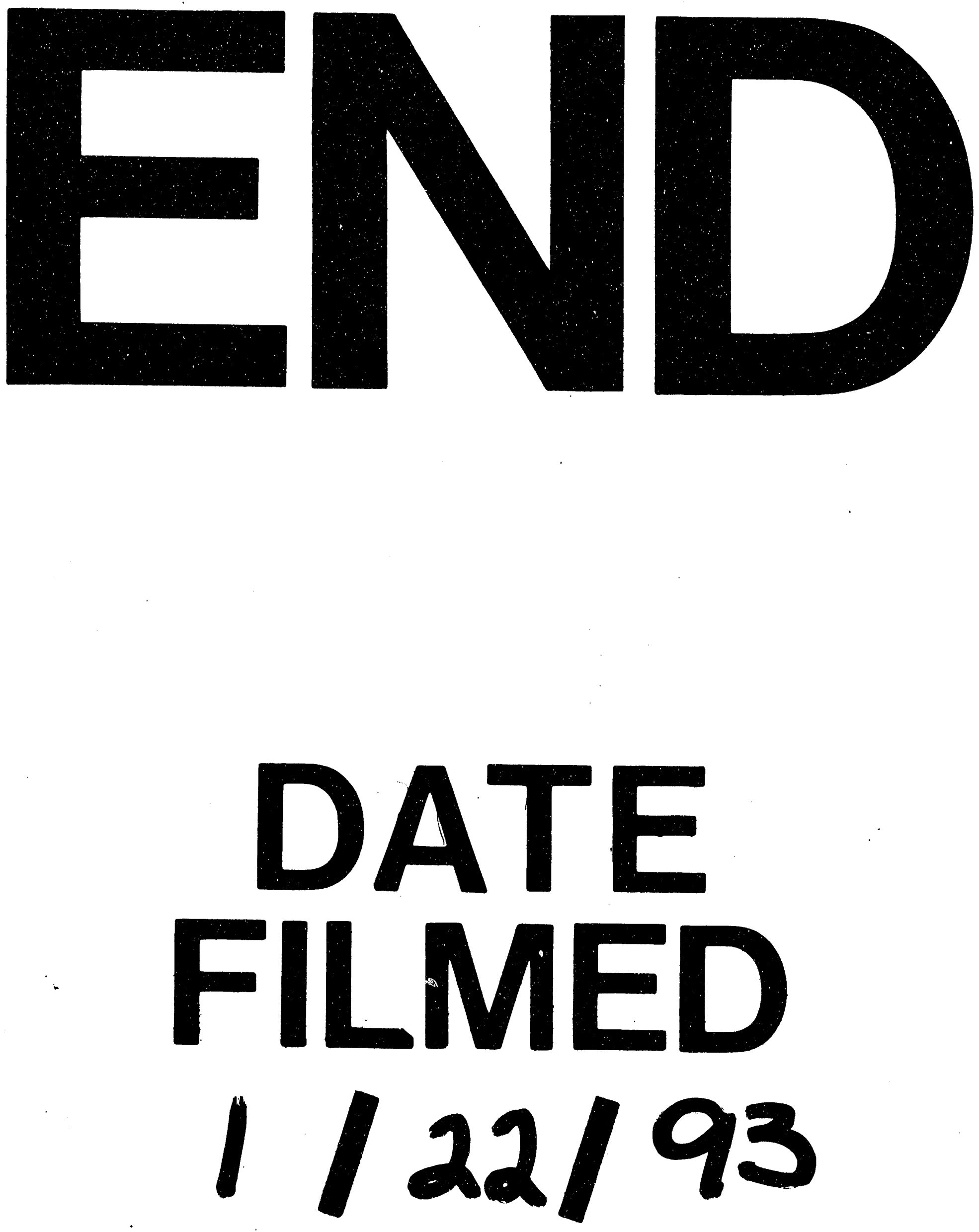
